\author{
Universidade de São Paulo \\ Instituto de Física de São Carlos
}

Departamento de Física e Ciência dos Materiais

\title{
Construção de uma Armadilha de Dipolo com Laser de $\mathrm{CO}_{2}$
}

\section{Carlos Renato Menegatti}

Tese apresentada ao Instituto de Física de São Carlos, da Universidade de São Paulo, para a obtenção do título de Mestre em Ciências: Física Básica.

Orientador: Prof. Dr. Luís Gustavo Marcassa.

São Carlos

2006 
Carlos Renato Menegatti

"Construção de uma armadilha de dipolo de $\mathrm{CO}_{2}$."

Carlos Renato Menegatti - São Carlos, 2006

Dissertação (Mestrado) - Instituto de Física de São Carlos, 2006 - Páginas: 82

Orientador: Prof. Dr. Luís Gustavo Marcassa

Física Atômica e Molecular. Aprisionamento de Átomos.

I.Título 
Dedico este trabalho a minha família pelo amor e a base em que me inspiro para todas as realizações. 


\section{Agradecimentos}

Ao professor Dr. Luís Gustavo Marcassa pela orientação e por tudo que tenho aprendido nesses últimos três anos nos laboratórios de física atômica, por ser o primeiro a dar a oportunidade de trabalhar com ciência, pelo apoio, profissionalismo e amizade durante todo esse caminho.

Ao professor Vanderlei Salvador Bagnato pelo suporte técnico, indispensável à realização dos experimentos discussões e por ser um grande líder administrando um grupo de quase 100 pessoas, característica que eu admiro muito e tento sempre tomar como exemplo.

Ao Gustavo Telles pela amizade, as baladas, os pães de queijo, as vitaminas e pelos ensinamentos no dia a dia no laboratório, hoje em dia tenho muita familiaridade com os instrumentos em laboratório graças a sua paciência em ensinar.

Ao Valter, Anderson, Lucas, André, pela companhia no trabalho, nas piadas e palhaçadas que tornam dias chatos em legais satirizando nosso duro e interminável trabalho.

Ao pessoal da iniciação (ICs) Jader, Bruno e Neto, pessoas muito legais que pude ensinar algumas coisas úteis e que os ajudarão futuramente, e muitas coisas inúteis que não servirá para nada.

A todos os companheiros de trabalho: Emanuel, Aida, Estella, Edimir, Kilvia, Daniel, Jorge. 
Ao pessoal oficina do Carlinhos e o pessoal da eletrônica (João, Edson, Orlando, Pink, Mindú) pela grande amizade e ajuda na construção de vários componentes deste trabalho.

Às secretárias do grupo de óptica: Isabel e Benê, pelo grande trabalho em organizar toda nossa papelada com $100 \%$ de eficiência.

Ao pessoal do grupo do lado pelo diário cafezinho bem quentinho na faixa: Daniel, Marcão, Baldão, PH, Fujão.

Aos grandes irmãos aqui de casa Daniel Papoti, Daniel Vieira ,Paulino e a irmã Samantha pelas grandes discussões sobre vários assuntos, acho que não existe turma melhor pra poder dividir uma república.

Aos "FERAS", Gian, Juliano, Waguim, Junior, Marcelo, Clayton, Vinni pelas melhores baladas semanais que alguém poderia ter ido na região de Tamba, se eu começar a falar aqui eu não paro mais.

À Banda: Alanis, Fein, Sombra, Thunder e Lucas pelas boas horas de metal pesado e descontração, acredito muito em vocês e estaremos sempre melhores.

Aos amigos de ontem e de toda vida: Codo, Diego, Rondinelli, Márcio, Veio, Niego, David, Bellotte, Clodoaldo.

Ao José, Maria, Fernanda e Carla minha família querida que sempre esteve presente e com quem posso sempre contar.

À minha namorada Jennifer a pessoa que eu amo e sempre reaprendo o jeito humilde de ver a vida, sentindo alegria nas coisas mais simples e me confortando em dias de desespero me incentivando a nunca desistir.

À FAPESP, pelo apoio financeiro.

À Deus, pela paz e o equilíbrio que me percorre. 


\section{Sumário}

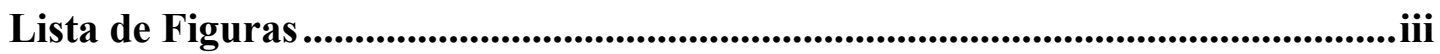

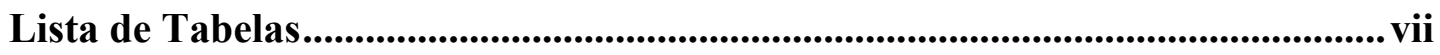

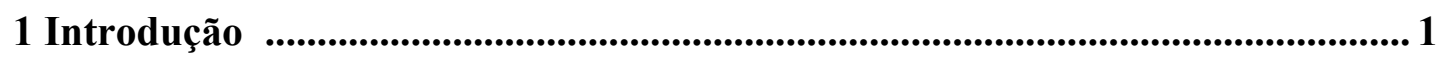

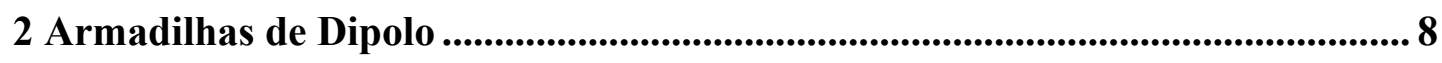

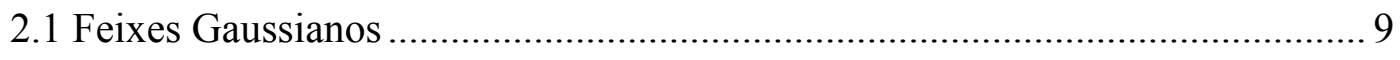

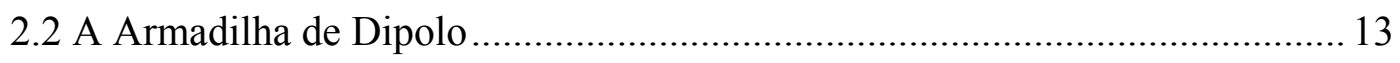

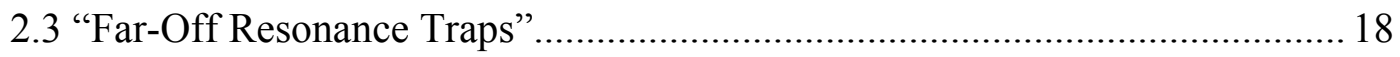

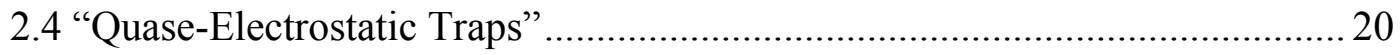

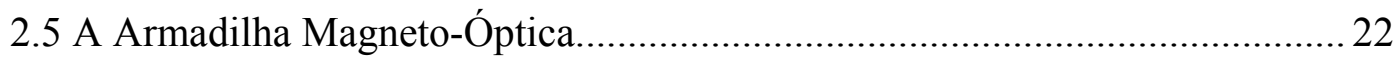

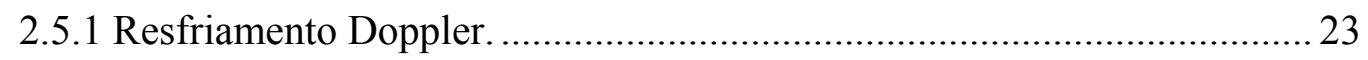

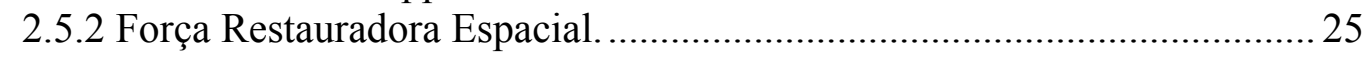

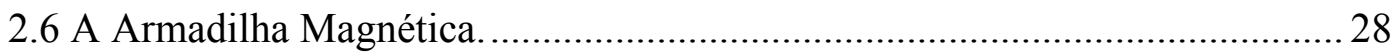

3 Construção da Armadilha de Dipolo........................................................................... 30

3.1 Lasers para Armadilha de Dipolo .......................................................... 30

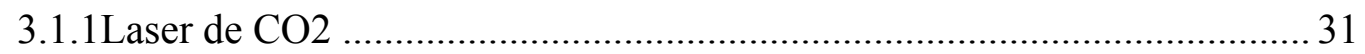

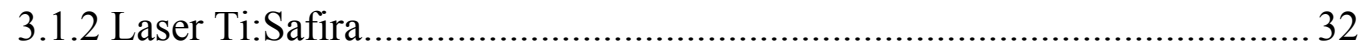

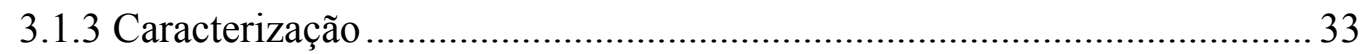

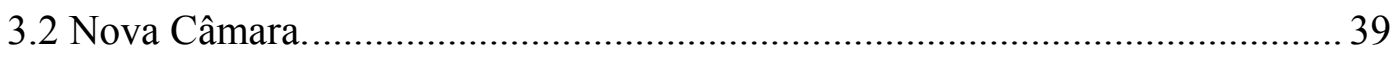




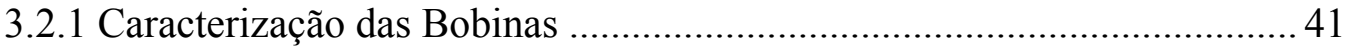

3.2.2 Ajuste do Foco no Interior da Câmara ....................................................... 44

3.2.3 Sistema à Vácuo e sua Evolução............................................................ 47

3.3 Construção da Armadilha Magneto-Óptica. ..................................................... 51

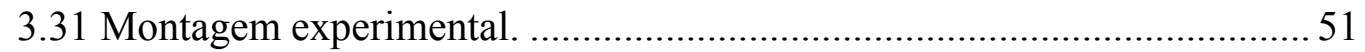

3.3.2 Sistemas para otimização de detecção da armadilha.................................. 55

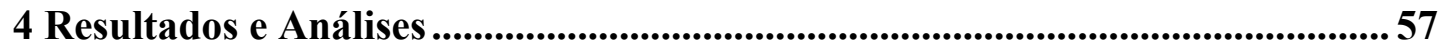

4.1 Caracterização da Armadilha Magneto-Óptica .............................................. 58

4.1.1 Caracterização da Distribuição Espacial ...................................................58

4.1.2 Caracterização do Número de Átomos Aprisionados ................................ 60

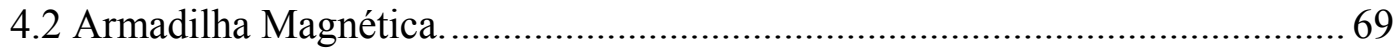

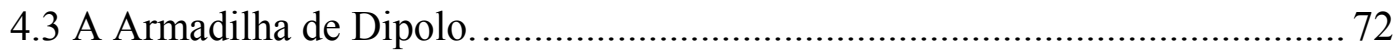

5 Conclusão e Perspectivas ......................................................................................... 74

Referências Bibliográficas ...................................................................................78 


\section{Lista de Figuras}

Figura 2-1: Propagação de um feixe gaussiano e variação da amplitude do campo com a coordenada radial. $\mathrm{R}(\mathrm{z})$ representa a curvatura da frente de onda, observamos sua variação enquanto a onda se propaga na direção $\mathrm{z}$.

Figura 2-2: Propagação de um feixe gaussiano e variação da amplitude do campo com a coordenada radial. $\mathrm{R}(\mathrm{z})$ representa a curvatura da frente de onda, observamos sua variação enquanto a onda se propaga na direção $\mathrm{Z}$.

Figura 2-3: Disposição dos átomos aprisionados. Devido a anisotropia do potencial a amostra se configura com simetria cilíndrica próximo ao foco.

Figura 2-4: Potencial de aprisionamento confinante para uma armadilha de dipolo com um feixe focalizado: Gráfico gerado a partir das seguintes polarizabilidades estáticas: $53 \times 10^{-40} \mathrm{~cm}^{2} / \mathrm{V}$ para $\mathrm{Rb}$ e $48 \times 10^{-40} \mathrm{~cm}^{2} / \mathrm{V}$ para $\mathrm{K}$. Com as respectivas profundidades: $\mathrm{U}_{0} / \mathrm{K}_{\mathrm{B}}=-1,4 \mathrm{mK}$ e $-1,3$ $\mathrm{mK}$. Em (A) temos um corte do potencial perpendicular ao eixo de propagação em $z=0$ e em (B) um corte transversal em $r=0$. Nota-se um fator de captura menor na direção radial em comparação com o eixo z.

Figura 2-5: Molasses óptico unidimensional. Dois feixes contrapropagantes sintonizados abaixo da ressonância $\left(\omega_{0}\right)$ incidindo em um átomo. 
Figura 2-6: Construção de uma armadilha magneto-óptica. Três pares de feixes contrapropagantes com suas respectivas polarizações $\left(\sigma^{+}\right.$e $\left.\sigma^{-}\right)$e uma bobina quadrupolar na configuração anti-Helmholtz.

Figura 2-7: Força restauradora espacial em uma dimensão. O estado fundamental $\mathrm{F}=0$, não sofre variação em sua energia $\Delta \mathrm{E}=0$, já o estado excitado $\mathrm{F}^{\prime}=1$ sofre variação de $\Delta \mathrm{E}=\left(\mathrm{m}_{\mathrm{F}},=-1,0,+1\right)$.

Figura 2-8: Diagrama das bobinas na configuração anti-Helmholtz. As linhas representam o campo magnético gerado pelas bobinas $\operatorname{com}|\mathrm{B}|=0$ no centro.

Figura 3-1: Sistema de Refrigeração do laser de $\mathrm{CO}_{2}$ e o modulador acusto-óptico (AOM).

Figura 3-2: Esquema do laser Titânio Safira (COHERENT 899). Cavidade "borboleta" bombeada com laser de Nd:YVO $4 ~ 2532 \mathrm{~nm}$.

Figura 3-3: Medida de w a $33 \mathrm{~cm}$ do orifício da saída do feixe. Para as medidas, utilizamos uma faca acoplada em um carrinho com escala digital. O aparelho nos oferece uma precisão de $0,005 \mathrm{~mm}$

Figura 3-4 : Cálculo de $\mathrm{w}_{0}$.

Figura 3-5: Primeiro telescópio para expansão do feixe

Figura 3-6: Cálculo de $\mathrm{w}_{0}$ para o feixe oriundo do telescópio da figura 3-5

Figura 3-7: Aparato para a medida do perfil longitudinal do foco no interior da câmara. O feixe é expandido através do telescópio já descrito e convergido com uma lente $\mathrm{f}=50 \mathrm{~mm}$.

Figura 3-8: Medida do perfil longitudinal do feixe em uma lente $\mathrm{f}=50 \mathrm{~mm}$

Figura 3-9: Peças projetadas no programa Solid Works 2004. Vemos os esboços tridimensionais dos componentes que formam a nova câmara de aprisionamento.

Figura 3-10: Foto do sistema à vácuo montado sobre a mesa óptica

Figura 3-11: Foto das bobinas para o interior da câmara

Figura 3-12: Gradiente referente ao eixo da bobina, obtemos $22,7 \mathrm{G} / \mathrm{cm}$ a $5 \mathrm{~A}$ de corrente.

Figura 3-13: Gradiente referente ao plano central da bobina, obtemos 10,2 G/ cm a 5 A de corrente.

Figura 3-14: Perfil do campo no eixo da bobina. 
Figura 3-15: Observação do foco através da incidência do laser de $\mathrm{CO}_{2}$ em uma chapa de alumínio.

Figura 3-16: Parâmetros para posição interna das lentes.

Figura 3-17: Superposição das armadilhas MOT e dipolo $\mathrm{CO}_{2}$.

Figura 3-18: Foto do interior da câmara através de uma das janelas de 6".

Figura 3-19: Ilustração do sistema a vácuo. A câmara é conectada através de uma de suas flanges inferiores (CF63) às bombas. Primeiramente temos uma bomba de sublimação de titânio e logo em seguida, debaixo da mesa, as bombas: Iônica e turbomolecular.

Figura 3-20: Gráfico da evolução da pressão no sistema á vácuo, atingimos o regime de $\mathrm{P}=10^{-8}$ torr em aproximadamente uma semana.

Figura 3-21: Diagrama de níveis de energia do ${ }^{85} \mathrm{Rb}$, e transições de aprisionamento.

Figura 3-22: Montagem experimental para formação e observação do MOT.

Figura 3-23: Sintonização do laser Ti:Safira na transição $5 \mathrm{~S}_{1 / 2}(\mathrm{~F}=3) \rightarrow 5 \mathrm{P}_{3 / 2}\left(\mathrm{~F}^{\prime}\right.$ =4) Feixe com detunning de $\Delta=27 \mathrm{MHz}$ maximizando o número de átomos aprisionados.

Figura 3-24: Câmara de aprisionamento e componentes ópticos montados em uma sobre mesa

Figura 3-25: Interface para controle da seqüência temporal do experimento feita em LabView. Neste programa garantimos a reprodutibilidade dos experimentos

Figura 4-1: Imagem por uma câmera CCD gerada em um monitor. O pequeno círculo intenso no centro da foto representa a flourescência dos átomos de $85 \mathrm{Rb}$ aprisionados observado através de uma das janelas de 2".

Figura 4-2: Imagem do MOT obtida por uma câmera fotográfica digital.

Figura 4-3: Imagem 3D do MOT, os eixos $x$ e y representam as dimensões do MOT (unidades arbitrárias) enquanto que o eixo $\mathrm{z}$ representa números de átomos, na realidade este números são da ordem típicas de $10^{7} \mathrm{a}$ $10^{8}$ átomos.

Figura 4-4: Montagem para medida de curvas de carga do MOT. 
Figura 4-5: Curva de carga de uma armadilha mageto-óptica com lasers de diodo ${ }^{87} \mathrm{Rb}$, obtivemos um sinal máximo de $80 \mathrm{mV}$ correspondendo a $6,6 \times 10^{7}$ átomos, "getter" ligado continuamente.

Figura 4-6: Curva de carga de uma armadilha magneto-óptica com laser de Titânio Safira ${ }^{85} \mathrm{Rb}$, obtivemos um número máximo correspondendo a $3,5 \times 10^{7}$ átomos, "getter" ligado continuamente (5,4 A).

Figura 4-7: Curva de carga de uma armadilha magneto-óptica com laser de Titânio Safira ${ }^{85} \mathrm{Rb}$, obtivemos um número máximo correspondendo a $4,8 \times 10^{7}$ átomos, getter ligado continuamente $(5,85 \mathrm{~A})$.

Figura 4-8: Curva de carga e tempo de vida da armadilha magneto-óptica com laser de Titânio Safira ${ }^{85} \mathrm{Rb}$, "getter" ligado continuamente até a saturação da armadilha e desligado em seguida.(5,85 A).

Figura 4-9: Número de átomos aprisionados na armadilha magneto-óptica pela corrente no "getter".

Figura 4-10: Medida do tempo de vida de descarga da armadilha em função da corrente aplicada ao "getter".

Figura 4-11 Medida do tempo de vida da armadilha magnética formada pelo par de bobinas anti-Helmholtz. O feixe de aprisionamento é desligado e ligado em alguns ms recapturando átomos remanescentes.

Figura 4-10: Tempo de vida da armadilha magnética evidenciando o efeito das bobinas de aprisionamento. 


\section{Lista de Tabelas}

Tabela 3-1: Valores obtidos para medidas de perfil do feixe até uma distância de 153 cm da saída do feixe do laser.

Tabela 3-2: Valores obtidos para medidas de perfil do feixe para telescópio da figura 3-4 até uma distância de $153 \mathrm{~cm}$ da saída do feixe do laser. 


\section{Resumo}

Neste trabalho apresentamos a construção de uma armadilha de dipolo com laser de $\mathrm{CO}_{2}$ que envolveu a utilização de novas e modernas tecnologias nunca utilizadas pelo nosso grupo até então. Podemos destacar a construção de uma nova câmara de aprisionamento com grande acesso óptico, "getters" como fonte de átomos e um laser de $\mathrm{CO}_{2}$ de alta potência e sua óptica. Demonstramos o aprisionamento de átomos de ${ }^{85} \mathrm{Rb}$ em uma armadilha magnética e magneto-óptica e analisamos sua dinâmica, obtendo resultados das taxas de perdas provocadas por colisões entre átomos aprisionados e átomos quentes provenientes do vapor de fundo e do "getter". Este entendimento será importante na implementação da técnica totalmente óptica de aprisionamento simultâneo de átomos de $\mathrm{Rb}$ e moléculas de $\mathrm{Rb}_{2}$ 


\section{Abstract}

In this work we present the construction of an optical dipole trap using a $\mathrm{CO}_{2}$ laser, which involves the use of news and modern technologies never utilized by our group up to now. We have builded a new trap chamber with large optical access, used atomic dispensers as an atomic source and a high power $\mathrm{CO}_{2}$ laser and its optical components. We have demonstrated trapping and cooling of ${ }^{85} \mathrm{Rb}$ in a magneto-optical trap as well as and magnetic trap. By analyze its dynamic, we have obtained results on the collisional loss rates between trapped atoms imprisoned and hot atoms originating from the background gas. This understanding will be important in the implementation of the technical one entirely optical trap for Rb atoms as well as $\mathrm{Rb}_{2}$ molecules. 


\section{Capítulo 1}

\section{Introdução}

A experiência e investigação dos fenômenos da natureza e seus elementos tem repercutido no grande avanço da sociedade e para o desenvolvimento de novas tecnologias. Através destes avanços a humanidade tem melhorado suas condições de vida manipulando o meio em seu benefício. A ciência, de um modo geral, impulsiona os projetos a novas descobertas e o aperfeiçoamento de novas técnicas para a obtenção de novos resultados que possibilitem descrever a natureza nos seus detalhes mais sutis.

O estudo da natureza atômica se enquadra no grande avanço ocorrido no século passado. Com o surgimento do laser e o desenvolvimento das teorias da interação da radiação com a matéria [1], surgiu a possibilidade de controlar o movimento do átomo, o que gerou um grande avanço e uma intensificação de estudos detalhados da estrutura atômica e molecular. As grandes dificuldades encontradas nos estudos de amostras atômicas gasosas estão na resolução e nas escalas de tempo em que os fenômenos ocorrem em relação ao meio macroscópico 
em que vivemos. Para observarmos com mais detalhes esses fenômenos surgem a necessidade de aprisionamento e resfriamento de átomos e moléculas.

Dos vários fenômenos que ocorrem no regime atômico, podemos citar as colisões atômicas. Apesar de existirem lasers de pequena largura espectral, a espectroscopia atômica é limitada por alargamentos inomogêneos, como por exemplo, o efeito Doppler. Na tentativa de minimizar estes problemas, desenvolveram-se técnicas de aprisionamento e resfriamento de amostras gasosas alcalinas em que se destacam dois trabalhos. Em 1985, Steven Chu e colaboradores [2] demonstrou um meio altamente viscoso para átomos utilizando a força da pressão de radiação que foi chamado de melado óptico (optical molasses). Logo a seguir no final da década de 80 Raab e colaboradores [3] consegue a primeira realização experimental de uma armadilha magneto-óptica, usualmente chamada de MOT (abreviação de “Magneto Optical Trap”).

Em uma armadilha magneto-óptica [4] os átomos são confinados por 3 pares de feixes contrapropagantes, sintonizados próximo a ressonância do átomo, e um gradiente de campo magnético na configuração anti-Helmholtz. Com esta técnica é possível o aprisionamento e o resfriamento de átomos a regimes de temperatura da ordem de $100 \mu \mathrm{K}$.

Existem também, outros tipos de armadilhas, armadilhas magnéticas e armadilhas de dipolo ópticas [4]. Em armadilhas magnéticas, é aplicado um campo magnético B com um mínimo local, átomos com um dipolo magnético permanente ( $\mu$ ) serão confinados na região de menor potencial, isto é, onde o campo magnético for mínimo. Com esta técnica de aprisionamento obtiveram-se em 1995 os primeiros condensados de Bose-Einstein $[5,6,7,8]$. 
Por outro lado, em armadilhas de dipolo ópticas ("Optical Dipole Traps”), os átomos são confinados pela força de dipolo que o campo magnético induz na amostra. Uma armadilha óptica é o resultado de um único feixe gaussiano e focalizado. Se o feixe é ajustado abaixo da freqüência de ressonância atômica, os átomos são atraídos para a região de maior intensidade. As armadilhas de dipolo classificam-se em duas FORT ("Farr off ressonace traps") e QUEST ("Quase eletrotatical traps”), nomes cunhados devido as suas características básicas, como potência e freqüência do laser.

O desenvolvimento destas técnicas de aprisionamento e resfriamento também conhecidas como laser cooling propiciou o avanço considerável no estudo das interações atômicas nos regimes frio e ultrafrio, onde se encontra um fascinante objeto de estudo, tanto experimental quanto teórico. Dentro deste cenário, podemos ressaltar o estudo de colisões atômicas e de estados moleculares formados durante a colisão de átomos frios aprisionados que teve seu início nos anos 90 e estende-se até os dias atuais.

O estudo de processos colisionais entre átomos neutros ultrafrios aprisionados [9] iniciou-se na tentativa de abordar fatores indesejáveis responsáveis por limitar o número de átomos e densidades nas amostras. Este tipo de estudo tornou-se relevante por revelar informações importantes sobre as interações atômicas de longo alcance e sobre os principais mecanismos de perdas em diferentes amostras alcalinas.

Conseqüentemente aos estudos de colisões ultrafrias surgiu a produção de moléculas diatômicas no regime de microKelvin pelo processo de fotoassociação, conhecido também como PA (photoassociation) [10]. Neste processo o um par atômico colidindo no estado fundamental absorve um fóton e tem a probabilidade de cair em um estado excitado de uma molécula. Esta técnica, PA, é considerada como 
sendo uma transição "free-bound", excitando um par atômico livre inicialmente no estado fundamental e levando a formação de um par atômico ligado no estado excitado.

Thorsheim e colaboradores propuseram pela primeira vez a formação de uma molécula eletronicamente excitada a partir da fotoassociação de dois átomos frios colidindo [11]. Porém, mesmo antes do desenvolvimento das técnicas de resfriamento e aprisionamento, o processo de fotoassociação já tinha sido observado em amostras térmicas. Scheingraber e colaboradores observaram a fotoassociação de dois átomos térmicos de magnésio durante um processo colisional utilizando um laser de Argônio com freqüência fixada na região do ultravioleta [12].

Os limitantes na resolução de processos de fotoassociação em amostras quentes está relacionado com a largura doppler gerada pela distribuição de velocidades dos átomos, sua resolução é da ordem de $\mathrm{k}_{\mathrm{B}} \mathrm{T}$, em que $\mathrm{k}_{\mathrm{B}}$ é a constante de Boltzman e T é a temperatura da amostra. Em átomos ultrafrios, cuja a temperatura é da ordem de $100 \mu \mathrm{K}$ a resolução se torna 3000000 maior com relação a resolução espectral de átomos térmico $(\mathrm{T}=300 \mathrm{~K})$.

Embora moléculas produzidas no estado excitado são altamente instáveis, em 1998, Fioretti e colaboradores observaram pela primeira vez a produção de dímeros $\mathrm{Cs}_{2}$ ultrafrios no estado eletrônico fundamental [13]. As moléculas eram produzidas com velocidades translacionais tão baixas quanto as dos átomos aprisionados em um MOT. A partir deste evento, o interesse na produção destas moléculas no estado fundamental vem crescendo, pois neste estado molecular elas são mais estáveis. Este trabalho gerou uma seqüência de novos trabalhos voltados a produção de moléculas diatômicas alcalinas frias no estado fundamental $[14,15,16]$. 
O interesse científico por estudos voltados a obtenção de moléculas frias vêem crescendo atualmente, abrangendo a possibilidade de estudos de interações inter-moleculares, espectroscopia e o laser de moléculas (em analogia ao laser de átomos [17]). Para tanto é necessário contar-se com uma fonte de moléculas frias no estado molecular eletrônico e vibracional fundamental, embora esta tarefa esteja longe de ser realizada.

O aprisionamento e resfriamento de moléculas em armadilhas magnetoópticas é uma tarefa impossível de ser realizada. Uma molécula por mais simples que seja apresenta estados de energia muito mais complexos do que os átomos apresentando, além dos estados eletrônicos, estados vibracionais e rotacionais, gerando múltiplos canais de decaimento espontâneo para níveis não ressonantes com a radiação de aprisionamento [18].

Uma solução para a obtenção de uma fonte contínua de moléculas frias aprisionadas é a utilização de uma armadilha híbrida, onde temos uma armadilha magneto-óptica e uma magnética demonstrada para aprisionar moléculas de $\mathrm{Cs}_{2}$ [19]. Ou o aprisionamento óptico em uma armadilha do tipo QUEST [20,21].

A armadilha magento-óptica, tem sido a base do sistema experimental em nosso laboratório para estudos de colisão de formação de moléculas. A observação experimental de estados ligados em moléculas homo e heteronucleares têm sido o foco principal das investigações do laboratório de física atômica do grupo de óptica da USP-São Carlos. Foi possível a observação da formação de moléculas de $\mathrm{K}_{2}, \mathrm{Rb}_{2}$, $\mathrm{KRb}$ no estado fundamental. No caso das moléculas homo e heteronucleares, o mecanismo de formação molecular é idêntico ao que já tinha sido reportado na literatura $[13,15]$. Recentemente, em experimentos realizados em nosso laboratório [22] foi observado que em condições normais de operação da armadilha ocorre a 
formação natural de moléculas diatômicas no estado fundamental. Porém, é conveniente introduzir um laser extra para catalisar a fotoassociação dessas moléculas, aumentando a taxa de produção.

A principal dificuldade na obtenção de resultados com relação a formação de moléculas é devido ao fato de uma armadilha magneto-óptica ser incapaz de aprisioná-las. A partir do momento que dois átomos de mesma ou diferente espécie interagem para formar uma molécula, deixam de interagir com os feixes de aprisionamento e escapam rapidamente da amostra limitando sua densidade $\left(\sim 10^{10}\right.$ átomos $\left(\mathrm{cm}^{3}\right)$. Porém, para melhorarmos esta situação é necessário aumentarmos a densidade das amostras para obtenção de melhores resultados.

Assim, neste trabalho, relataremos a construção de um novo sistema experimental, trata-se de uma armadilha de dipolo totalmente óptica, onde será possível o aprisionamento de átomos e moléculas $\mathrm{Rb}$ em densidades muito altas, e em longo período de tempo ( 100 s), com apenas um laser de $\mathrm{CO}_{2}$ gaussiano infravermelho intenso $(\sim 130 \mathrm{~W})$ e focalizado numa cintura de $\mathrm{w}=30 \mu \mathrm{m}$. Mostraremos também as caracterizações preliminares na tentativa de adaptá-la a futuros experimentos.

No próximo capítulo, apresentaremos os fundamentos teóricos sobre a armadilhas magneto-ópticas e magnéticas ressaltando as armadilhas de dipolo. As armadilhas do tipo FORT e QUEST serão discutidas, as suas principais características serão apontadas, como profundidade do potencial de aprisionamento, geometria espacial de aprisionamento, volume de captura, tempo de aprisionamento, caracterizados por taxas de carga e descarga, taxa de espalhamento e aquecimento das amostras. Também mostraremos a instrumentação necessária para se construí-las. 
No capítulo 3, mostraremos toda a etapa de construção do novo laboratório, desde os projetos da nova câmara de aprisionamento, sistema de vácuo e bombeamento, caracterização de lasers, construção e caracterização de uma armadilha magneto-optica, dispositivos eletrônicos para controles do experimento e aquisição de dados.

Seguiremos com o capítulo 4 em que mostraremos o aprisionamento de átomos de ${ }^{85} \mathrm{Rb}$ em uma armadilha-magneto-óptica e uma armadilha magnética a partir de reservatórios químicos getters [34] instalados na nova câmara de aprisionamento e mostraremos a praticidade na sua utilização. Os resultados tratamse de curvas de carga e de tempo de vida dos átomos aprisionados para uma dada condição experimental em que analisaremos o número de átomos aprisionados, a densidade e o processos de perda da armadilha por colisões. Analisando esses fatores teremos finalmente no capítulo 5 as conclusões e perspectivas para a transferência desses átomos de uma armadilha magneto-óptica para uma armadilha de dipolo. 


\section{Capítulo 2}

\section{Armadilhas de Dipolo}

Armadilhas de dipolo produzem um potencial atrativo confinante que é independente dos níveis atômicos e moleculares, pois não depende da absorção de fótons ressonantes. Com apenas um simples feixe focalizado e com freqüência sintonizada abaixo da ressonância é possível gerar uma força restauradora confinante onde sua única exigência está na capacidade da polarizabilidade da amostra devido ao campo de radiação externa.

Neste capítulo, estudaremos as propriedades das armadilhas de dipolo. Começaremos com uma ilustração sistemática a respeito da geometria de um feixe gaussiano. Continuando, faremos uma derivação simples do potencial atrativo óptico dipolar que surge a partir da interação entre o momento de dipolo elétrico induzido no átomo com o feixe gaussiano. Mostraremos que um potencial tridimensional confinante pode ser formado com apenas um feixe focalizado. Embora átomos nesta armadilha possam ser aquecidos por excitações ópticas, mostraremos que a taxa de 
aquecimento pode ser desconsiderada no limite de grandes detunings do laser de aprisionamento da freqüência de ressonância atômica.

Apresentaremos dois tipos de armadilhas de dipolo e suas diferenças: FORTs

e QUESTs nomes cunhados em respeito a suas principais características, Far-Off Resonance Traps (armadilhas longe da ressonância ) e Quase-Eletrostatical Traps (armadilhas quase-eletrostáticas ). Finalizaremos com um tópico sobre os conceitos teórico de uma armadilha magnética e magneto - óptica construída para obtermos um pré-aprisionamento e resfriamento de átomos uma vez que são oriundos de reservatórios quentes possuindo tal energia permitindo que escapem facilmente de um potencial atrativo dipolar.

\subsection{Feixes Gaussianos}

Na maioria das pesquisas na área de física atômica é indispensável o uso da radiação como um meio de se obter informações do sistema atômico em estudo. A interação da radiação com a matéria e suas conseqüências gerou uma vasta variedade de aplicações que vêm evoluindo trazendo novas idéias e resultados. Dado essa grande importância, faremos neste tópico um estudo analítico de um feixe gaussiano, o qual em geral é o modo de radiação emitido pela maioria dos lasers.

Em 1879, James Clerk Mawell introduziu um conjunto de equações envolvendo os campos elétrico e magnético, as quais ficaram conhecidas como as equações de Maxwell, tais equações permitem descrever uma onda eletromagnética: 


$$
\nabla^{2} \vec{E}-\frac{1}{c} \frac{\partial^{2} \vec{E}}{\partial t^{2}}=0
$$

A solução desta equação é uma onda, cujo valor de campo elétrico da radiação $\mathbf{E}$ dependerá da posição $(\mathrm{x}, \mathrm{y}, \mathrm{z})$ e do tempo. Um caso particular desta solução é aquela obtida ao se utilizar o Laplaciano em coordenadas cilíndricas:

$$
\nabla^{2}=\frac{\partial^{2}}{\partial r^{2}}+\frac{1}{r} \frac{\partial}{\partial r}+\frac{\partial^{2}}{\partial z^{2}}
$$

Tal solução se ajusta muito bem ao comportamento da radiação emitida por lasers quando se impõem condições de contorno com simetria azimutal. Não entraremos em detalhes da resolução desta equação diferencial, apenas supomos que sua solução deve ser uma onda que se propaga apenas na direção axial, isto é, direção z. Neste caso a equação para o campo elétrico da radiação fica:

$$
E(r, z)=E_{0} \frac{w_{0}}{w(z)} \exp \left\{-\frac{r^{2}}{w^{2}(z)}\right\} \exp \left\{-i\left[k z-\eta(z)+\frac{i k r^{2}}{2 R(z)}\right]\right\}
$$

Em que, para o modo fundamental, temos:

$$
\begin{gathered}
w^{2}(z)=w_{0}^{2}\left\{1+\left(z / z_{0}\right)^{2}\right\} \\
R(z)=z\left\{1+\left(z_{0} / z\right)^{2}\right\}
\end{gathered}
$$




$$
\eta(z)=\operatorname{tg}^{-1}\left(z / z_{0}\right)
$$

As equações (2.4) e (2.5) definem respectivamente a cintura e a frente de onda do feixe ao se propagar (figura 2-1). A principal característica desta solução para os nossos objetivos é a primeira parte da expressão (2.3) que relaciona à amplitude do campo. Vemos que a amplitude do campo apresenta um perfil gaussiano em torno do eixo de propagação z, figura 2-2.

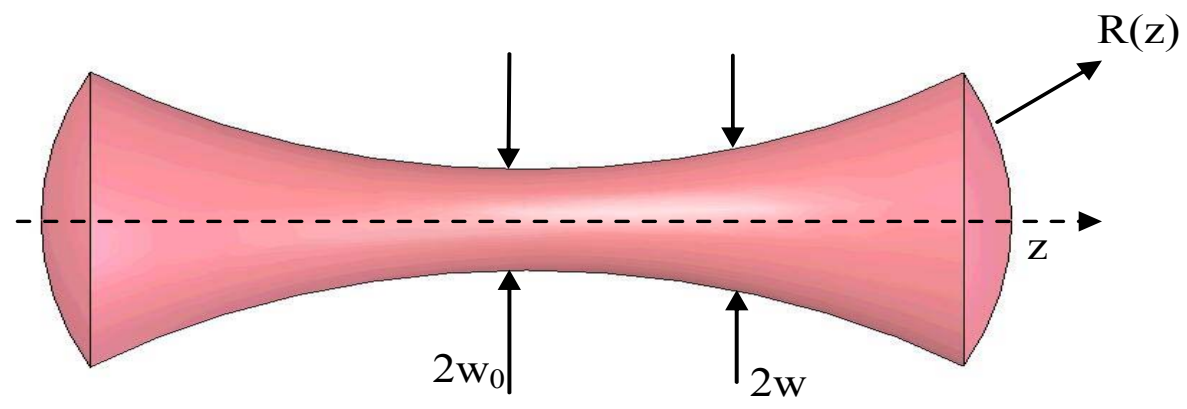

Figura 2-1: Propagação de um feixe gaussiano e variação da amplitude do campo com a coordenada radial. $\mathrm{R}(\mathrm{z})$ representa a curvatura da frente de onda, observamos sua variação enquanto a onda se propaga na direção $z$.

Para uma distância $r=w(z)$, o valor de E cai para $1 /$ e do valor em $z=0$ e esta distância é chamada de raio do feixe. De acordo com a equação (2.4), na origem o raio mínimo é $\mathrm{w}_{0}$, nesta posição temos a "cintura do feixe" (figura 2-1). Ainda nesta equação temos $\mathrm{z}_{0}=\pi \mathrm{nw}_{0}{ }^{2} / \lambda$ que é chamado de comprimento de Rayleigh e é importante notar que existe um valor mínimo para o raio do feixe relacionado a fenômenos de difração. 


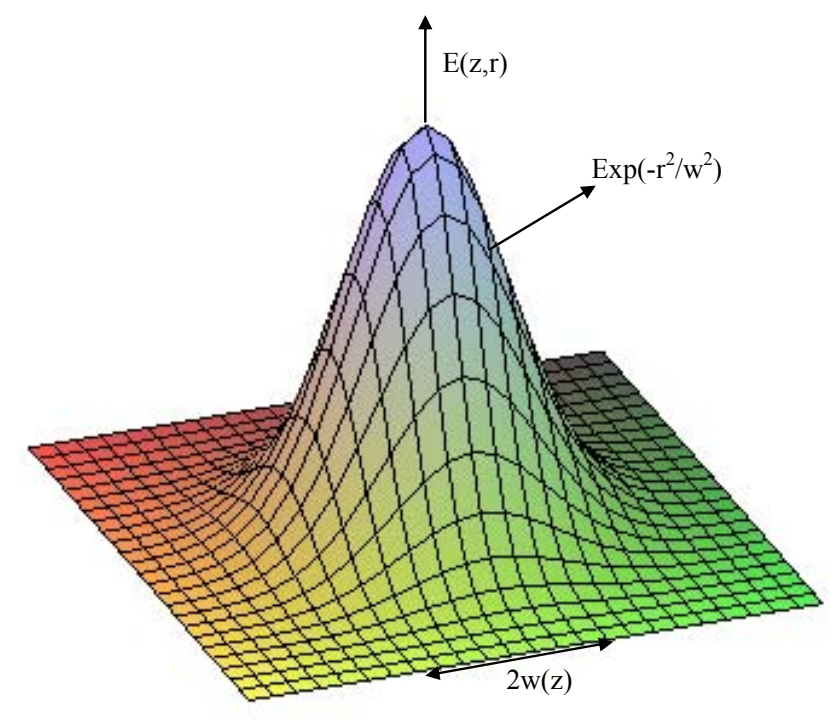

Figura 2-2: Variação da amplitude do campo com a coordenada radial. Observa-se que o feixe possui um perfil gaussiano com a máxima amplitude em $r=0$.

Ainda na figura 2-1 vemos o raio de curvatura da onda $R(z)$ variando conforme a onda se propaga. Devido a essa peculiaridade, os feixes gaussianos não seguem as leis da óptica geométrica, mas sim da óptica ondulatória, onde o fenômeno de difração é importante. A propagação do feixe gaussiano segue a lei matricial (lei $\mathrm{ABCD}$ ) $[23,24]$ que prevê as características do feixe após percorrer certa distância ou atravessar componentes ópticos dados suas características iniciais em algum ponto do percurso. Não nos aprofundaremos neste tipo de estudo, mas voltaremos a falar nos próximos capítulos da sua importância no planejamento e caracterização da armadilha. 


\subsection{A Armadilha de Dipolo}

Nesta seção derivaremos o potencial de aprisionamento e a taxa de espalhamento de fótons para um átomo na presença de um campo de radiação. A força dipolar óptica surge da interação entre o momento de dipolo induzido (d) em um átomo e o campo elétrico $\mathbf{E}$ do feixe óptico. O momento de dipolo é induzido pelo próprio campo elétrico da radiação e é dado por $\mathbf{d}=\alpha \mathbf{E}$ onde $\alpha$ é a polarizabilidade do átomo [25]. O potencial de interação $\mathbf{U}$ entre o momento de dipolo induzido e o campo da radiação é dado por:

$$
U=-\frac{1}{2} \overline{d \cdot E}
$$

em que o fator $1 / 2$ é devido ao fato de que o dipolo é induzido e não permanente. Em termos de polarizabilidade o momento de dipolo pode ser escrito como $\mathbf{d}=\alpha \mathbf{E}$ tornando o potencial de interação uma função da intensidade da radiação:

$$
U=-\frac{1}{4} \alpha E^{2}=-\frac{2 \pi}{c} \alpha I
$$

Note que o potencial é proporcional à intensidade da radiação e pode ser atrativo ou repulsivo, dependendo do sinal de $\alpha$. Quando focalizamos um feixe geramos uma região de cintura mínima semelhante ao mostrado na figura 2-1. Sendo a intensidade da radiação proporcional ao quadrado do campo elétrico $\mathbf{E}$ podemos utilizar a expressão 2.3 para escrevermos o potencial tridimensional confinante para 
átomos e moléculas, sugerido pela primeira vez por Ashkin (1977) [26] e demonstrado por Chu (1986) [27]:

$$
U(r, z, \phi)=-\frac{U_{0}}{1+\left(z / z_{R}\right)^{2}} \exp \left(-2 \frac{r^{2}}{w_{o}^{2}}\right)
$$

em que a profundidade do potencial assume o valor $U_{0}=\frac{\alpha_{\text {stat }} P_{0}}{\varepsilon_{0} c \pi w^{2}{ }_{0}}$, onde $\mathrm{P}_{0}$ é a potencia do laser. Para átomos ultrafrios a temperatura $\mathrm{T}$ é muito menor que o potencial $\mathrm{U}_{0}$, assim os átomos são confinados próximos a região de menor potencial, isto é, no foco do laser. As figuras 2-3 e 2-4 mostram respectivamente a anisotropia espacial e um esboço tridimensional do potencial confinante, simulado para átomos de $\mathrm{K}$ e $\mathrm{Rb}$.

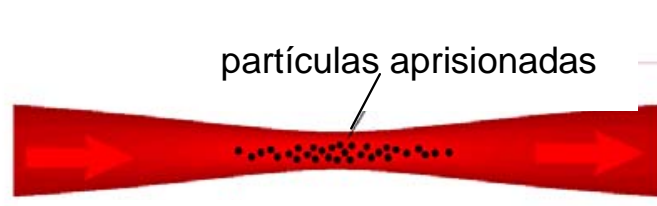

feixe focalizado

Figura 2-3: Disposição dos átomos aprisionados. Devido a anisotropia do potencial a amostra se configura com simetria cilíndrica próximo ao foco. 

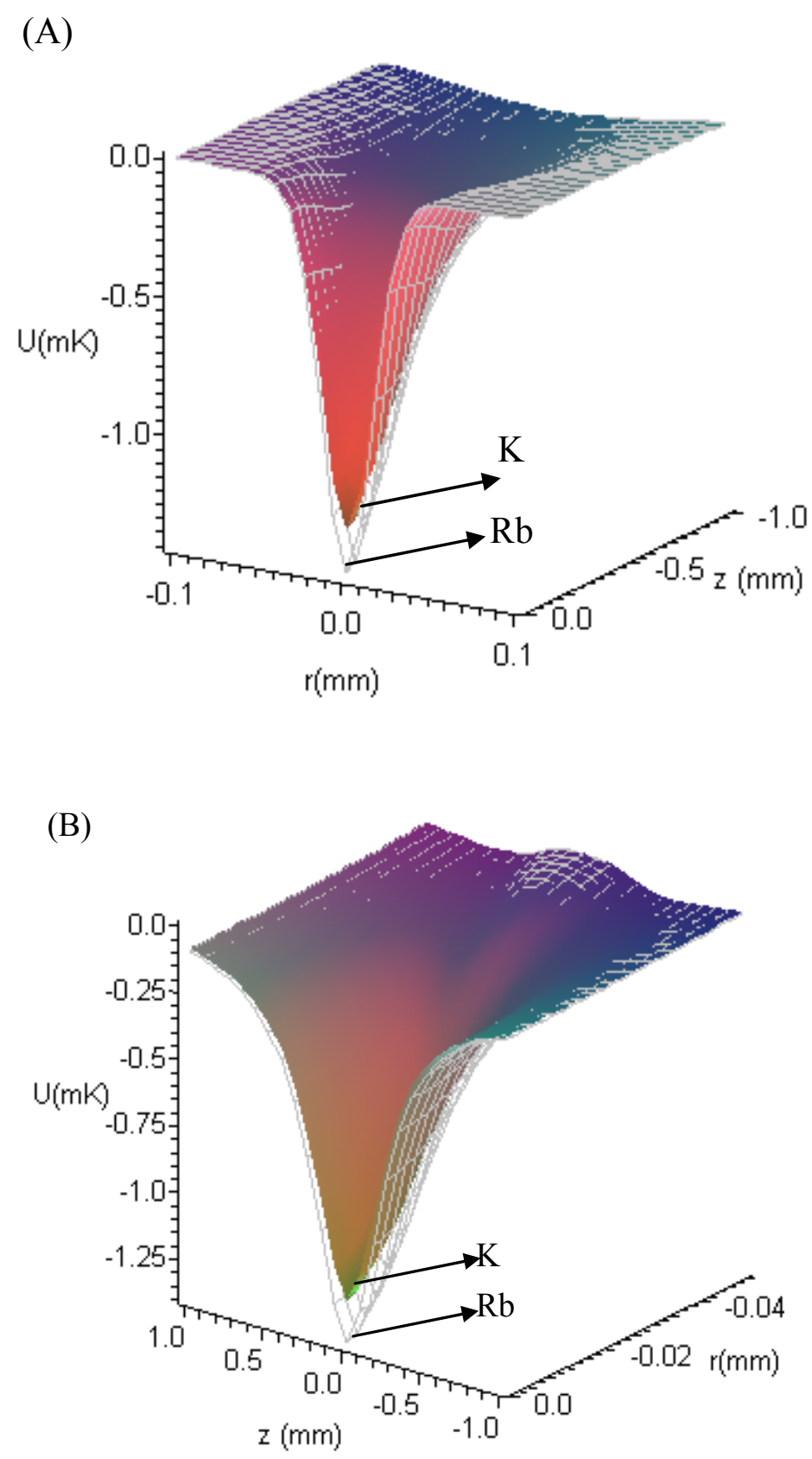

Figura 2-4: Potencial de aprisionamento confinante para uma armadilha de dipolo com um feixe focalizado: Gráfico gerado a partir das seguintes polarizabilidades estáticas: $53 \times 10^{-40} \mathrm{Cm}^{2} / \mathrm{V}$ para $R b$ e $48 \times 10^{-40} \mathrm{Cm}^{2} / \mathrm{V}$ para $\mathrm{K}$. Com as respectivas profundidades: $U_{0} / K_{B}=-1,4 \mathrm{mK}$ e $-1,3$ mK. Em (A) temos um corte do potencial perpendicular ao eixo de propagação em $z=0$ e em (B) um corte transversal em $\mathbf{r}=\mathbf{0}$. Nota-se um fator de captura menor na direção radial em comparação com o eixo z. 
A expressão (2.9) pode ser expandida em valores de $r$ e z próximos de zero tornando o potencial aproximadamente harmônico.

$$
U(r, z, \phi) \approx-U_{0}+\frac{1}{2} M\left(w_{z}{ }^{2} z_{2}+w_{r}{ }^{2} r^{2}\right)
$$

Desse modo, próximo à região do fundo do potencial (foco do laser) o átomo está sujeito à influência de um potencial harmônico anisotrópico com as respectivas freqüências axial de radial $\omega_{z}=\left(2 U_{0} / M z_{0}^{2}\right)^{1 / 2}$ e $\omega_{r}=\left(4 U_{0} / M w_{0}^{2}\right)^{1 / 2}$ onde M é a massa do átomo. Sabendo que a intensidade do laser é diretamente proporcional a $\mathrm{U}_{0}$, as freqüências de oscilação da armadilha também serão relacionadas com a potência do laser.

Em uma armadilha de dipolo, a amostra está sujeita a aquecimentos indesejáveis que surgem de vários mecanismos como: colisões inelásticas entre átomos com estado excitado, flutuações na força dipolar (devido ao fato de que a polarizabilidade para o estado excitado é, em geral, diferente da do estado fundamental), e o espalhamento de fótons. Este último pode ser minimizado com base na potencia radiada por um dipolo oscilante dado pela fórmula de Larmor:

$$
P=\frac{2 \overline{\ddot{d}}^{2}}{3 c^{3}}=\frac{\omega^{4} \alpha^{2} E^{2}}{3 c^{3}}
$$

Em que $\omega$ é a freqüência do campo da radiação e $d=\operatorname{er}_{0} \cos (\omega t)$, nesta expressão $r_{0}$ é escrito em termos da amplitude da radiação interagente $\left(r_{0}=\alpha E\right)$. A 
taxa de espalhamento de fótons no foco do laser pode ser escrita em termos da secção de choque de espalhamento:

$$
R_{s c}=\frac{P}{\hbar \omega}=\frac{\sigma_{s} I_{0}}{\hbar c k}
$$

em que:

$$
\sigma_{s}=\frac{8 \pi}{3} \alpha^{2} k^{4}
$$

Precisamos determinar o valor da polarizabilidade do átomo. Para isso, podemos supor um átomo cujo elétron está harmonicamente ligado ao núcleo e sua equação de movimento é governada por:

$$
\ddot{x}+\omega_{0}{ }^{2} x=\frac{e E(t)}{m_{e}},
$$

em que $\omega_{0}$ é a freqüência natural de oscilação, $e$ e $m_{e}$ são respectivamente a carga e a massa do elétron. Na resolução desta equação podemos obter a polarizabilidade $(\alpha)$ considerando $\mathbf{d}=\mathrm{ex}=\alpha \mathbf{E}$ :

$$
\alpha=\frac{e^{2}}{2 \omega_{0} m_{e}}\left[\frac{1}{\omega_{0}-\omega}+\frac{1}{\omega_{0}+\omega}\right]=\frac{\mu^{2}}{\hbar}\left[\frac{1}{\omega_{0}-\omega}+\frac{1}{\omega_{0}+\omega}\right]
$$


Este resultado reproduz os resultados da mecânica quântica quando usamos a primeira ordem da teoria da perturbação dependente do tempo, assim $\mu=e \sqrt{\hbar / 2 m e \omega_{0}}$ pode ser substituído por $\mu_{\mathrm{eg}}$ que é o elemento da matriz de dipolo calculado entre o estado excitado e o fundamental [28]. Note que o dipolo oscila em fase quando $\alpha>0$, isto é, quando o campo aplicado tem freqüência abaixo da ressonância $\left(\omega<\omega_{0}\right)$, assim o átomo é atraído para a região de maior intensidade, por outro lado, se o laser é sintonizado acima da transição atômica, isto é, $\omega>\omega_{0}$ o dipolo oscila $180^{\circ}$ fora de fase e o átomo é repelido da região de maior intensidade.

Estamos interessados em minimizar a taxa de espalhamento de fótons, assim devemos escolher $\omega$ de modo que o detuning $\Delta=\omega_{0}-\omega$ seja grande comparado à largura natural da transição atômica. Em muitos casos o valor de $\Delta$ é escolhido de modo a ser muito maior do que a diferença dos espaçamentos da estrutura hiperfina do átomo. Neste caso a estrutura fina e a hiperfina não pode ser resolvida e as transições podem ser simplificadas considerando apenas transições ocorrendo entre estados de momento angular orbital $L=0$ e $L^{\prime}=1$.

\section{3 "Far-Off Resonance Traps"}

Vimos anteriormente que é necessário utilizarmos uma freqüência abaixo da ressonância para gerarmos um potencial atrativo para o aprisionamento e é utilizado $\Delta>>\Gamma$ para reduzirmos a taxa de espalhamento de fótons. Entretanto, em muitos experimentos, pode-se usar $|\Delta|<<\omega_{0}$ tornando o termo $1 /\left(\omega_{0}+\omega\right)$ desprezível em 
relação ao termo $1 /\left(\omega_{0}-\omega\right)=1 / \Delta$ na expressão da polarizabilidade, equação (2.15). Assim:

$$
\alpha=\frac{\mu_{e g}{ }^{2}}{\hbar \Delta}
$$

e o potencial se torna:

$$
U=\frac{-\mu_{e g}^{2} E_{2}}{4 \hbar \Delta}=-\frac{\hbar \Omega^{2}}{4 \Delta}
$$

em que $\Omega \equiv \mu_{e g} E / \hbar$ é a freqüência de oscilação de Rabi. Note que a quantidade $\Omega^{2}$ é proporcional à intensidade da radiação. Substituindo (2.16) e (2.12) em (2.13) temos a taxa de espalhamento de fótons para este limite:

$$
R s c=\frac{4 \omega_{0}^{3} \mu_{e g}^{2}}{3 \hbar c^{3}}\left(\frac{\omega}{\omega_{0}}\right)^{3} \frac{\Omega^{2}}{4 \Delta^{2}} \cong \frac{\Gamma \Omega^{2}}{4 \Delta^{2}}
$$

Examinando estas equações (2.17) e (2.18) vemos que a profundidade do potencial de um feixe gaussiano focalizado para esta aproximação é proporcional a $\mathrm{I}_{0} / \Delta$ enquanto que a taxa de espalhamento de fótons é proporcional a $\mathrm{I}_{0} / \Delta^{2}$. A taxa de espalhamento de fótons pode ser expressa em termos de potencial $\mathrm{U}_{0}$ :

$$
R_{s c}=\frac{\Gamma}{\hbar \Delta} U_{0}
$$


Então, podemos reduzir a taxa de espalhamento de fótons enquanto mantemos um dado potencial ajustando a freqüência longe da ressonância e aumentando a potencia do laser.

Na primeira demonstração de uma armadilha totalmente óptica [27] foi usado $220 \mathrm{~mW}$ de potencia em uma cintura de $\mathrm{w}=10 \mu \mathrm{m}$ ajustado a $650 \mathrm{GHz}$ abaixo da ressonância. Isto produziu um potencial com uma profundidade de $5 \mathrm{mK}$ para átomos neutros de sódio. Com esses parâmetros, uma grande taxa de espalhamento de fótons limitou o tempo de vida da armadilha em $4 \mathrm{~ms}$. Utilizando um grande detuning longe da ressonância, Miller e colaboradores [29] demonstraram um FORT no qual a taxa de espalhamento de fótons foi reduzida. Em seu experimento foi usado um laser com $800 \mathrm{~mW}$ de potencia focalizado em uma cintura de $\mathrm{w}=10 \mu \mathrm{m}$ ajustado a $19 \mathrm{~nm}$ abaixo da ressonância gerando uma profundidade de $6 \mathrm{mK}$ no potencial para átomos de $\mathrm{Rb}$. Neste caso a taxa de espalhamento de fótons foi de $400 \mathrm{~Hz}$ sendo esperado um tempo de vida de $43 \mathrm{~s}$, mas devido a pressão de fundo do seu sistema este tempo de vida foi reduzido para $200 \mathrm{~ms}$.

\section{4 "Quase-Electrostatic Traps"}

Há também a possibilidade do uso de lasers $\left(\mathrm{CO}_{2}\right)$ que produzem $10.6 \mu \mathrm{m}$ de radiação com detuning grandes excedendo a freqüência de ressonância $\left(\Delta>>\omega_{0}\right)$ que reduz drasticamente, comparavelmente com um FORT, a taxa de espalhamento óptico nas amostras $[30,31,32,33]$. Para esta aproximação, onde $\Delta>>\omega_{0}$, a polarizabilidade pode ser expressa como: 


$$
\alpha=\alpha_{s} \frac{1}{1-\omega^{2} / \omega_{0}^{2}}
$$

em que $\alpha_{s} \equiv 2 \mu^{2} / \hbar \omega_{0}$ é a polarizabilidade estática de um átomo de dois níveis. Então, para $\omega<<\omega_{0}$ o potencial de interação de dipolo para um campo oscilante é idêntico para um campo estático:

$$
U=-\frac{1}{2} \alpha_{s} E_{r m s}^{2}=-\frac{1}{4} \alpha_{s} E^{2}
$$

Com esta aproximação o dipolo elétrico induzido no átomo oscila em fase com o campo elétrico do laser variando lentamente com o tempo. Assim o nome armadilha quase-eletrostática (QUEST, em inglës) foi cunhado para essa implementação particular de uma armadilha de dipolo. A taxa de espalhamento óptico é dada pela fórmula de Larmor:

$$
R_{s c}=\sigma_{s} I_{0} / \hbar c k
$$

com a seguinte secção de choque de espalhamento:

$$
\sigma_{s}=\frac{8 \pi}{3} \alpha_{s}^{2} k^{4}
$$

Comparando com o resultado da equação (2.19) podemos reescrever a taxa de espalhamento em termos da profundidade do potencial $U_{0}=2 \pi \alpha_{s} I_{0} / \mathrm{c}$ como: 


$$
R_{s c}=\frac{2 \Gamma}{\hbar \omega_{0}}\left(\frac{\omega}{\omega_{0}}\right)^{3} U_{0}
$$

Aqui usamos $\alpha_{s} \equiv 2 \mu^{2} / \hbar \omega_{0}$ e $\Gamma=4 \mu_{e g}{ }^{2} \omega_{0}{ }^{3} / 3 \hbar c^{3}$ na aproximação de um átomo de dois níveis. Comparando com as equações (2.19) e (2.24) vemos que a taxa de espalhamento no regime quasi-electrostatic é proporcional a um fator $2\left(\omega / \omega_{0}\right)^{3}$, neste caso geramos valores para taxa de espalhamento típicos $<10^{-3} \mathrm{~Hz}$, ou seja, da ordem de um fóton por hora.

Takekoshi e colaboradores [31] demonstraram um QUEST confinando átomos de Cs utilizando um laser de $\mathrm{CO}_{2}$ com comprimento de onda $\lambda=10,6 \mu \mathrm{m}$ e uma potência de $20 \mathrm{~W}$ focalizado em uma cintura de $100 \mu \mathrm{m}$ gerando uma profundidade de $115 \mu \mathrm{K}$. A taxa de espalhamento neste sistema $\left(2 \times 10^{-4} \mathrm{~Hz}\right)$ é totalmente desprezada, onde o principal limitante para tempo de vida da armadilha está nas colisões devido aos átomos frios (átomos aprisionados) e aos átomos quentes, que geram a pressão de fundo em seu sistema.

\subsection{A Armadilha Magneto-Óptica.}

Para atingirmos o grande objetivo deste projeto, o aprisionamento de átomos e moléculas em uma armadilha de dipolo, é indispensável o uso de uma armadilha magneto-óptica. Em uma armadilha de dipolo a radiação intensa, longe de qualquer ressonância atômica, induz um dipolo na amostra atômica gerando uma força atrativa, ao contrário da armadilha magneto-óptica que opera em um regime de 
transição de níveis atômicos, onde o átomo recebe momento $\hbar k$ da radiação para ser aprisionado.

Este pré-armadilhamento ou pré-carregamento é necessário, pois uma armadilha de dipolo tem um baixo poder e captura de átomos de alta energia, uma vez que são emitidos de uma fonte quente $\cong 800^{\circ} \mathrm{C}$ (getters $\left.[34,35]\right)$. Assim são necessários um resfriamento e confinamento atômico que a armadilha magnetoóptica nos fornece. Neste tópico abordaremos as características principais deste tipo de armadilha e sua base teórica de funcionamento em modelos atômicos simplificados.

\subsubsection{Resfriamento Doppler.}

Sintonizando a freqüência do laser abaixo da ressonância atômica, a pressão de radiação exercerá uma força retroativa nos átomos. Para ver isto, considere o átomo em uma dimensão iluminado por feixes de laser contrapropagantes sintonizados abaixo da ressonância, com mostra a figura 2-5.

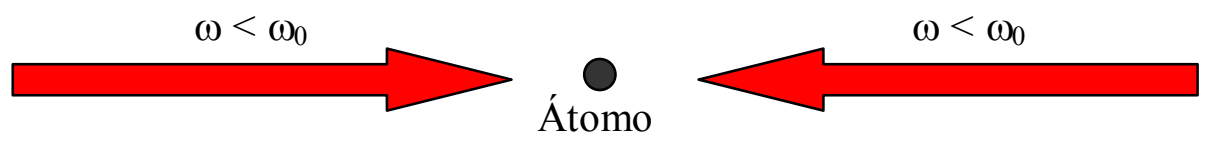

Figura 2-5: Molasses óptico unidimensional. Dois feixes contrapropagantes sintonizados abaixo da ressonância $\left(\omega_{0}\right)$ incidindo em um átomo.

Se o átomo se move para a direita, o feixe que se propaga para a esquerda terá sua freqüência deslocada para próximo da ressonância atômica devido ao efeito 
Doppler, ao contrário do feixe que se move para a direita, que terá sua freqüência deslocada para longe da ressonância. Isso produz uma força que se opõe ao movimento do átomo provocando uma desaceleração em seu movimento. Considerando um sistema atômico de dois níveis, podemos escrever a força da radiação exercida no átomo como:

$$
\vec{F}=-\frac{\hbar \Gamma \Omega^{2} \nabla \theta}{4(\Delta+\dot{\theta})^{2}+\Gamma^{2}+2 \Omega^{2}}
$$

Esta é a força que o átomo recebe a cada absorção e emissão de fótons, onde $\theta=-\vec{k} \cdot \vec{r}$ para uma onda plana, $\dot{\theta}=-\vec{k} \cdot \vec{v}, \Delta$ é a diferença entre a freqüência de transição e a freqüência da radiação, $\Gamma$ é a taxa de emissão espontânea e $\Omega$ a freqüência de Rabi. Note que para pequenas velocidades $(|\dot{\theta}|<<|\Delta|, \Gamma)$, a força líquida é linear com a velocidade $F_{\text {tot }}=-\alpha v$, em que:

$$
\alpha=-4 \hbar k^{2} \frac{I}{I_{0}} \frac{2 \Delta / \Gamma}{\left[1+(2 \Delta / \Gamma)^{2}\right]^{2}}
$$

Essa força viscosa retira energia do átomo a uma taxa de $(\mathrm{dE} / \mathrm{dt})_{\text {resfriamento }}=\mathrm{Fv}_{\mathrm{V}}$ $=-\alpha v^{2}$ embora ela nunca seja reduzida a zero. Devido ao fato do átomo estar continuamente espalhando fótons, ele também executa um movimento randômico no espaço dos momentos. Recebe um recuo em uma direção definida, devido à absorção, mas recebe um impulso em uma direção qualquer devido à emissão. Assim existe um aquecimento devido ao espalhamento de fótons descrito na expressão a seguir: 


$$
\left(\frac{d E}{d t}\right)_{\text {aquecimento }}=\frac{1}{2 M} 2 \Gamma_{s c} \hbar^{2} k^{2}
$$

Em que $\Gamma_{s c}$ é a taxa de espalhamento de fótons. No equilíbrio a taxa de aquecimento e de resfriamento deve ser igual e para a condição de $\Delta=-\Gamma / 2$, teremos $v^{2}=\hbar \Gamma / 2 M$ como um valor mínimo $(\mathrm{M}=$ massa do átomo $)$. Pelo teorema de eqüipartição de energia $\mathrm{K}_{\mathrm{B}} \mathrm{T} / 2=\mathrm{mV}^{2} / 2$ teremos uma temperatura mínima correspondente:

$$
T_{\min }=\frac{\hbar \Gamma}{2 K_{B}}
$$

Esta temperatura é conhecida como o limite [36] Doppler. Para o ${ }^{85} \mathrm{Rb}, \mathrm{T}_{\min }=$ $141 \mu \mathrm{K}$, este são valores típicos de temperatura em uma armadilha magneto-óptica causados pela técnica de resfriamento Doppler.

\subsubsection{Força Restauradora Espacial.}

Os seis feixes contrapropagantes abaixo da ressonância atômica $\left(\omega<\omega_{0}\right)$ constituem um meio viscoso para os átomos, este meio foi chamada de melaço óptico ou optical molasses e criado pela primeira vez em 1985 por Steven Chu e colaboradores [2]. Embora os átomos sejam desacelerados não temos uma amostra confinada espacialmente. Para resolver este problema devemos introduzir um gradiente de campo magnético quadrupolar, gerando uma origem de campo nulo e um gradiente linear ao afastarmos desta origem em qualquer direção do espaço. 
Disso surgiu o nome MOT (Magneto-optical trap) ou Armadilha MagnetoÓptica demonstrada experimentalmente em 1987 por Raab e colaboradores [3]. Na figura 2-6 temos um aparato experimental para a construção de um MOT, duas bobinas são usados para gerar o campo de quadrupolo magnético (configuração antiHelmholtz). O campo magnético $\mathbf{B}$ cresce linearmente da origem em qualquer das direções.

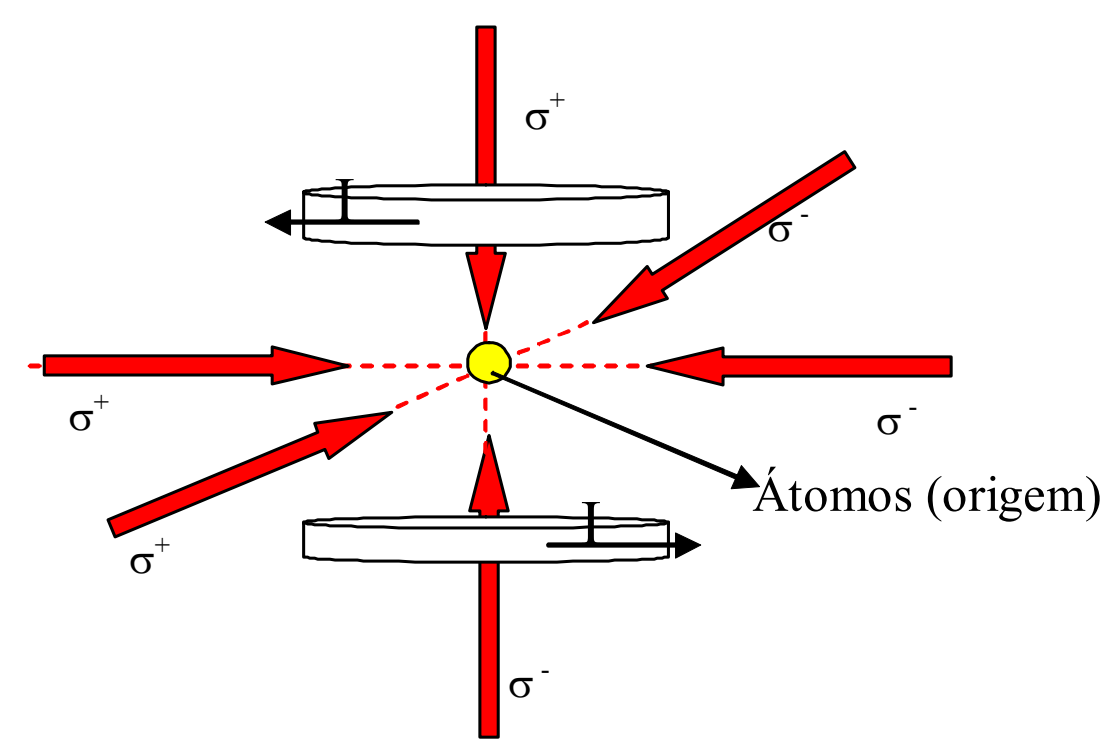

Figura 2-6: Construção de uma armadilha magneto-óptica. Três pares de feixes contrapropagantes com suas respectivas polarizações $\left(\sigma^{+}\right.$e $\left.\sigma^{-}\right)$e uma bobina quadrupolar na configuração anti-Helmholtz.

Para melhor compreensão da força restauradora que rege o sistema, consideremos um átomo de dois níveis onde o estado fundamental possui momento angular total $\mathbf{F}=\mathbf{0}$ e o estado excitado $\mathbf{F}^{\prime}=\mathbf{1}$. Ao aplicarmos um campo magnético $\mathbf{B}$ neste átomo quebra-se a degenerescência dos estados formando subníveis de energia determinados pelo número quântico $\mathbf{m}_{\mathbf{F}}$. Esses níveis de energia tendem a se separar proporcionalmente com a intensidade do campo magnético, $\Delta \mathbf{E} \alpha \mathbf{B}$. A figura 2-7 
mostra esse efeito, em uma dimensão, para um átomo em um gradiente de campo magnético.

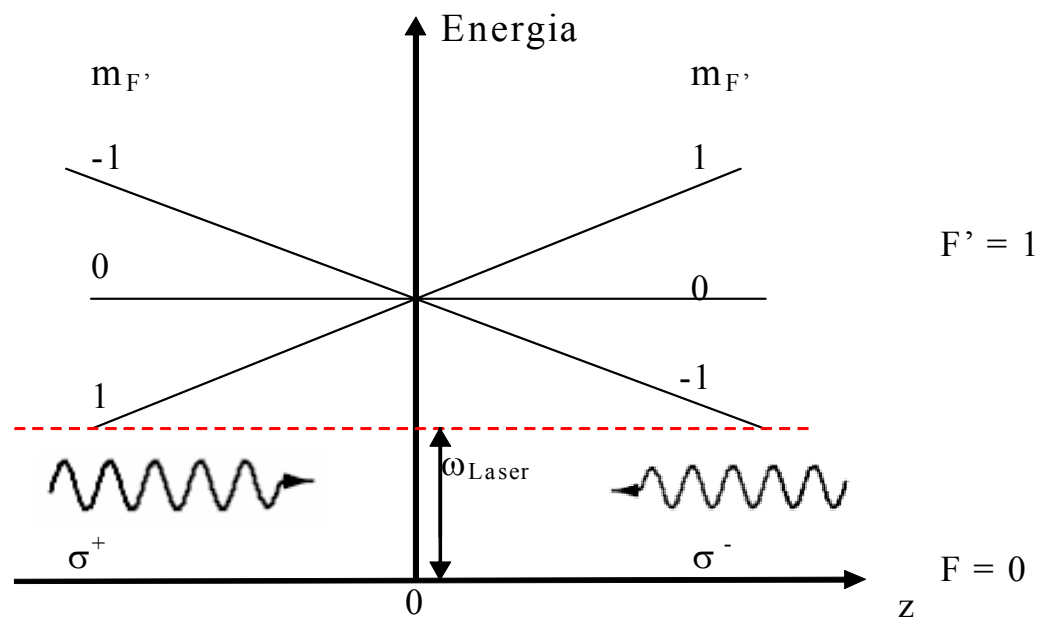

Figura 2-7: Força restauradora espacial em uma dimensão. $O$ estado fundamental $F=0$, não sofre variação em sua energia $\Delta E=0$, já o estado excitado $F^{\prime}=1$ sofre variação de $\Delta E=\left(m_{F}\right.$, = $1,0,+1)$.

O laser que se propaga para a esquerda é ajustado para uma polarização circular $\sigma^{-}$e só pode realizar transições de $\mathrm{F}=0$ para o subnível $\mathrm{m}_{\mathrm{F}},=-1$. Ao contrário do que acontece com o laser que se propaga para a direita, é ajustado para uma polarização circular $\sigma^{+}$onde só poderá realizar transições de $\mathrm{F}=0$ para o subnível $\mathrm{m}_{\mathrm{F}}$, $=+1$. Deste modo o átomo tende a se localizar na região de menor potencial, isto é, onde o campo magnético é nulo, nesta posição ele sofrerá menor interação com a radiação. Para um problema real devemos considerar as três dimensões, e para isso basta fazer as mesmas considerações para o eixo x e y, assim esse sistema de feixes aprisiona os átomos na região de menor campo magnético. 


\subsection{A Armadilha Magnética.}

Com o mesmo gradiente de campo magnético utilizado para a armadilha magneto-óptica, podemos utilizar para o aprisionamento magnético. Este tipo de armadilha é o método mais simples para aprisionamento de átomos neutros necessitando de apenas um par de bobinas na configuração anti-Helmholtz (figura 28). Um átomo com um momento magnético $\vec{\mu}$ pode ser confinado por um campo magnético inomogêneo devido a interação entre seu momento e o campo produzindo uma força da por:

$$
\vec{F}=\vec{\nabla}(\vec{\mu} \cdot \vec{B})
$$

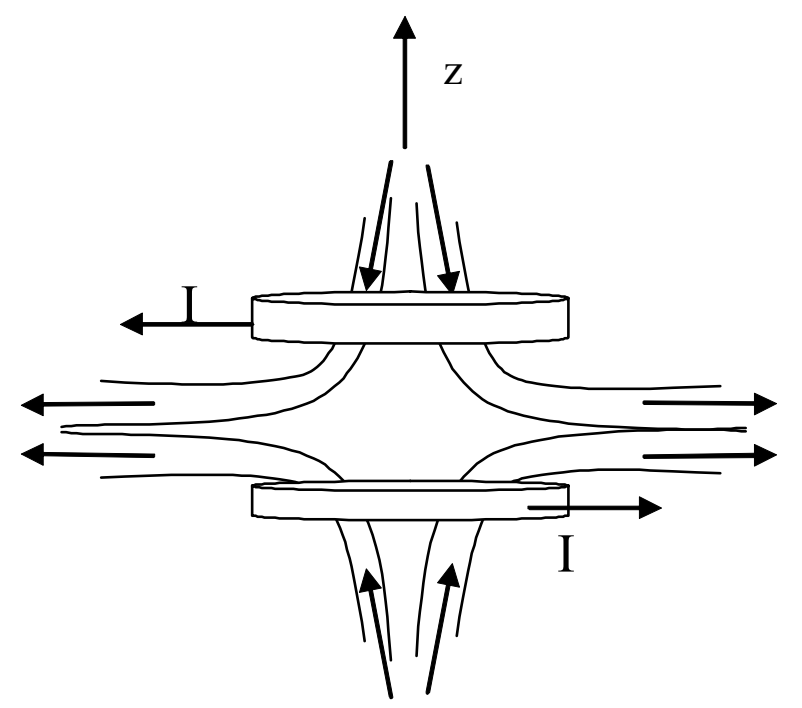

Figura 2-8: Diagrama das bobinas na configuração anti-Helmholtz. As linhas representam o campo magnético gerado pelas bobinas $\operatorname{com}|B|=0$ no centro.

Com esta configuração o campo magnético é nulo no centro e aumenta em qualquer das direções seguindo: 


$$
B=A \sqrt{\left(\rho^{2}+4 z^{2}\right)}
$$

em que $\rho^{2}=x^{2}+y^{2}$ e o gradiente de campo A é constante. Com a expressão 2.30 fica claro que o campo aumenta linearmente em qualquer direção partindo do centro $(\mathrm{z}=$ $\rho=0$ ), tendo um gradiente duas vezes maior em $\mathrm{z}$ do que no plano xy da bobina. 


\section{Capítulo 3}

\section{Construção da Armadilha de}

\section{Dipolo}

Neste capítulo, serão apresentadas todas as etapas da construção da armadilha de dipolo incluindo: a construção de uma nova câmara de aprisionamento, projetada para obtermos melhor acesso óptico com relação às antigas câmaras e pressões na região de ultra-alto vácuo; a construção da armadilha magneto-óptica, essencial para o carregamento da armadilha de dipolo; e descreveremos os lasers utilizados nos experimentos e suas características.

\subsection{Lasers para Armadilha de Dipolo}

Como vimos no capítulo 2, para o aprisionamento de átomos e moléculas por interação de dipolo, é necessário radiação com freqüência abaixo da ressonância 
atômica. Neste caso podemos utilizar um laser de $\mathrm{CO}_{2}$ ou um laser Ti-Safira para a formação de um QUEST ou FORT respectivamente.

\subsubsection{Laser de $\mathrm{CO} 2$}

O desenvolvimento de um QUEST dependerá essencialmente do laser de $\mathrm{CO}_{2}$ cuja principal característica é sua potência, que é da ordem de $100 \mathrm{~W}$. Nosso grupo possui um laser GEM - 100 de classe industrial, produzido pela COHERENT com $110 \mathrm{~W}$ de potência a $10.6 \mu \mathrm{m}$.

Diferente de um laser de diodo que necessita de uma boa estabilidade e uma freqüência bem sintonizada na transição atômica, o laser de $\mathrm{CO}_{2}$ opera em uma freqüência longe de qualquer transição atômica (10.6 $\mu \mathrm{m}$ - infravermelho). Seu poder de aprisionamento está ligado ao seu intenso gradiente de campo elétrico que é obtido após focalização, gerando um potencial atrativo e conservativo.

Para gerarmos este gradiente de campo necessitamos de um conhecimento específico de seus parâmetros, onde o principal deles é sua cintura $\mathbf{w}_{\mathbf{0}}$ que nos dirá qual a profundidade da armadilha $U o=2 \alpha_{\text {esta }} P / \pi \varepsilon_{0} c \boldsymbol{w}_{\boldsymbol{o}}$ [37]. Quanto menor $\mathbf{w}_{\mathbf{0}}$ mais profunda será nossa armadilha, por isso o feixe deve ser focalizado no centro da amostra.

Devido à alta potência que será dissipada pelo laser, necessitamos de um sistema de refrigeração e "interlock" que garanta grande segurança tanto no sistema do laser e em componentes que receberão sua radiação como, por exemplo, seu modulador de potência (Acusto-Óptical Modulator) que receberá sua potência máxima. Para isso utilizamos um Chiller, fabricado pela Thermo Neslab modelo M- 
33 que refrigera o sistema com uma mistura de 50/50 de água e etileno glycol. $\mathrm{O}$ esquema a seguir representa o circuito de refrigeração do sistema (Figura 3-1).

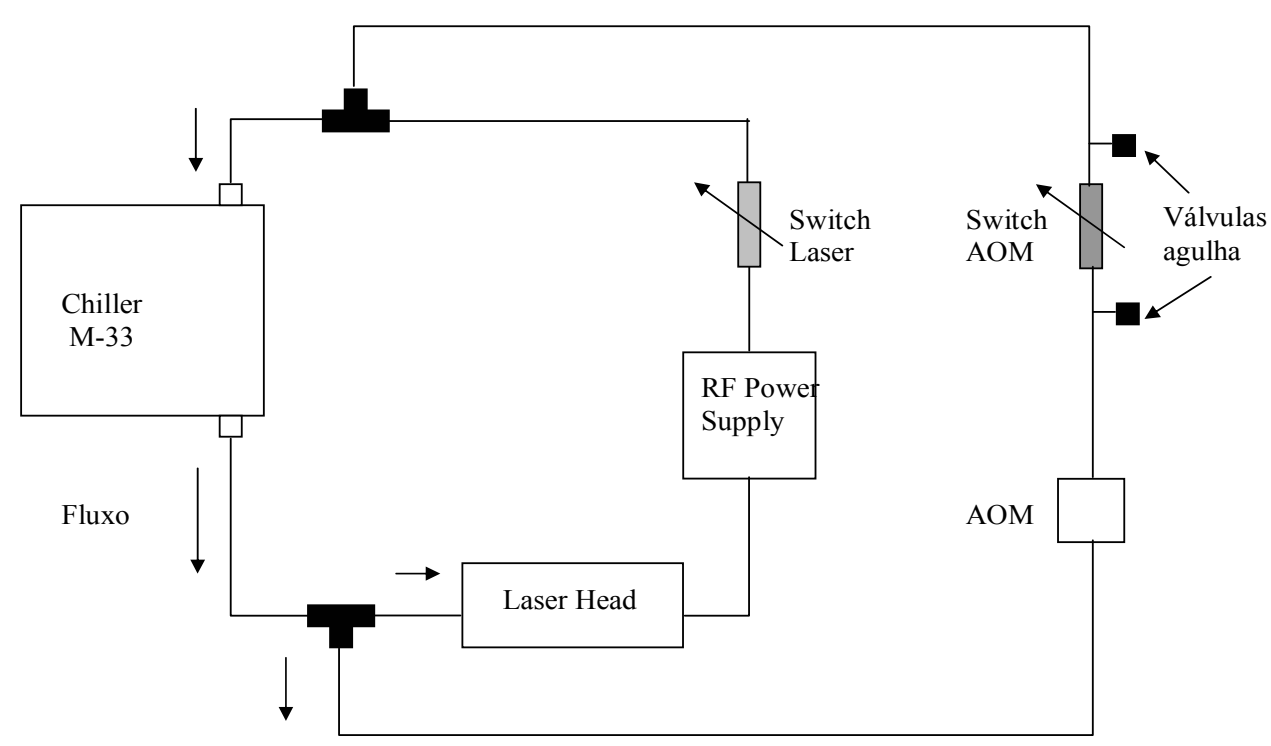

Figura 3-1: Sistema de refrigeração do laser de $\mathrm{CO}_{2}$ e o modulador acusto-óptico (AOM).

O sistema opera a 65PSI onde o máximo suportado pelo chiller é 80PSI. O circuito refrigera primeiramente o laser seguindo depois para sua fonte de alimentação. Através de duas válvulas do tipo "agulha", conseguimos controlar o sistema em paralelo que refrigera a AOM. Um conjunto de sensores e um circuito desligam automaticamente o sistema a qualquer sinal de irregularidade na refrigeração.

\subsubsection{Laser Ti:Safira}

Para a construção de um FORT $(\lambda \sim 1 \mu \mathrm{m})$ utilizaremos um laser Titânio Safira modelo 899 bombeado por um laser de Nd:YVO $\mathrm{YV}_{4}$ Veri - V10 ambos 
fabricado pela COHERENT. A radiação de aproximadamente $532 \mathrm{~nm}$ gerada pelo laser de argônio incide no cristal de titânio safira montado em uma cavidade em anel (borboleta) como mostrado na figura 3-2. Com este esquema geramos comprimento de onda que pode ser ajustado entre $750 \mathrm{~nm}$ a $1000 \mathrm{~nm}$ e uma potência de no máximo $1 \mathrm{~W}$.

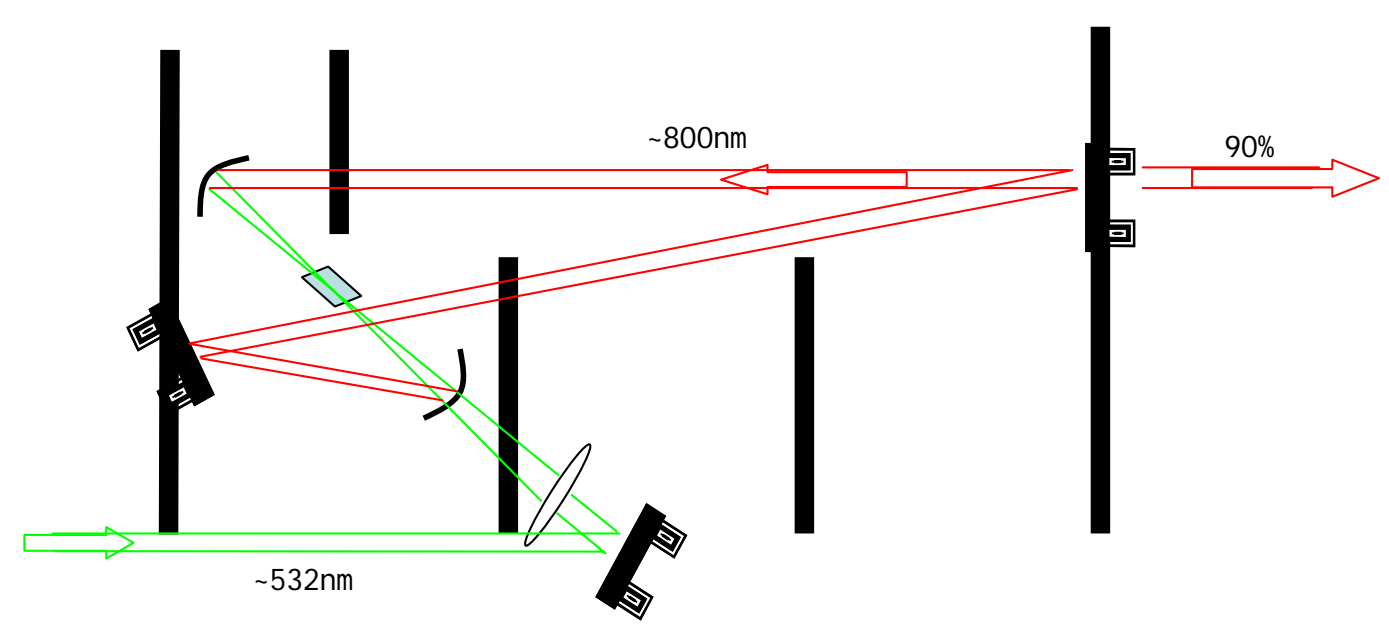

Figura 3-2: Esquema do laser Titânio Safira (COHERENT 899). Cavidade "borboleta" bombeada com laser de $\mathrm{Nd:} \mathrm{YVO}_{4} \sim 532 \mathrm{~nm}$.

\subsubsection{Caracterização}

Como discutido anteriormente, uma das características de nosso laser é a distribuição de potência de modo gaussiano e torno do seu eixo de propagação o que define uma cintura $\mathbf{w}$ em função da direção de propagação $\mathbf{z}$ (figura 2-1). A expressão $3.1[23,24]$ controla o tamanho da cintura como função do eixo.

$$
w^{2}(z)=w_{0}^{2}\left(1-\left[\frac{\left(z-z_{c}\right) \lambda}{\pi n w_{0}^{2}}\right]^{2}\right)
$$


Utilizando o método knife-edge [38, 39], que consiste na medida da potência de um feixe interrompido por uma peça metálica afiada (faca) e de alta refletividade, estamos calculando a integral da intensidade na área que ficou exposta, assim obtemos a expressão (3.2), que será utilizada nos ajustes das medidas experimentais. Nesta expressão $\mathbf{P}$ é a potência total, $\mathbf{I}$ o ponto central gaussiana, $\mathbf{x}$ a posição da faca e w a cintura do feixe que é o valor que nos interessa.

$$
P(x)=\frac{P}{2}\left\{1+\operatorname{erf}\left[\frac{\sqrt{2}(x-l)}{w}\right]\right\}
$$

Fizemos cinco cortes no feixe partindo de $33 \mathrm{~cm}$ a $153 \mathrm{~cm}$ do orifício do laser que correspondem à tabela 3-1. O gráfico da figura 3-3 ilustra uma destas medidas. Com estes cinco valores podemos calcular o valor de $\mathrm{w}_{0}$ através de um ajuste com a expressão para w(z), figura 3-4.

\begin{tabular}{|l|l|}
\hline $\mathbf{z}(\mathbf{c m})$ & $\mathbf{w}(\mathbf{z}) \mathbf{( m m})$ \\
\hline \hline 33 & 2.42 \\
\hline 63 & 2.97 \\
\hline 93 & 3.67 \\
\hline 123 & 4.7 \\
\hline 153 & 5.38 \\
\hline
\end{tabular}

Tabela 3-4: Valores obtidos para medidas de perfil do feixe até uma distância de $153 \mathrm{~cm}$ da saída do feixe do laser. 


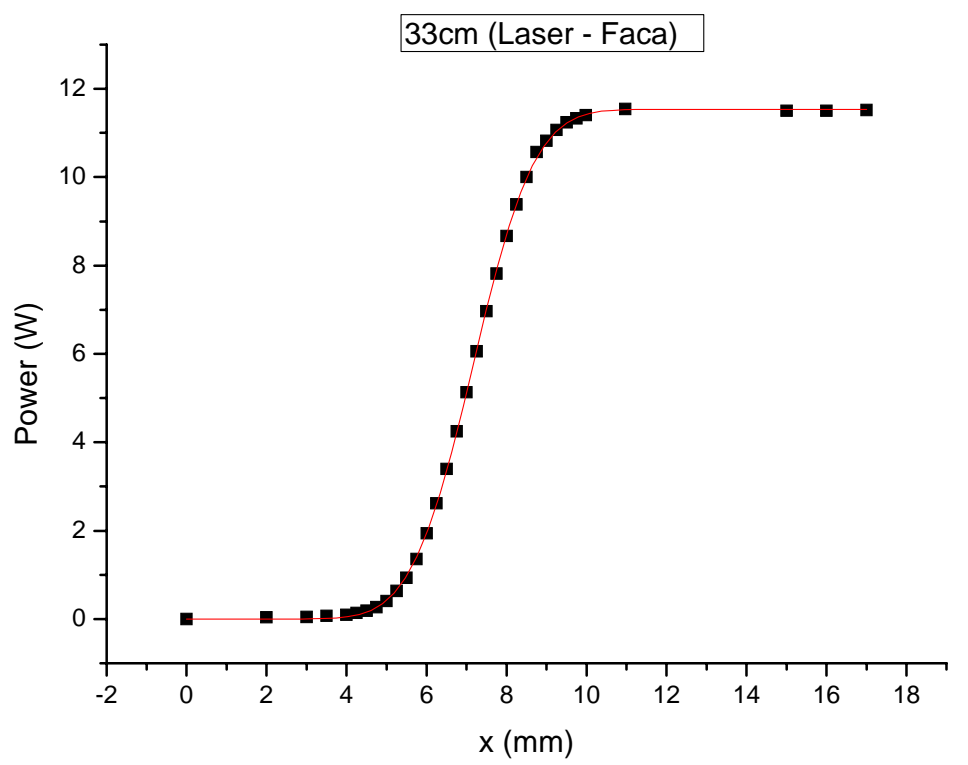

Figura 3-3: Medida de w a $33 \mathrm{~cm}$ do orifício da saída do feixe. Para as medidas, utilizamos uma faca acoplada em um carrinho com escala digital. $O$ aparelho nos oferece uma precisão de 0,005 mm

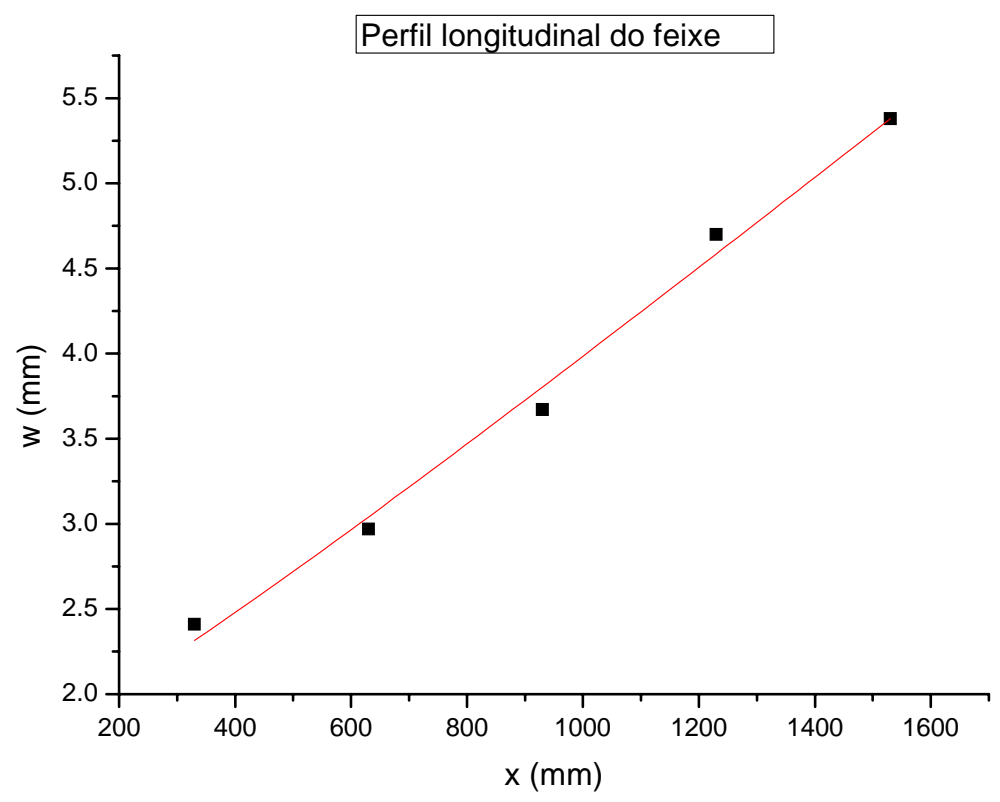

Figura 3-4 : Cálculo de wo. 
Obtemos $\mathbf{w}_{\mathbf{0}}=1,23 \mathrm{~mm}$ e $\theta_{\text {divergência }}=\lambda / n \pi w_{0}=2,7 \mathrm{mrad}$. O próximo passo seria a construção do primeiro telescópio (figura 3-5), formado por uma lente divergente $(f=-2$ “) e uma convergente $(f=7,5 ")$, ambas de $\mathrm{ZnSe}$, isto expandiria o feixe em 3,75X. Se considerássemos a óptica geométrica, veríamos que à distância (d) entre as lentes necessárias para formar o telescópio seria de 5,5 “= $=137,5 \mathrm{~mm}$, mas aplicando a lei de propagação (lei $\mathrm{ABCD}$ ) para feixes gaussianos vemos que a distância se torna um pouco maior chegando a $d=200 \mathrm{~mm}$, resultado que o experimento confirma.

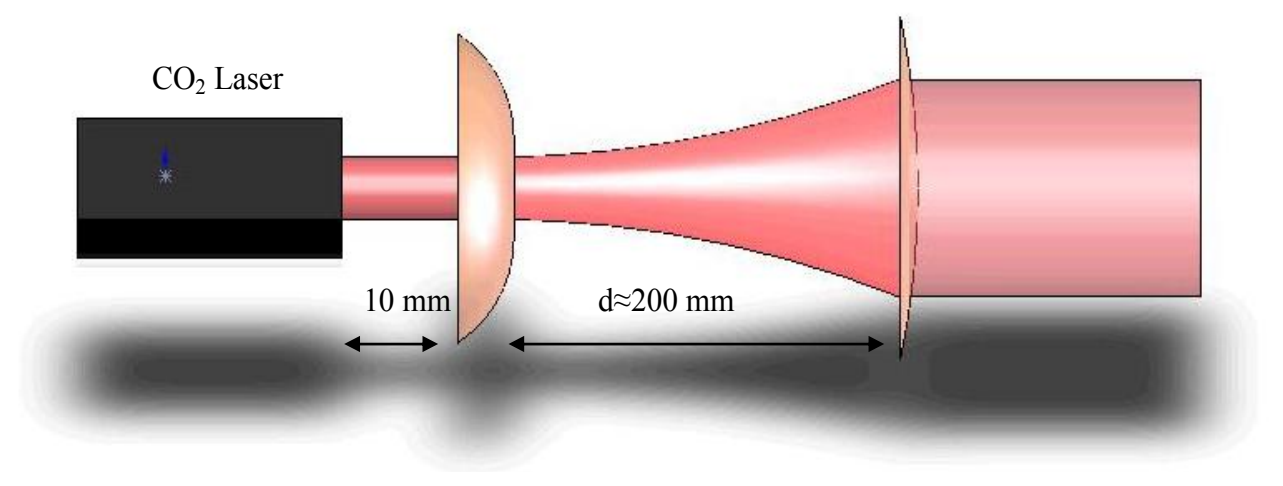

Figura 3-5: Primeiro telescópio para expansão do feixe.

Do mesmo modo, medimos w(z) fazendo cortes no feixe em $44 \mathrm{~cm}, 92 \mathrm{~cm} \mathrm{e}$ $153 \mathrm{~cm}$ do orifício do laser (tabela 3-2). Devido a pouca dispersão do feixe, a quantidades de pontos foi limitada em relação à medida do feixe sem óptica.

\begin{tabular}{|l|l|}
\hline $\mathbf{z}(\mathbf{c m})$ & $\mathbf{w}(\mathbf{z}) \mathbf{( ~ m m})$ \\
\hline 44 & 8.13 \\
\hline 92 & 8.59 \\
\hline 153 & 8.89 \\
\hline
\end{tabular}

Tabela 3-5: Valores obtidos para medidas de perfil do feixe para telescópio da figura 3-4 até uma distância de $153 \mathrm{~cm}$ da saída do feixe do laser. 


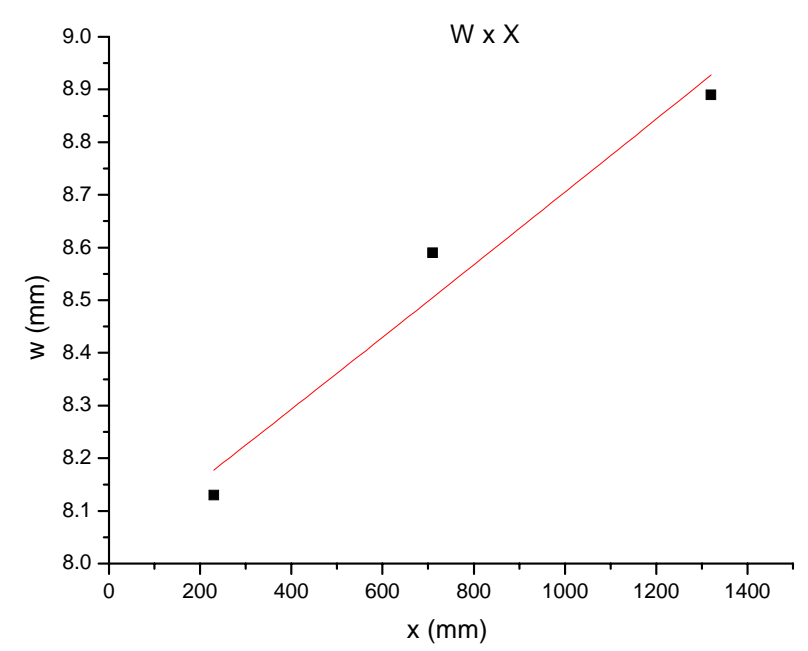

Figura 3-6: Cálculo de $w_{0}$ para o feixe oriundo do telescópio da figura 3-5.

Com estes resultados obtemos para o feixe expandido $\mathrm{w}_{0}=(4,3 \pm 0,6) \mathrm{mm}$, que corresponde ao aumento de $3,75 \mathrm{X}$ sobre $\mathrm{w}_{0}=1,23 \mathrm{~mm}$ do feixe inicial e também ao calculado (Maple 9.0) pela lei $\mathrm{ABCD}, \mathrm{w}_{0}=4,57 \mathrm{~mm}$. O último passo foi a caracterização do foco de uma lente de $\mathrm{ZnSe}(\mathrm{f}=50 \mathrm{~mm})$ que irá no interior da câmara de aprisionamento. O aparato utilizado está descrito na figura 3-7. Medimos sete pontos que vão de $6 \mathrm{~mm}$ a $95 \mathrm{~mm}$ da face plana da lente $(\mathrm{f}=50 \mathrm{~mm})$. Esses pontos montam o perfil que podemos observar no gráfico da figura 3-8.

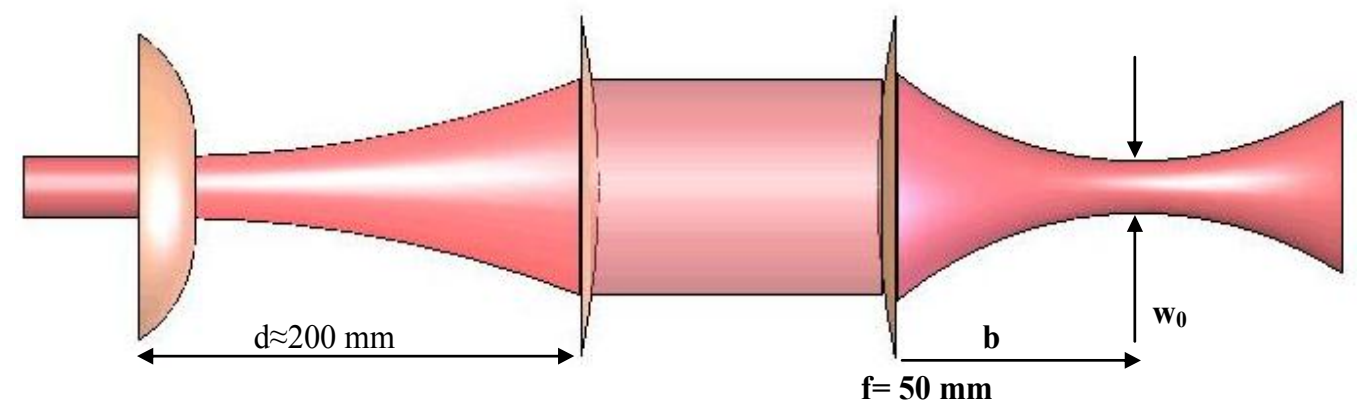

Figura 3-7: Aparato para a medida do perfil longitudinal do foco no interior da câmara. $O$ feixe é expandido através do telescópio já descrito e convergido com uma lente f $=50 \mathrm{~mm}$. 


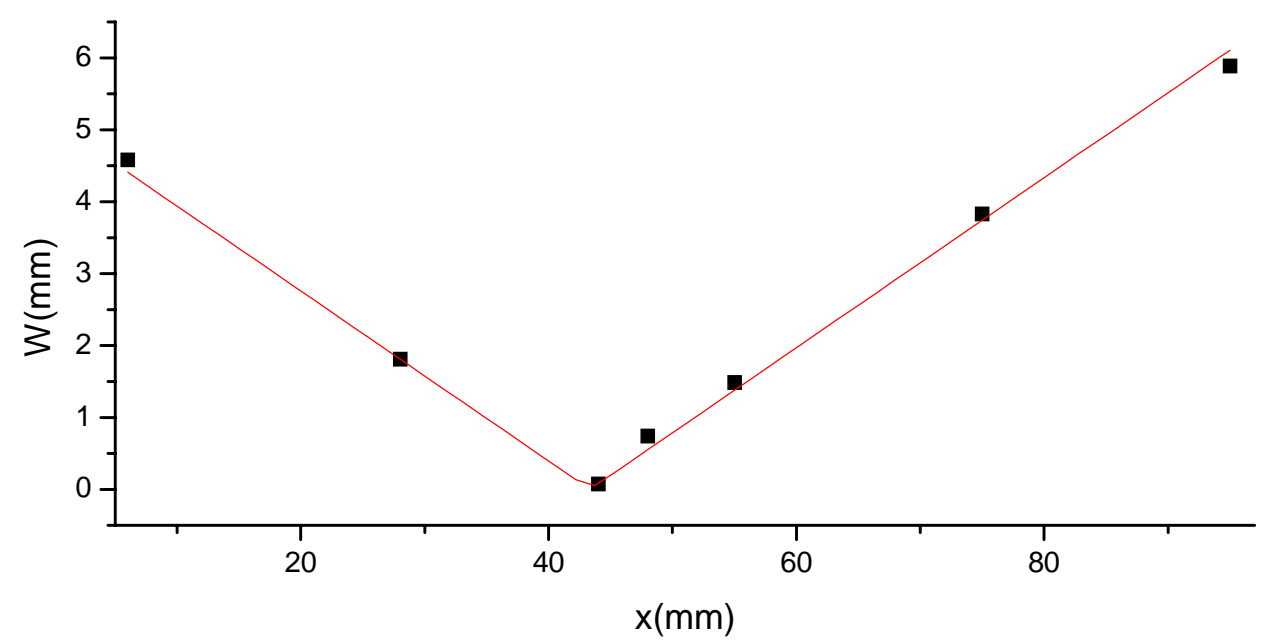

Figura 3-8: Medida do perfil longitudinal do feixe em uma lente $F=50 \mathrm{~mm}$

Obtemos $\mathrm{w}_{0}=28 \mu \mathrm{m}$ onde o valor teórico para o poder de foco de uma lente para um feixe gaussiano é $\mathrm{w}_{0} \approx 2 \lambda \mathrm{f} / \pi \mathrm{D}[23]$, em que f é a distância focal da lente, $\mathbf{D}$ o diâmetro do feixe na lente e $\lambda$ é o comprimento de onda da radiação. Considerando efeitos de difração o valor obtido está de acordo com o esperado. $\mathrm{O}$ parâmetro $\mathrm{b}=$ 43,3 mm é o valor da posição do foco medido a partir da face plana da lente. A distância fornecida pelo fabricante $\mathrm{f}=50 \mathrm{~mm}$ leva em consideração a espessura da lente que é aproximadamente $7 \mathrm{~mm}$.

Com o mesmo procedimento de medidas caracterizamos o foco do laser de Titânio Safira com $784 \mathrm{~nm}$ de comprimento de onda gerado com uma lente de $25 \mathrm{~cm}$ de distância focal. O feixe incidia na lente com um diâmetro de $4 \mathrm{~mm}$ resultando em uma cintura de $\mathrm{w}_{0}=31 \mu \mathrm{m}$ no foco, valores que podem ser encontrados em outros trabalhos [40]. 


\subsection{Nova Câmara.}

A nova câmara foi projetada em meados do segundo semestre de 2004 sendo finalmente concluída em fevereiro deste ano. As principais vantagens desse novo projeto é o grande acesso óptico formado por 4 flanges 6" (transversais), 10 flanges de conexão 4-1/2" (diagonais, topo e fundo) e 4 flanges de 2-3/4" (transversais $\mathrm{ZnSe}$ ), onde as últimas serão utilizadas para a incidência do laser de $\mathrm{CO}_{2}$. Devido ao diâmetro relativamente grande dessas flanges, teremos a possibilidade de agilizar o processo de obtenção de vácuo a regimes de ultravácuo $\mathrm{P} \cong 10^{-12}$ torr.

A câmara foi projetada a partir de um programa CAD (Solid Works 2004), uma ferramenta muito importante para que o projeto da câmara fosse concluído com sucesso. Com esse programa tínhamos uma visão geral 3D que auxiliava no posicionamento e dimensionamento de seus componentes internos tais como bobinas e suportes internos para lentes de ZnSe. Durante o processo de confecção e fechamento da câmara, construímos e caracterizamos as bobinas e posicionamos as lentes internas. Na figura 3-9 temos um esboço das peças projetadas pelo programa Solid Works 2004. 

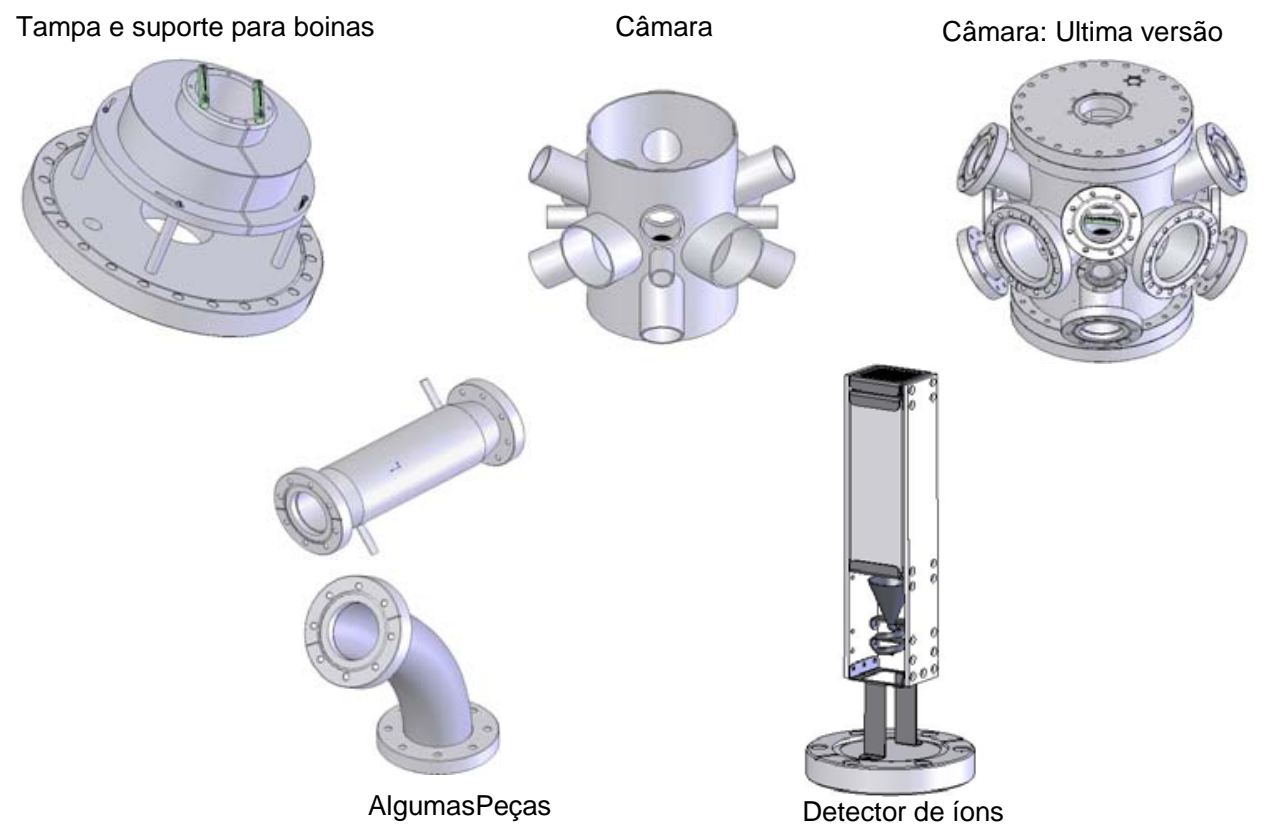

Figura 3-9: Peças projetadas no programa Solid Works 2004. Vemos os esboços tridimensionais dos componentes que formam a nova câmara de aprisionamento.

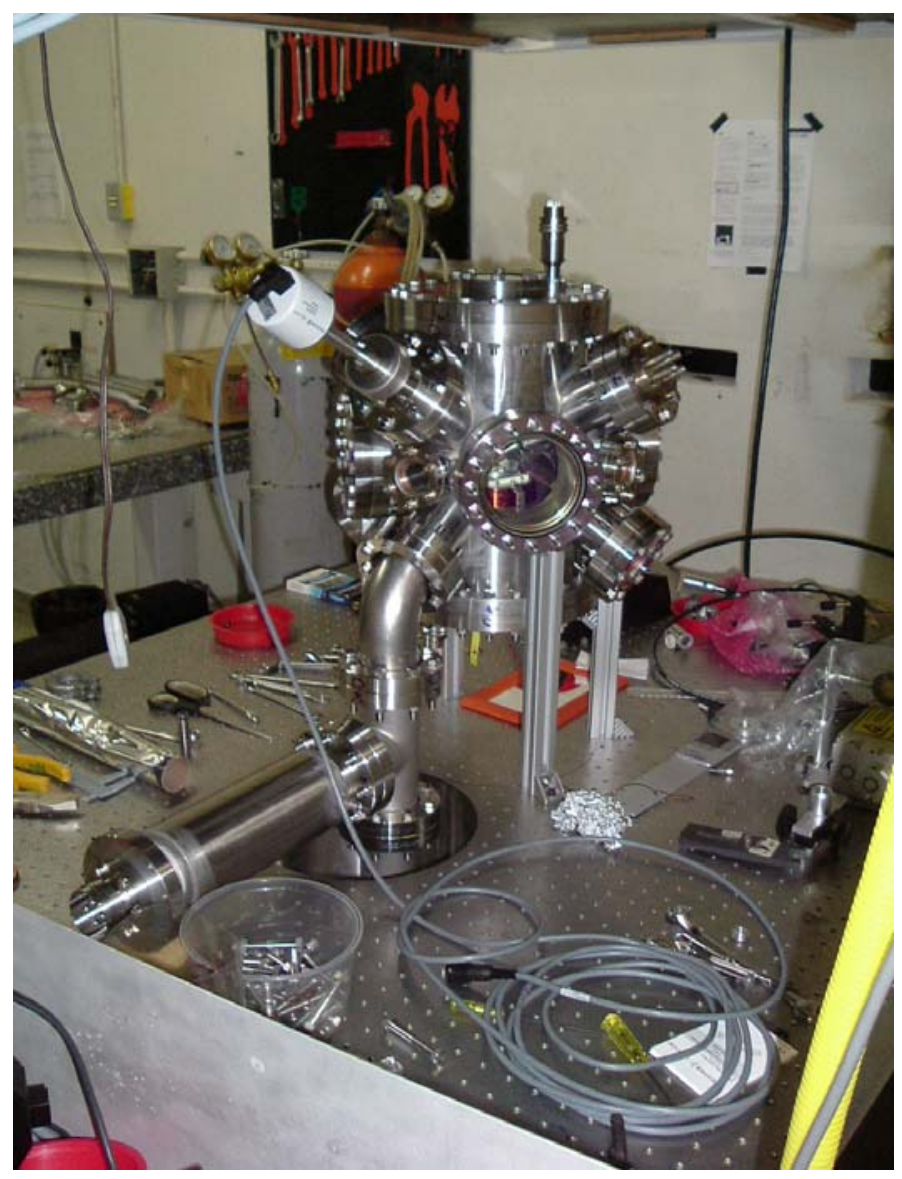

Figura 3-10: Foto do sistema a vácuo montado sobre a mesa óptica 


\subsubsection{Caracterização das Bobinas}

A foto a seguir (figura 3-11) mostra um aparato formado pelas duas bobinas enroladas (fio de capton para ultravácuo) em uma peça de alumínio e quatro barras a fim de simular a posição real que ficarão no interior da câmara. Na parte mais interna temos as bobinas de MOT (aprox. $4 \Omega$ ) e as externas (5 $\Omega$ ) serão utilizadas em futuros experimentos, como por exemplo, a ressonância de Feshbach.

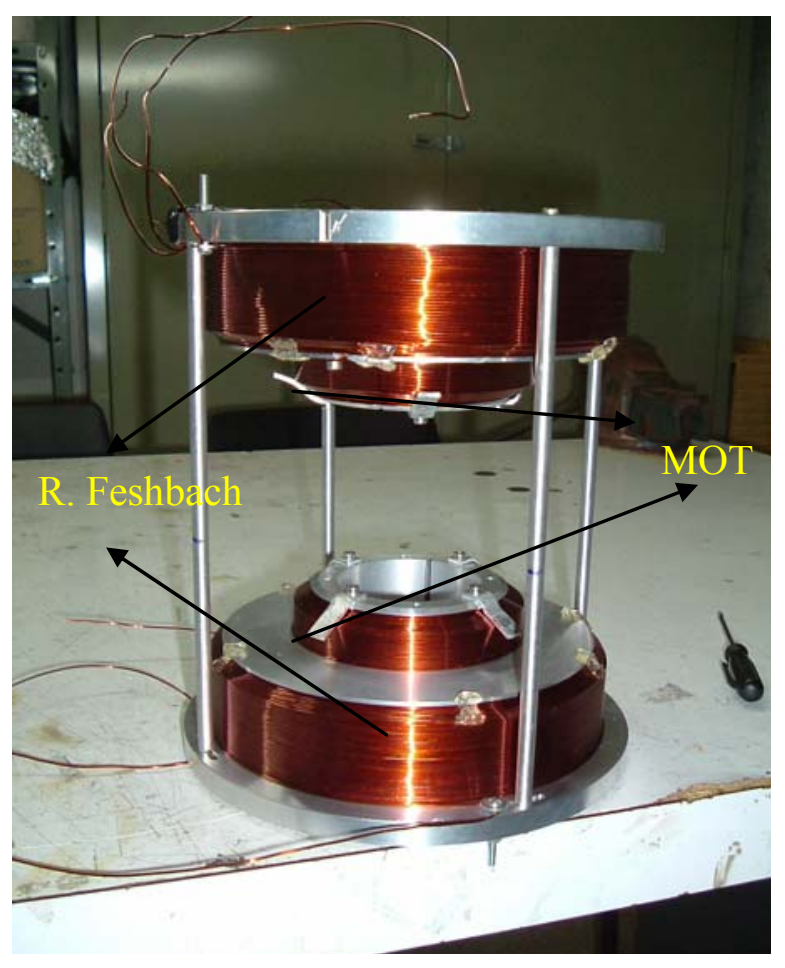

Figura 3-11: Foto das bobinas para o interior da câmara

Para a formação de uma armadilha magneto-óptica (MOT) são necessários três pares de feixes contrapropagantes trabalhando em conjunto com um par de bobinas na configuração anti-Helmholtz, isto é, campo nulo na origem (centro geométrico das bobinas), e aumentando de forma linear ao se afastar do centro em qualquer direção. Os gráficos das figuras 3-12 e 3-13 mostram o perfil deste campo 
em um raio de $25 \mathrm{~mm}$ do centro geométrico das bobinas, onde se localizarão os átomos.

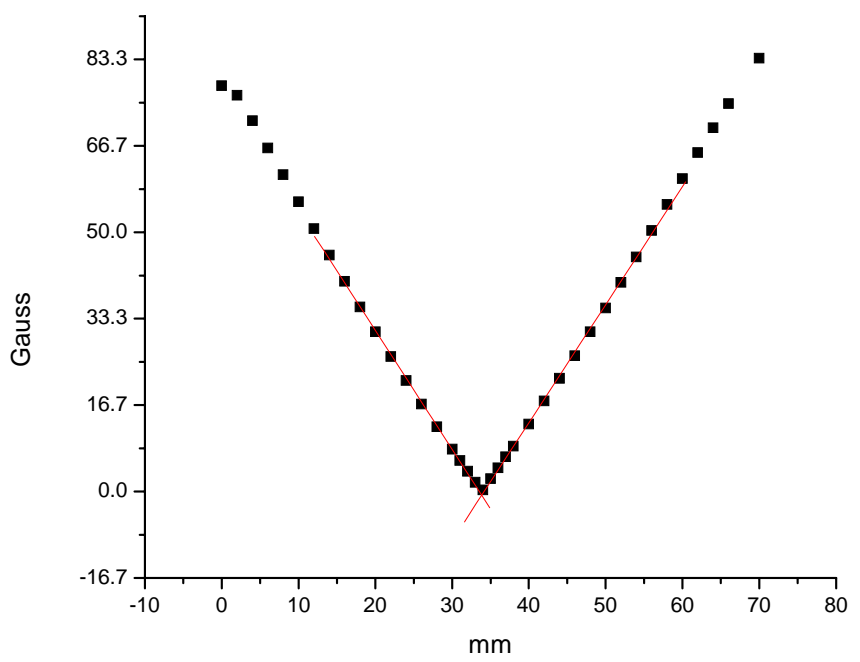

Figura 3-12: Gradiente referente ao eixo da bobina, obtemos 22,7 G/ cm a 5 A de corrente.

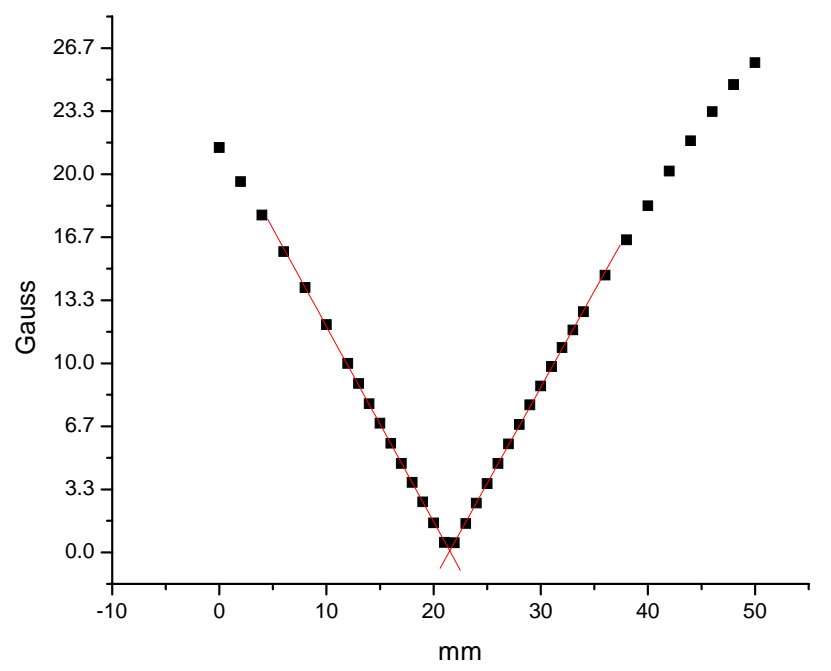

Figura 3-13: Gradiente referente ao plano central da bobina, obtemos 10,2 G/ cm a 5 A de corrente.

Os valores obtidos estão de acordo com os sugeridos na literatura [41] para a formação de um MOT mais eficiente. Outras medidas foram feitas para outros valores de correntes e chegamos à conclusão que obtemos um gradiente de 4,5 G/ cm 
por Ampére aplicado aos fios. As bobinas externas foram montadas na configuração Helmholtz de modo a se obter um campo constante na amostra atômica, figura 3-14.

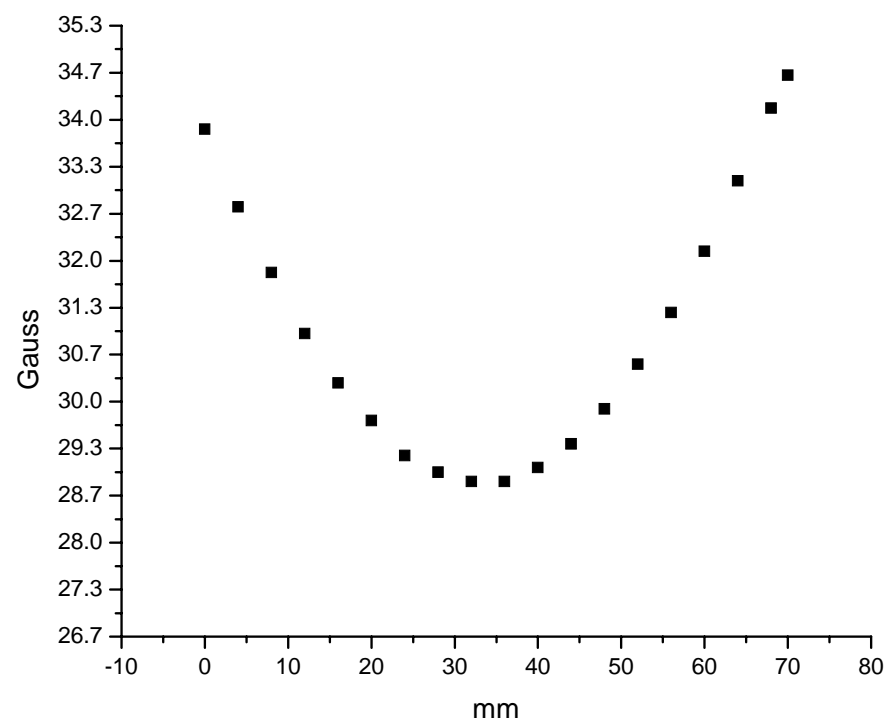

Figura 3-14: Perfil do campo no eixo da bobina.

Apesar da condição Helmholtz não esteja ideal, podemos dizer que a variação do campo é pouco relevante na região de interesse, entre $15 \mathrm{~mm}$ e $55 \mathrm{~mm}$. Na posição de aproximadamente $33 \mathrm{~mm}$, onde será o centro da amostra, temos um campo de 29 G a 2 A e a variação na região citada é de no máximo 1,3 G. 


\subsubsection{Ajuste do Foco no Interior da Câmara}

Tendo conhecimento das características básicas do laser de $\mathrm{CO}_{2}$, podemos seguir para o último passo antes do fechamento da câmara que é o posicionamento das lentes internas. Como já descrito, precisamos obter o foco no centro geométrico da câmara e feixe colimado ao sair.

Com o telescópio da figura 3-5 podemos obter um feixe de $\mathrm{w}=9 \mathrm{~mm}$ na entrada da câmara e através dos suportes com rosca podíamos posicionar as lentes. Para aferir o foco, utilizamos uma chapa fina de alumínio jateada com areia. Quando nos aproximamos do foco com esta chapa, observamos um brilho intenso. Conforme abaixamos a potência do laser este ponto vai se tornando mais perceptível apenas na região de maior concentração da radiação, isto é, no foco.

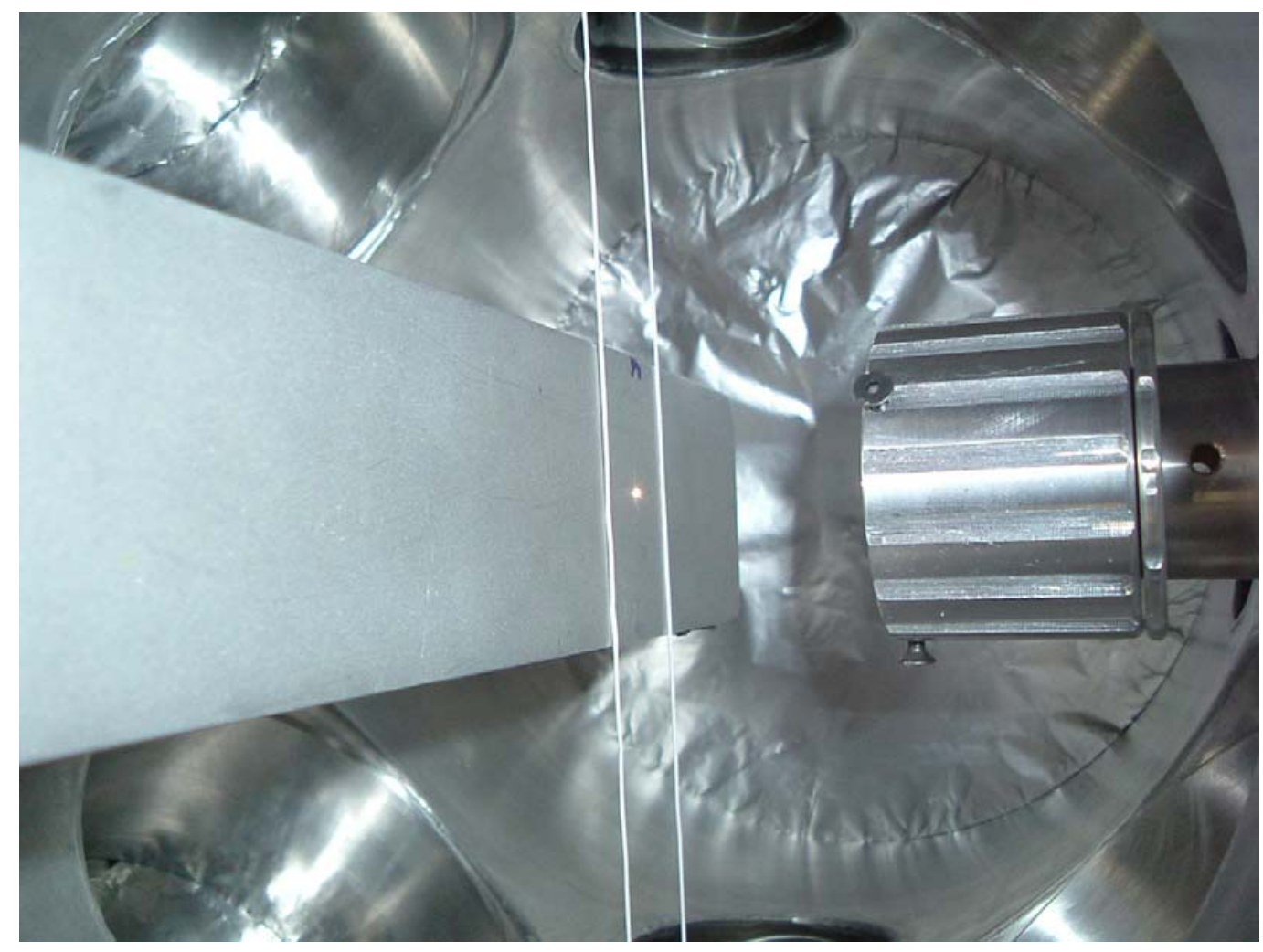

Figura 3-15: Observação do foco através da incidência do laser de $\mathrm{CO}_{2} \mathrm{em}$ uma chapa de alumínio. 
As medidas foram feitas com paquímetro e o método nos dá uma precisão de $1 \mathrm{~mm}$ que é suficiente comparado ao tamanho da amostra atômica que será carregada pelo MOT que tem um raio de aproximadamente 1,5 mm. Os parâmetros resultantes desse ajuste estão mostrados na figura 3-16.

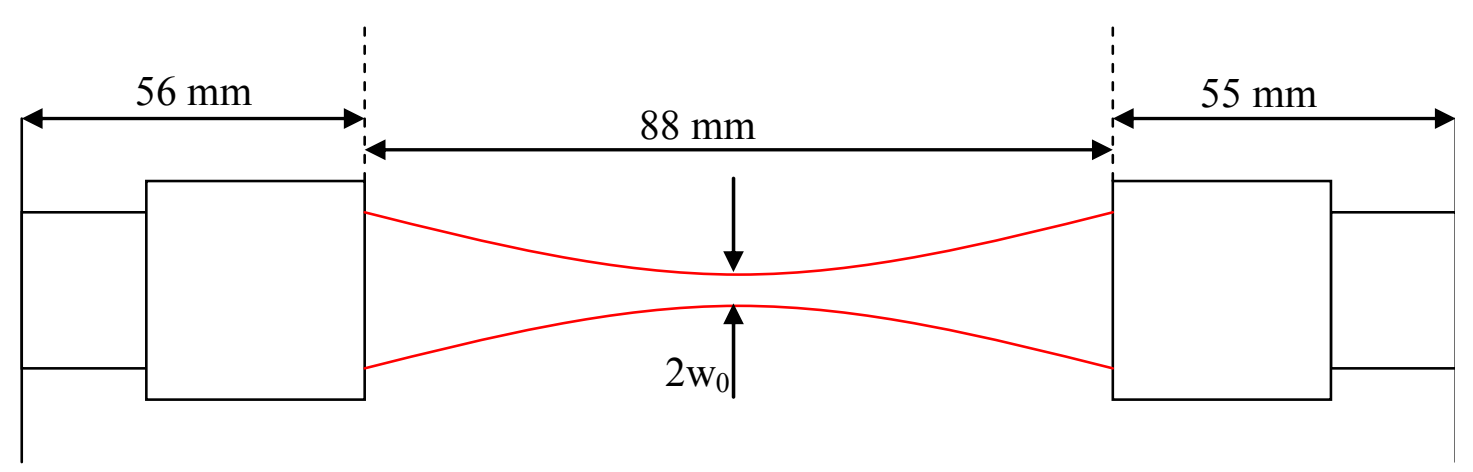

Figura 3-16: Parâmetros para posição interna das lentes.

Para que o feixe voltasse a ser paralelo na saída da câmara, observávamos o seu padrão em uma folha de papel de fax que é sensível ao calor. Durante a exposição de aproximadamente $2 \mathrm{~s}$ medíamos o circulo formado logo na saída e a uma distância de 3 metros, assim obtemos um feixe paralelo na precisão de $1 \mathrm{~mm}$. A principio o feixe será bloqueado, mas eventualmente iremos reutilizá-lo passando mais uma vez pela amostra de modo perpendicular e focalizado com lentes externas.

Chegamos ao fim das caracterizações e ajustes preliminares. Depois da instalação dos componentes elétricos como os terminais das bobinas, "getters" para emissão dos átomos de $\mathrm{Rb}$ e também $\mathrm{K}$, e o detector de íons, pudemos fechar a câmara formando o esquema de aprisionamento da figura 3-17. 


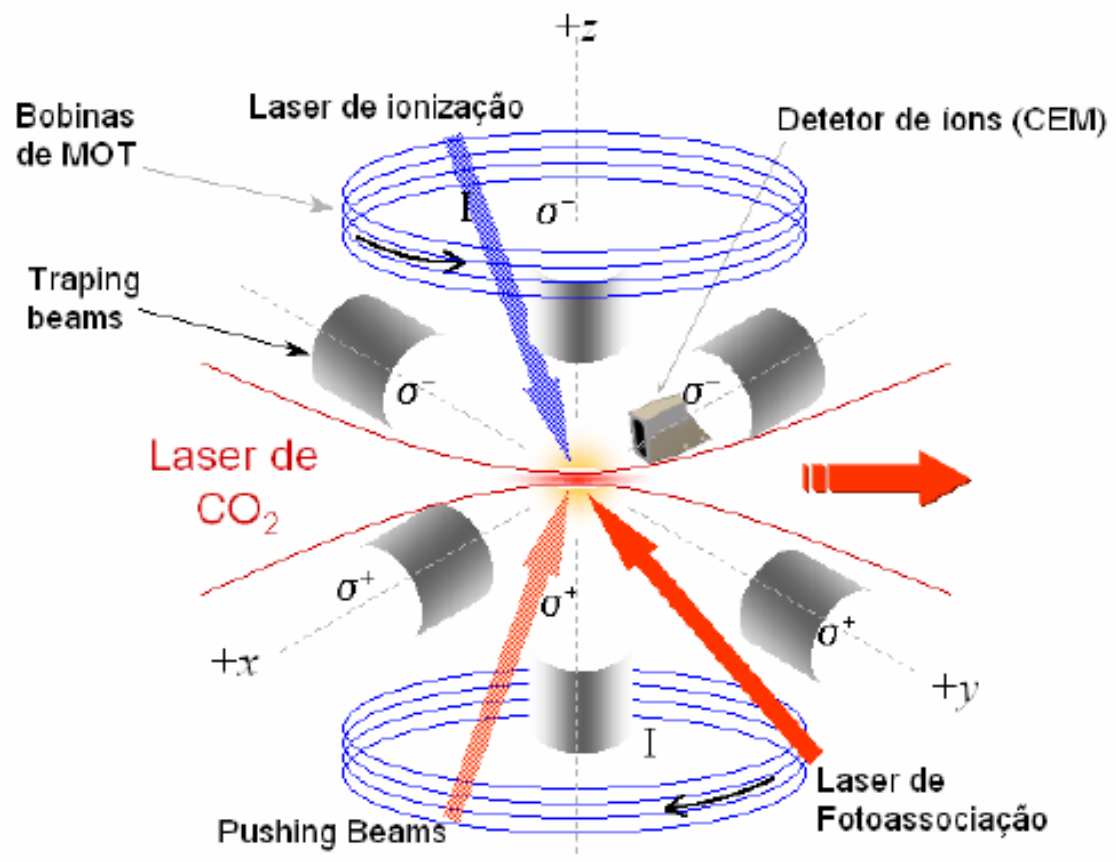

Figura 3-17: Superposição das armadilhas MOT e dipolo $\mathrm{CO}_{2}$.

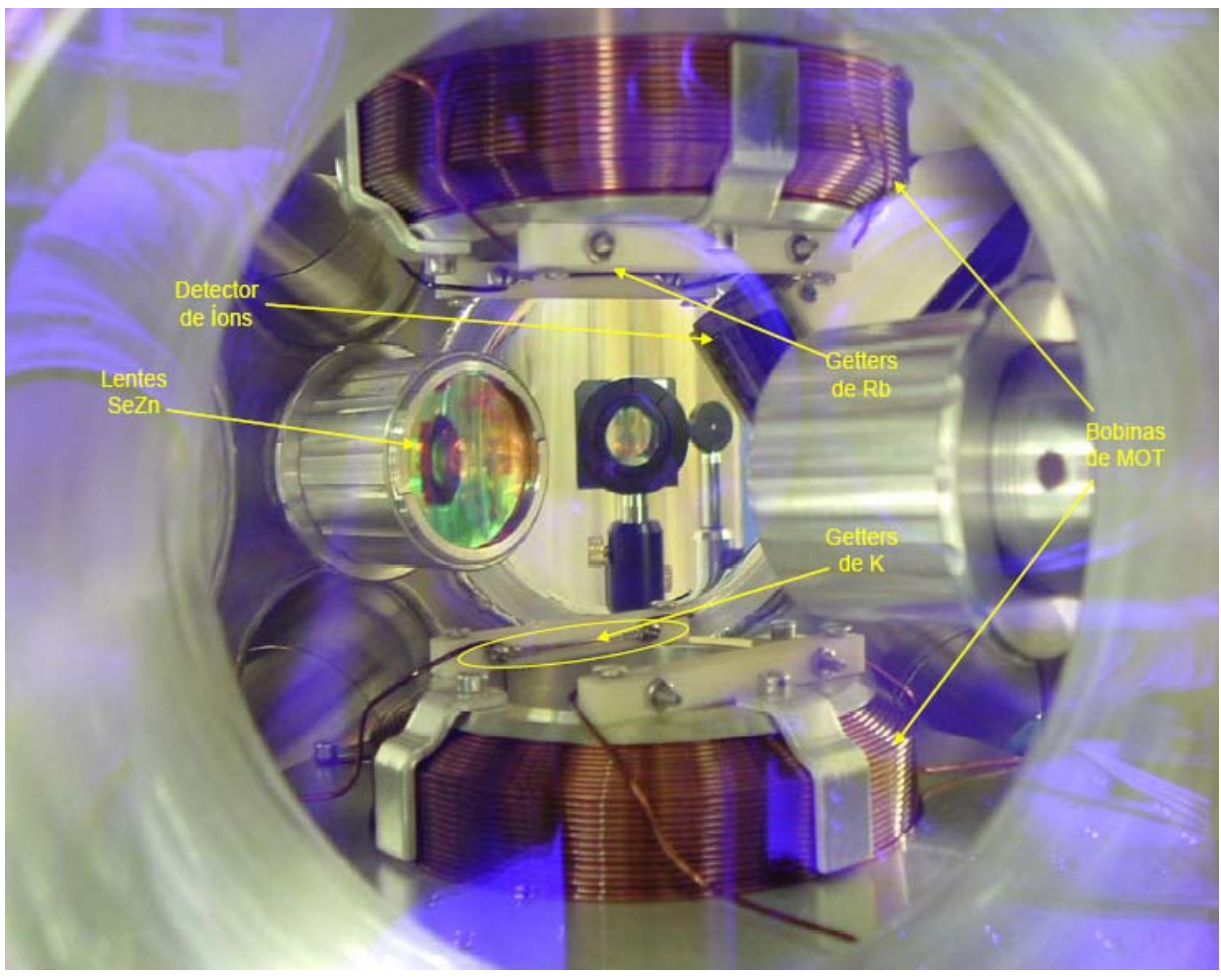

Figura 3-18: Foto do interior da câmara através de uma das janelas de 6". 


\subsubsection{Sistema à Vácuo e sua Evolução.}

Logo após as caracterizações dos componentes internos da câmara, bobinas e lentes, pudemos fechá-la e conectá-la ao sistema a vácuo. Nesta secção descreveremos o sistema de ultra alto vácuo (UHV - Ultra High Vacuum) usado nos experimentos e os pontos críticos para a obtenção desta baixa pressão.

O sistema á vácuo consiste em quatro partes: (1) a região de aprisionamento, (2) câmara de sublimação de titânio, (3) bomba iônica e (4) bomba turbomolecular ligada em série à linha de baixo vácuo dos laboratórios (figura 3-19). O primeiro procedimento para obter pressões a regime de UHV [42] é a limpeza dos componentes internos com bons solventes como acetona e tricloroetileno, é indispensável o uso de luvas para evitar o contato das mãos as partes internas da câmara. Em seguida, o sistema é ligado à linha de baixo vácuo até a obtenção de pressões aproximadas de $10^{-3}$ torr, a partir desse ponto ligamos a bomba turbomolecular (fabricante Pfeiffer Vacuum vazão $=56$ Litros/segundo) e começamos a aquecer o sistema (baking out) com resistências e isolando termicamente de modo a aumentar a taxa de degaseificação das impurezas do sistema.

Este processo de baking out pode demorar de uma a duas semanas até a obtenção de pressões próximas $\mathrm{a} \cong 10^{-8}$ torr, onde a temperatura do sistema é diminuída até a temperatura ambiente. Nesta etapa, devido à dilatação dos metais (aço e anéis de cobre), os parafusos do sistema devem ser cuidadosamente verificados necessitando de reapertos de manutenção. 


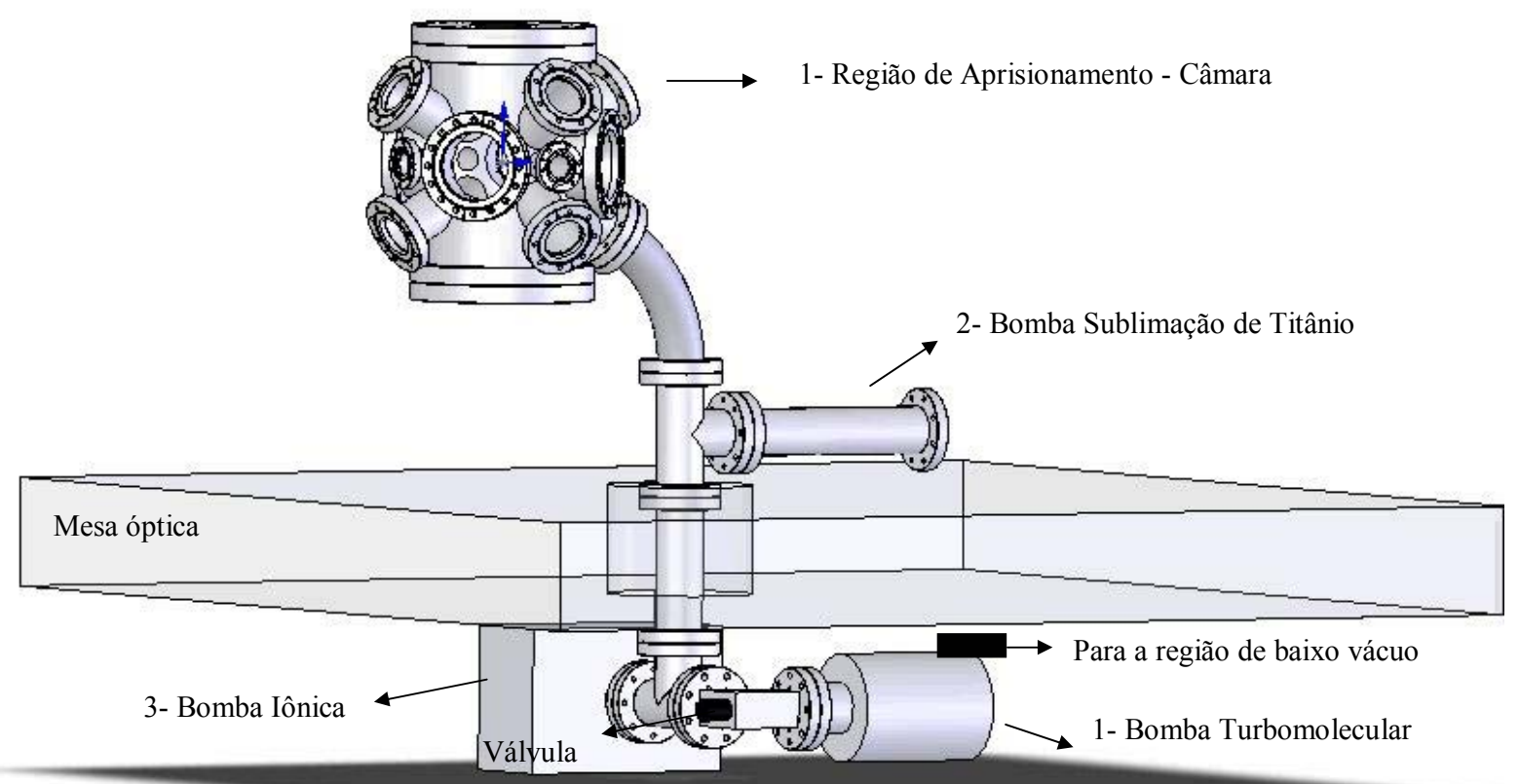

Figura 3-19: Ilustração do sistema a vácuo. A câmara é conectada através de uma de suas flanges inferiores (CF63) às bombas. Primeiramente temos uma bomba de sublimação de titânio e logo em seguida, debaixo da mesa, as bombas: Iônica e turbomolecular.

Com esse regime de pressão podemos isolar o sistema da bomba turbomolecular e a região de baixo vácuo através de uma válvula comercial $(M D C)$, isso nos garante que quedas de tensão não venham a destruir a baixa pressão, uma vez conquistada, e também diminuímos vibrações indesejáveis causada pela rotação da própria bomba turbomolecular. A partir daí ligamos a bomba iônica (fabricante Varian, modelo Vaclon Plus 55), que ioniza a atmosfera próxima a sua saída e atrai as partículas para seu interior impedindo que retornem ao sistema, atingindo regimes de pressão $<10^{-9}$ torr. 
Ligamos então a bomba de sublimação de titânio onde se aplica uma alta corrente (50 A) em barras de titânio (fabricante Varian), fazendo-o sublimar, criando assim filmes em sua câmara de sublimação. O titânio, quando encontra uma superfície a uma baixa temperatura $\left(20^{\circ} \mathrm{C}\right)$ condensa-se e forma ligações estáveis, o mesmo acontece quando uma partícula se choca com ele. O titânio é sublimado três vezes ao dia em ciclos de 7 minutos e intervalos de 30 minutos nos primeiros dias, elevando a taxa de bombeamento à $10^{4}$ Litros/segundo para $\mathrm{O}_{2}$. Ao atingirmos regimes $<10^{-10}$ torr o titânio é sublimado uma vez a cada duas semanas para manutenção do sistema.

Todas as bombas possui conexões de 4" e o gráfico da figura 3-20 representa a evolução da pressão do sistema antes do reaperto de manutenção dos parafusos. Com este procedimento chegamos a uma pressão de $\mathbf{5 x 1 0 ^ { - 1 0 }}$ torr em um intervalo de aproximadamente um mês a partir da pressão atmosférica. As medidas eram feitas por um medidor de pressão comercial modelo Cold Cathode Gauge, fabricante Pfeiffer Vacuum.

$\mathrm{Na}$ realidade tivemos certos problemas com as janelas de $\mathrm{ZnSe}$ que apresentavam grande vazamento na etapa de backing, o problema foi de difícil detecção, tivemos que reiniciar o processo de backing algumas vezes para podermos medir e localizar os vazamentos. Este procedimento era feito injetando-se gás He por todo o corpo do sistema e medindo sua vazão com espectrômetro de massa ligado na saída de baixo vácuo, logo após a bomba turbomolecular, procedimento conhecido como leak detection (detecção de vazamento).

$\mathrm{O}$ vazamento se agravava e ficava mais evidente quando as janelas de $\mathrm{ZnSe}$ eram aquecidas e acabamos substituindo-as por janelas de vidro, para que pudéssemos evoluir com o trabalho enquanto eram retificadas. Ainda na figura 3-20 
vemos duas linhas, a mais clara representa o processo com as janelas de $\mathrm{ZnSe}$, e a linha mais escura com as janelas de vidro, a principal diferença é que não conseguíamos pressões inferiores a $10^{-8}$ torr com as janelas de $\mathrm{ZnSe}$.

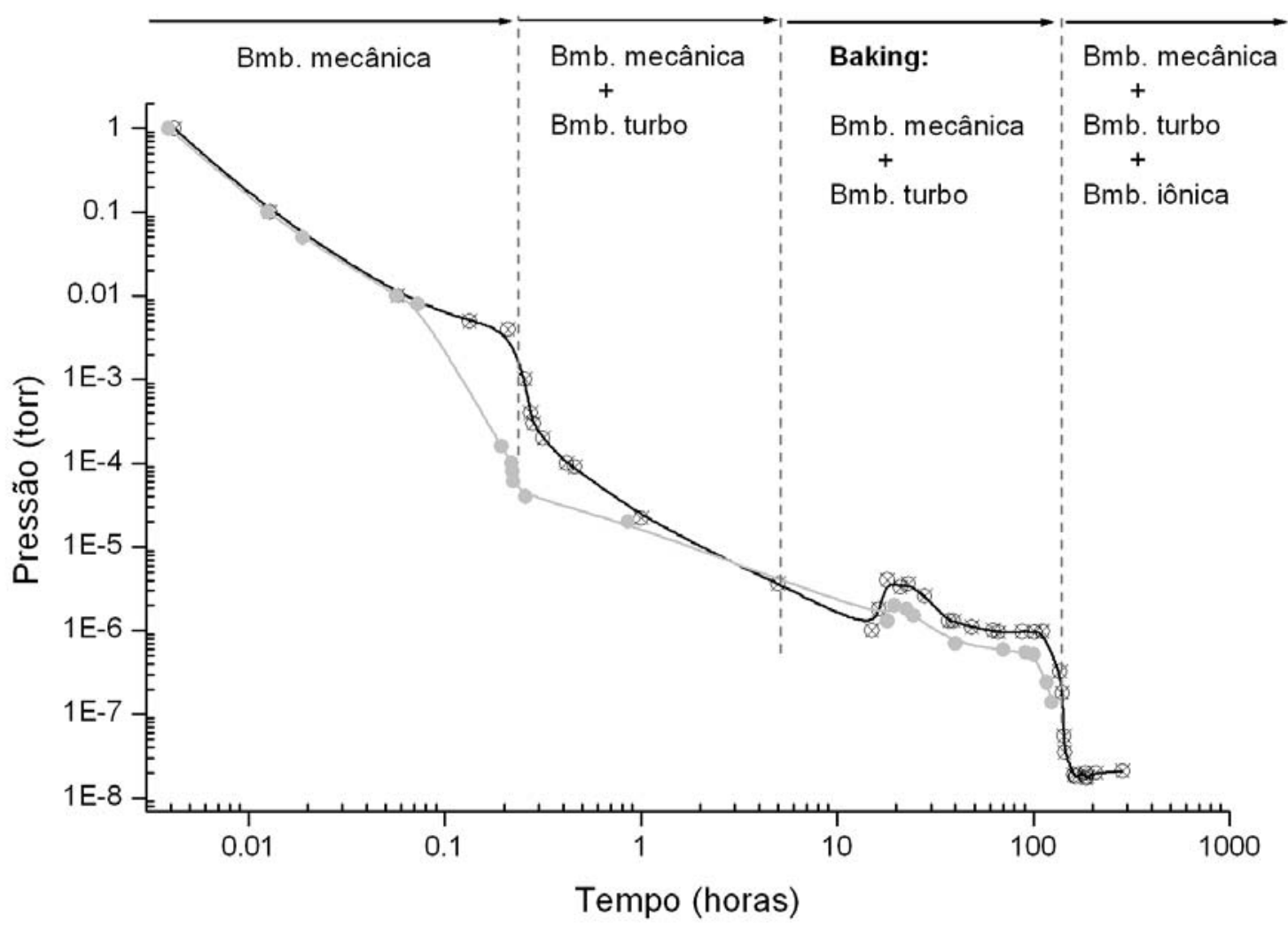

Figura 3-20: Gráfico da evolução da pressão no sistema á vácuo, atingimos o regime de $P=10^{-8}$ torr em aproximadamente uma semana.

Com o tempo a pressão tende sempre a diminuir, claro que com uma velocidade cada vez mais lenta, mas estabelecido este regime de pressão de $5 \times 10^{-10}$ torr, estamos prontos para seguir com a montagem óptica para a construção da armadilha magento-óptica que será o próximo tópico abordado. 


\subsection{Construção da Armadilha Magneto-Óptica.}

O próximo avanço após a obtenção de pressões da ordem de $5 \times 10^{-10}$ torr foi a construção da armadilha magneto-óptica. A princípio os lasers disponíveis para este projeto foram: DLX-110 e Tiger, fabricados por Toptica e Sacher Lasertekinic respectivamente, ambos com potência em torno de $800 \mathrm{~mW}$ a 780,2 nm. A idéia inicial era aprisionar ${ }^{87} \mathrm{Rb}$ [43] gerando os feixes de aprisionamento com o DLX-110 (transição $F=2$ para $F^{\prime}=3$ ) e rebombeio com o Tiger (transição $F=3$ para $F^{\prime}=4$ ). Logo de inicio notamos certa instabilidade na freqüência do laser Tiger, por isso optamos utilizar o DLX-110 para aprisionamento, pois seu sistema de travamento (lock) garantia mais de duas horas com o sistema na ressonância.

Devido a problemas com o laser Tiger, tivemos que substituir a montagem experimental da figura 1, passamos a utilizar um laser Titânio Safira cujo seu sistema de aprisionamento será descrito a seguir e passamos a aprisionar ${ }^{85} \mathrm{Rb}$, pois seu sistema já estava otimizado para essa espécie atômica. Mesmo com esses problemas podemos observar uma curva de carga de átomos de ${ }^{87} \mathrm{Rb}$ na armadilha magnetoóptica no capíulo 4 gerada com lasers de diodo.

\subsection{Montagem experimental.}

O aprisionamento de ${ }^{85} \mathrm{Rb}$ exige $780,24 \mathrm{~nm}$ de comprimento de onda da radiação, nesta região conseguimos realizar a transição do estado fundamental para o primeiro estado excitado $(5 \mathrm{~S} \rightarrow 5 \mathrm{P})$. Radiação com esse comprimento de onda é obtida por um laser titânio safira (Coherent modelo 899). 
O diagrama abaixo descreve os níveis de energia da estrutura hiperfina do ${ }^{85} \mathrm{Rb}$ [44] e as transições utilizadas para o aprisionamento (figura 3-21). Vendo o diagrama, notamos duas transições importantes: A transição $5 \mathrm{~S}_{1 / 2}(\mathrm{~F}=3) \rightarrow 5 \mathrm{P}_{3 / 2}\left(\mathrm{~F}^{\prime}\right.$ =4) é responsável pelo aprisionamento dos átomos, dela é que surge a força restauradora explicada no primeiro capítulo e a outra transição é chamada de rebombeio. Nas duas transições sintonizamos o laser a $27 \mathrm{MHz}$ abaixo da transição.

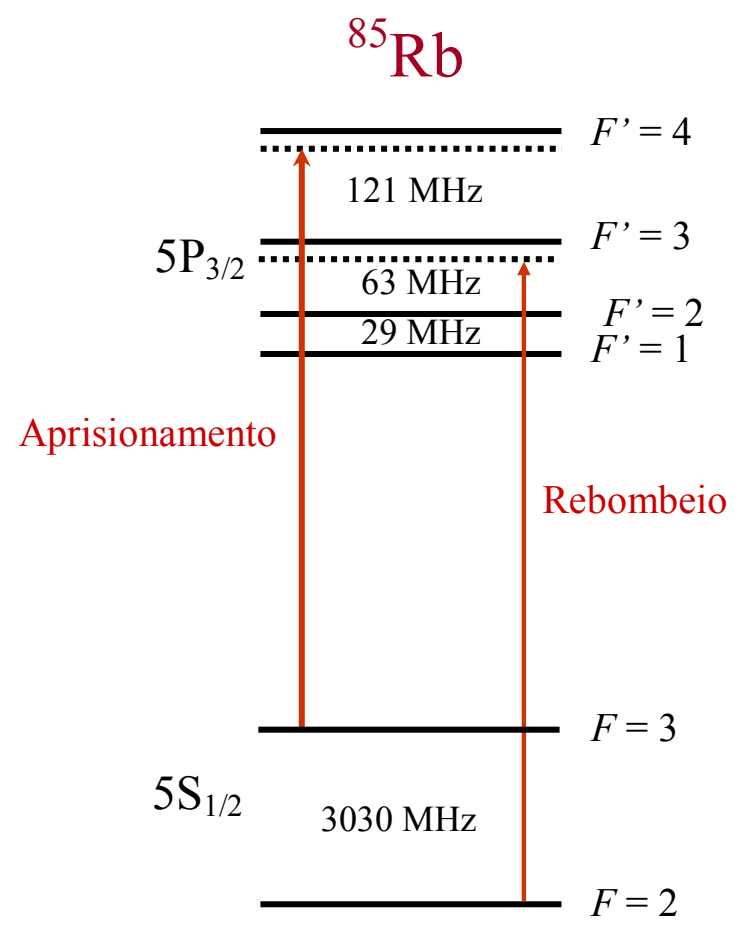

Figura 3-21: Diagrama de níveis de energia do ${ }^{85} \mathrm{Rb}$, e transições de aprisionamento.

Com o átomo no estado $5 \mathrm{P}_{3 / 2}\left(\mathrm{~F}^{\prime}=4\right)$ temos transições indesejáveis que ocorrem com certa probabilidade desse estado para o estado $5 \mathrm{~S}_{1 / 2}(\mathrm{~F}=2)$ atrapalhando o processo de aprisionamento dos átomos. $\mathrm{O}$ nível $5 \mathrm{P}_{3 / 2}\left(\mathrm{~F}^{\prime}=3\right)$ tem probabilidade de $7 / 12$ de decair para $5 \mathrm{~S}_{1 / 2}(\mathrm{~F}=3)$, que participa do processo de aprisionamento, e 5/12 para transição $5 \mathrm{~S}_{1 / 2}(\mathrm{~F}=2)$, os átomos que estão neste último 
estado deixam de interagir com laser, pois estão fora de sintonia e não serão aprisionados.

Assim para manter o processo de aprisionamento é necessário excitar esses átomos novamente segundo a transição $5 \mathrm{~S}_{1 / 2}(\mathrm{~F}=2) \rightarrow 5 \mathrm{P}_{3 / 2}\left(\mathrm{~F}^{\prime}=3\right)$, pois estando novamente em $5 \mathrm{P}_{3 / 2}\left(\mathrm{~F}^{\prime}=3\right)$ tem a chance de decair para o estado $5 \mathrm{~S}_{1 / 2}(\mathrm{~F}=3)$ e participar do processo de aprisionamento. Este ciclo de rebombeamento torna o processo eficiente, conseguindo uma amostra com uma densidade ideal. Na figura 322 temos o aparato experimental para o aprisionamento com a nova câmara, também o sistema para a geração das freqüências e os seis feixes contrapropagantes.

O feixe depois de sintonizado por um circuito de travamento (lock) e absorção saturada (figura 3-23) na transição $5 \mathrm{~S}_{1 / 2}(\mathrm{~F}=3) \rightarrow 5 \mathrm{P}_{3 / 2}\left(\mathrm{~F}^{\prime}=4\right)$ e com uma modulação de $\Delta=27 \mathrm{MHz}$ abaixo da ressonância por um modulador acusto-óptica $(\mathrm{AOM})$, segue até o modulador eletro-óptico $(\mathrm{EOM})$ onde é gerada a freqüência de rebombeio. Ao mesmo tempo é expandido em 6x por um telescópio, tornando o feixe com um diâmetro de aproximadamente uma polegada aumentando a região de captura da armadilha. Com esse aumento ele é divido em 3 feixes de mesma potencia através $\lambda / 2$ e cubos polarizadores. A potência total do feixe é de $350 \mathrm{~mW}$ e com esta configuração obtivemos o primeiro MOT na nova câmara.

Com uma câmera CCD obtínhamos a imagem de florescência do MOT que podia ser visto no micro através de uma placa de aquisição. Um fotodetector também recebia este sinal, e usamos para caracterizar o MOT, discutiremos as caracterizações no próximo tópico. Temos uma foto de nossa montagem na figura 3-24. 


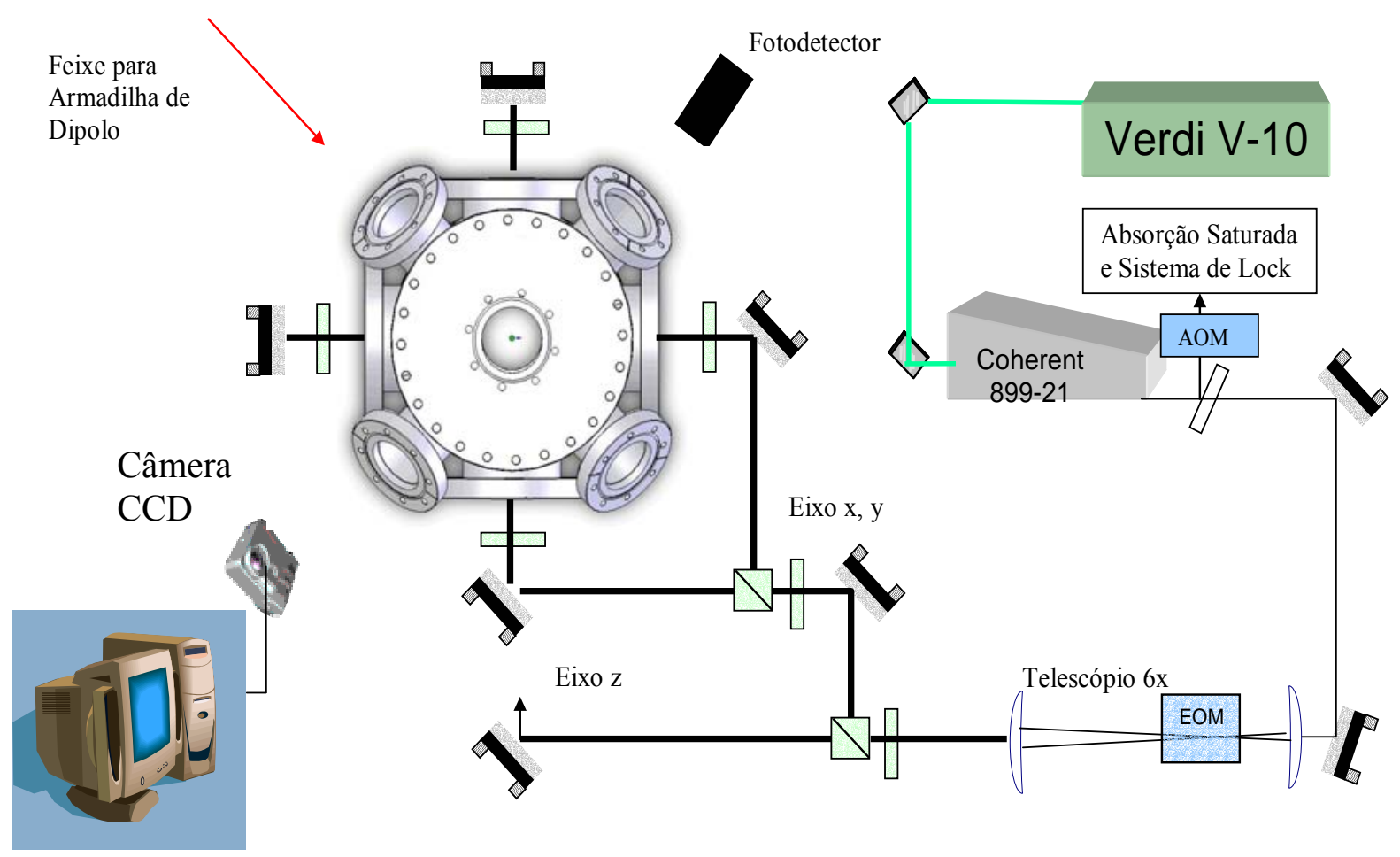

Figura 3-22: Montagem experimental para formação e observação do MOT.

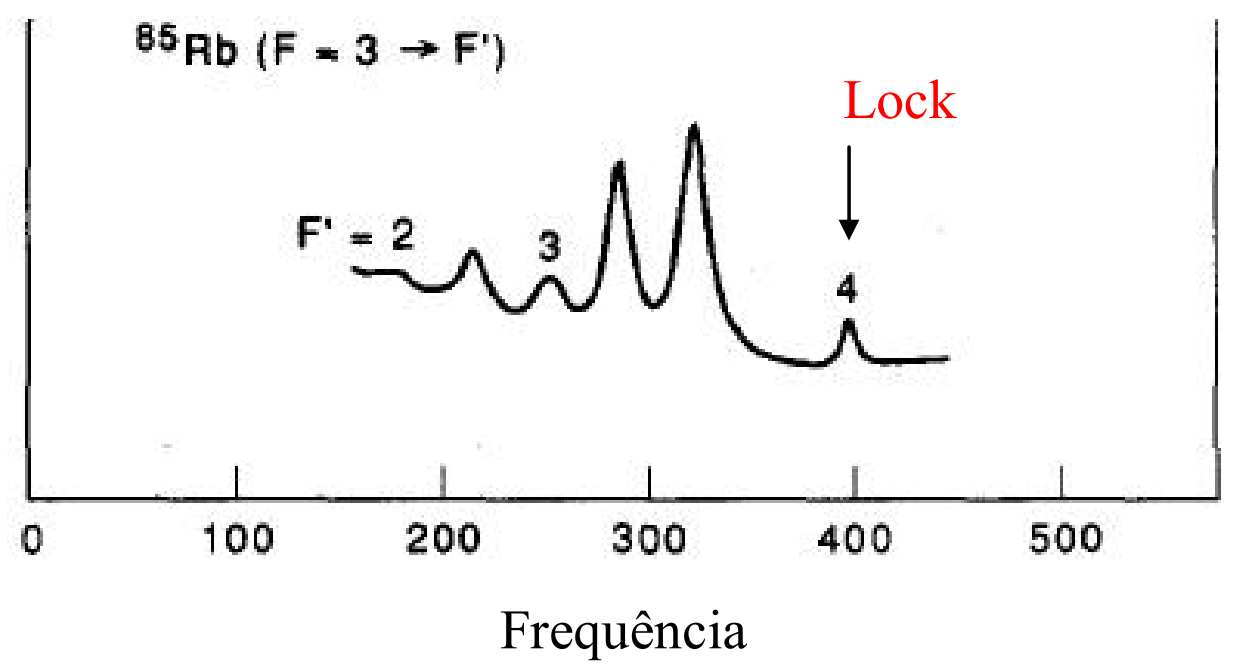

Figura 3-23: Sintonização do laser Ti:Safira na transição $5 S_{1 / 2}(F=3) \rightarrow 5 P_{3 / 2}\left(F^{\prime}=4\right)$ Feixe com detunning de $\Delta=27 \mathrm{MHz}$ maximizando o número de átomos aprisionados. 


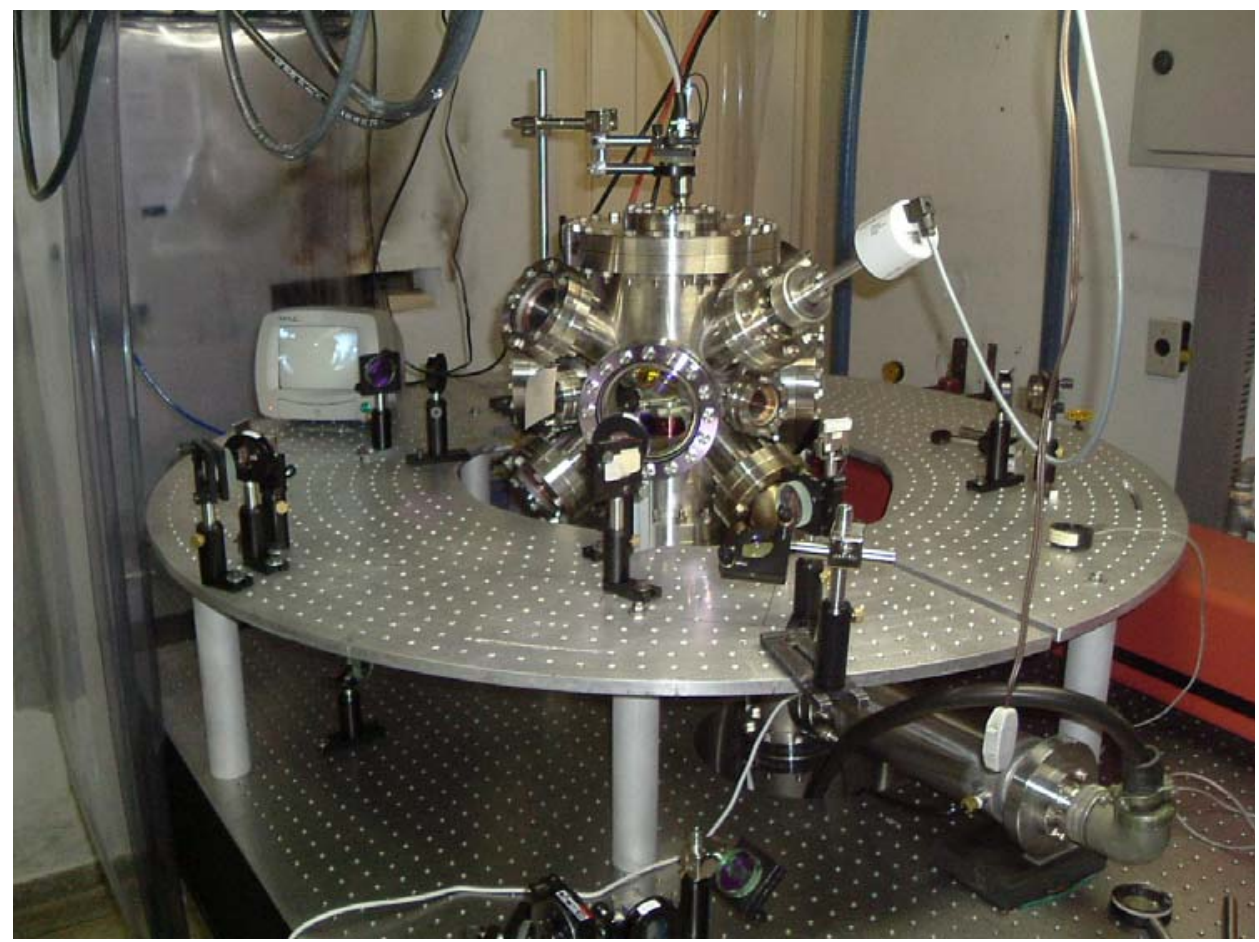

Figura 3-24: Câmara de aprisionamento e componentes ópticos montados em uma sobre mesa redonda.

\subsubsection{Sistemas para otimização de detecção da armadilha}

Os passos preliminares para a obtenção da armadilha de dipolo são as otimizações do sistema de transferência dos átomos entre as duas armadilhas, para isso construímos componentes eletrônicos e "drivers" controlados via microcomputador. Esses componentes tratam-se de obstrutores mecânicos para os feixe de MOT e feixe da armadilha de dipolo, controladores de corrente para desligamento e ajuste dos "getters" (reservatórios químicos dos átomos) e das bobinas de MOT.

Um dos obstrutores mecânicos, responsável pelo desligamento do feixe de MOT foi construído a partir de um relê acoplado a uma peça metálica, o 
desligamento do feixe da armadilha de dipolo era feito por um obstrutor comercial UNIBLITZ. Tanto esses obstrutores quanto os reguladores de corrente (também construídos, mas não entraremos em detalhes) são controlados por sinal TTL gerados pela placa de aquisição do micro com interface feita em LabView. Neste programa a seqüência temporal do experimento é controlada sistematicamente nos garantindo a reprodutibilidade dos experimentos, figura 3-25.

Os principais controles que obtemos com este programa são: o tempo de carregamento do MOT, os intervalos de tempo de desligamento dos feixes de MOT, bobina e "getters", a incidência do feixe da armadilha de dipolo na amostra. A seqüência temporal é ajustada dependendo do diagnóstico que se deseja obter da armadilha, no capítulo 4, onde teremos os resultados, fizemos medidas alterando esses parâmetros.

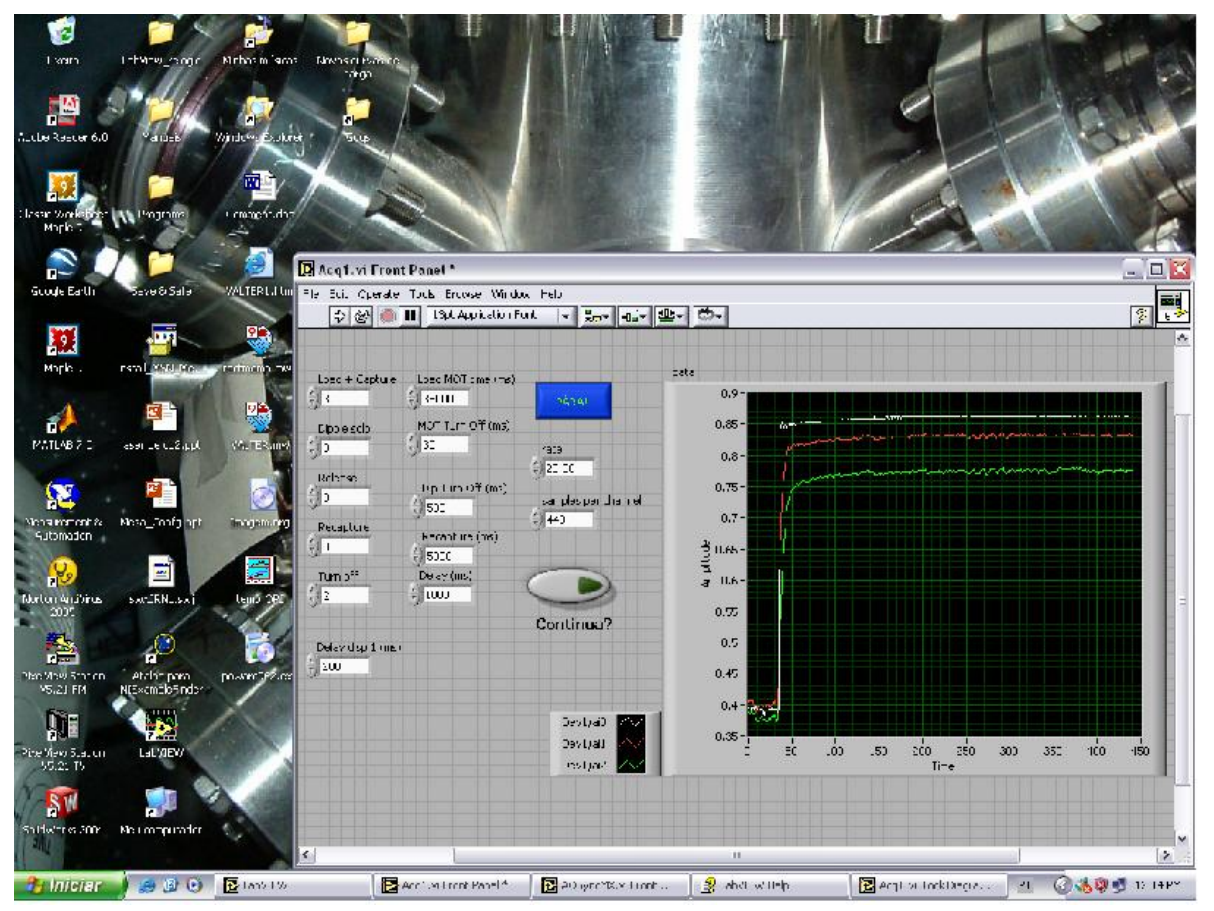

Figura 3-25: Interface para controle da seqüência temporal do experimento feita em LabView. Neste programa garantimos a reprodutibilidade dos experimentos. 


\section{Capítulo 4}

\section{Resultados e Análises}

Para ter certeza que o sistema estava operando de forma planejada, resolvemos operar a armadilha magneto óptica com todos os componentes internos da câmara ligados em modo contínuo. As bobinas internas que possuem um gradiente de campo magnético de 4 Gauss/(cm.A) operaram com uma corrente de 3A, resultando em um gradiente de $12 \mathrm{Gauss} / \mathrm{cm}$. Enquanto que nossa fonte de átomos ("getters") operaram com uma corrente em torno de 4,5 A. Devido a esse modo de operação, nossa pressão que era em torno de $5 \times 10^{-10}$ torr teve uma elevação de um fator de 4 vezes, chegando a valores próximos de $2 \times 10^{-9}$ torr mas retornava ao valor incial após algumas horas depois que o getter era desligado. As intensidades dos feixes utilizados eram de $270 \mathrm{~mW}$ para o feixe de aprisionamento com detuning de $\Delta=27 \mathrm{MHz}$ e $80 \mathrm{~mW}$ para o feixe de rebombeio. 


\subsection{Caracterização da Armadilha Magneto-Óptica}

\subsubsection{Caracterização da Distribuição Espacial}

As imagens dos átomos aprisionados foram obtidas utilizando uma câmera CCD de alta resolução. Esta técnica nos permite obter informações sobre volume, dimensões, números de átomos e sua distribuição espacial. As figuras 4-1 e 4-2 nos mostram fotos da observação do MOT primeiro por uma imagem gerada em um monitor pela câmera CCD, e segundo uma foto tirada diretamente da amostra por uma câmara digital.

Devido à alta corrente no "getter", obtivemos uma amostra muito densa, diminuindo a luminosidade do laboratório e treinando bem a visão, podíamos vê-lo a olho nu. Com esse tipo de imagem, pudemos capturar o sinal por uma placa de aquisição de vídeo (PixelView) e digitalizar a imagem no computador. Este processo gera uma matriz com valores de intensidades luminosas e posição que podemos observar em um gráfico (figura 4-3). 


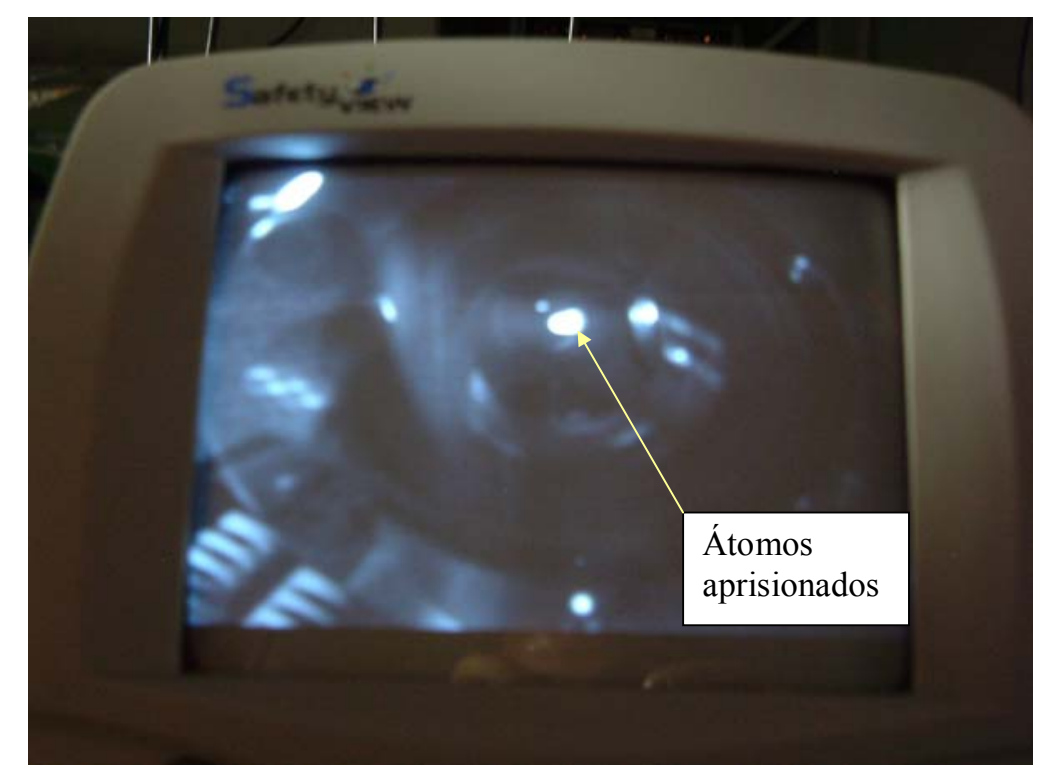

Figura 4-1: Imagem por uma câmera CCD gerada em um monitor. O pequeno círculo intenso no centro da foto representa a florescência dos átomos de 85Rb aprisionados observado através de uma das janelas de 2 ".

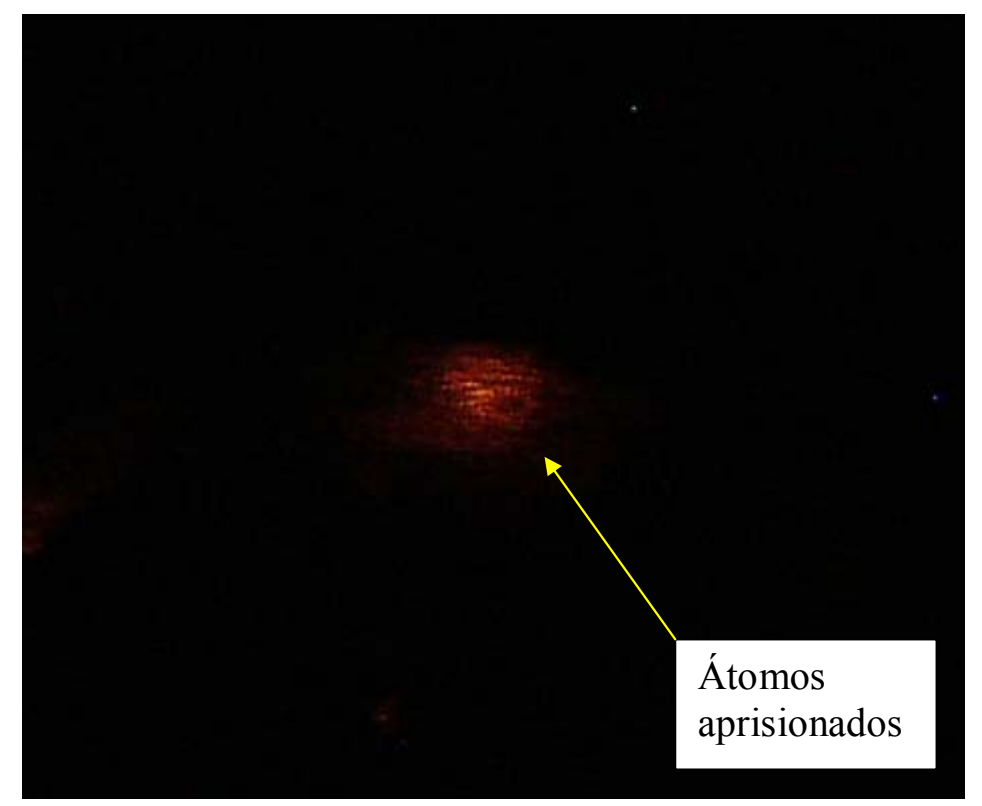

Figura 4-2: Imagem do MOT obtida por uma câmera fotográfica digital. 


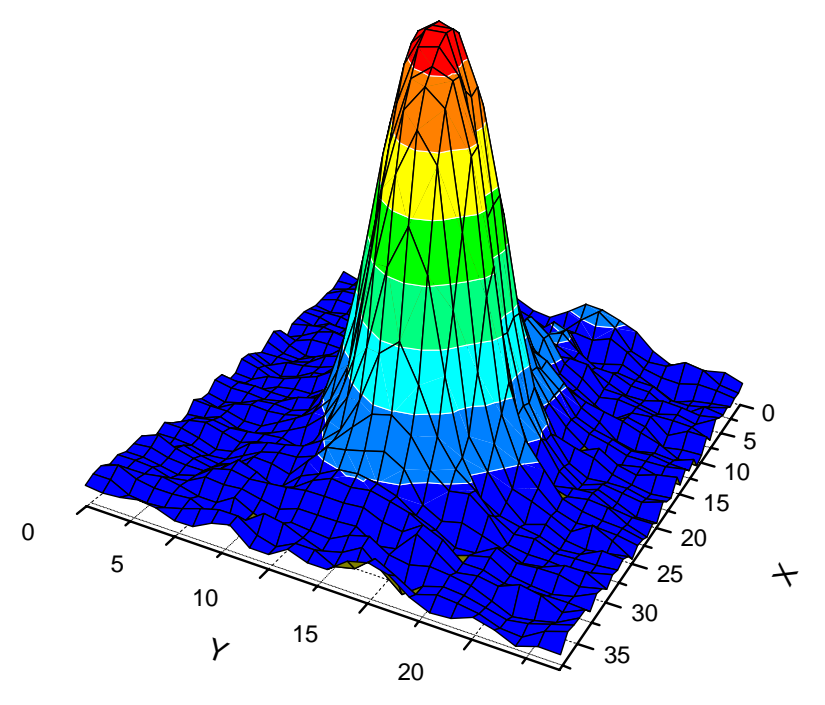

Figura 4-3: Imagem 3D do MOT, os eixos x e y representam as dimensões do MOT (unidades arbitrárias) enquanto que o eixo z representa números de átomos, na realidade este números são da ordem típicas de $10^{7}$ a $10^{8}$ átomos.

Com a ilustração da figura 4-3, observamos uma distribuição de densidade em formato gaussiano. Este fato é importante e nos ajuda a compreender melhor o mecanismo de carregamento e processos de perdas na armadilha $[45,46]$. Com uma distribuição gaussina: $\mathrm{n}(\mathrm{r}, \theta, \phi)=\mathrm{n}_{0} \mathrm{e}^{-2(\mathrm{r} / \mathrm{w})^{2}}$ é possível obter o valor de $\mathrm{w}$, no caso obtivemos $\mathrm{w}=1,5 \mathrm{~mm}$.

\subsubsection{Caracterização do Número de Átomos Aprisionados}

Outro resultado muito importante e que se pode retirar bastante informação são as curvas de carga de um MOT. A idéia básica deste tipo de medida é medir a flourescência [47] do MOT em função do tempo enquanto é preenchido por átomos 
até a saturação, ou ao contrário, medir a o tempo de vida da armadilha quando a fonte de átomos é desligada.

Para este tipo de medida geralmente utilizam-se fotomultiplicadoras ou fotodetectores e um conjunto de lentes para coletar a imagem do MOT até os sensores dos componentes. Em nossas medidas usamos um fotodetector de baixo ganho, aproveitamos umas das lentes de ZnSe internas da câmara cuja transmitância é de $40 \%$ para $780 \mathrm{~nm}$ e outra lente externa para gerar a imagem.

O sinal do MOT é obtido com o aparato da figura 4-4, nesta medida obtivemos o número de átomos calculado através da calibração do fotodetector por um medidor de baixa potencia e por fatores geométricos que envolvem a posição dos átomos aprisionados e o instrumento de medida escritos na equação abaixo (4.1):

$$
N_{\text {Atomos }}=2 \frac{\lambda}{\Gamma h c} \frac{G}{T} \mathrm{P}
$$

P corresponde à potência medida no fotodetector, $\mathbf{G}$ são fatores geométricos, $\mathbf{T}$ corresponde à transmissão dos componentes ópticos, $\boldsymbol{\lambda}$ é o comprimento de onda, $\mathbf{h}$ a constante de Planck, c a velocidade da luz, $\Gamma$ a taxa de emissão de fótons dos átomos de $\mathrm{Rb}$, o fator $\mathbf{2}$ significa que metade dos átomos da amostra está no estado excitado e metade no estado fundamental, pois estamos trabalhando com os feixes acima da intensidade de saturação [36]. 


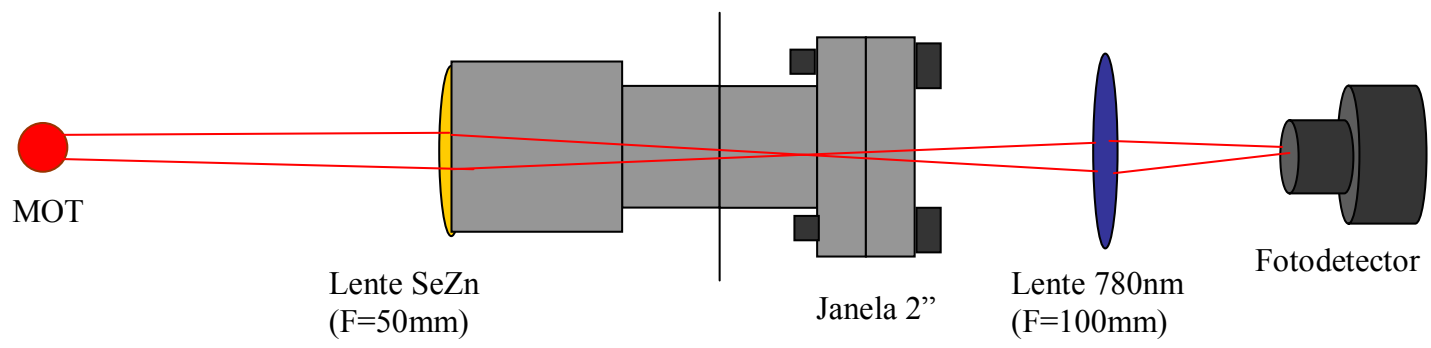

Figura 4-4: Montagem para medida de curvas de carga do MOT.

Os resultados a seguir, são curvas de carga e de tempo de vida dos átomos aprisionados para uma dada condição experimental, no caso variamos os valores de corrente no "getter" mantendo os valores de intensidades dos feixes nos valores mencionados. O gráfico da figura 4-5 representa uma curva de carga de átomos de ${ }^{87} \mathrm{Rb}$ aprisionados com lasers de diodo ${ }^{*}$, aqui usamos $350 \mathrm{~mW}$ no laser de aprisionamento e $100 \mathrm{~mW}$ no laser de rebombeio, a curva foi gerada com os "getters" funcionando continuamente a uma corrente de 4 A e bobinas com corrente de 3 A correspondendo a um gradiente de $12 \mathrm{G} / \mathrm{cm}$. Nesta seqüência ligamos as bobinas e os feixes de aprisionamento (MOT) e deixamos carregar ate um valor de saturação da armadilha, obtivemos $80 \mathrm{mV}$ de sinal máximo que correspondem a $6,6 \times 10^{7}$ átomos e com um tempo de carga de $6 \mathrm{~s}$.

Nas figuras 4-6 e 4-7 temos a mesma seqüência temporal do gráfico 4-5, embora seja uma curva de carga de armadilha magneto-óptica com átomos de ${ }^{85} \mathrm{Rb}$ aprisionados com laser de Titânio Safira. Tínhamos $270 \mathrm{~mW}$ de potencia no laser de aprisionamento e $80 \mathrm{mV}$ no laser de rebombeio. O "getter" era ligado continuamente

* Os lasers diponíveis para este projeto foram DLX-110 e Tiger, fabricados por Toptica e Sacher Lasertekinic respectivamente, devido a problemas com o laser Tiger, substituímos este sistema por um laser Ti:Safi, onde sucedeu-se os outros resultados. 
com os valores de corrente 5,4 A e 5,85 A, nesta fase suspeitamos que o "getter" já esteja no seu estágio final precisando ser substituído. Observamos isso claramente comparando os valores de corrente aplicados e o tempo de carga com o gráfico 4-5 que foi construído logo no início da montagem experimental.

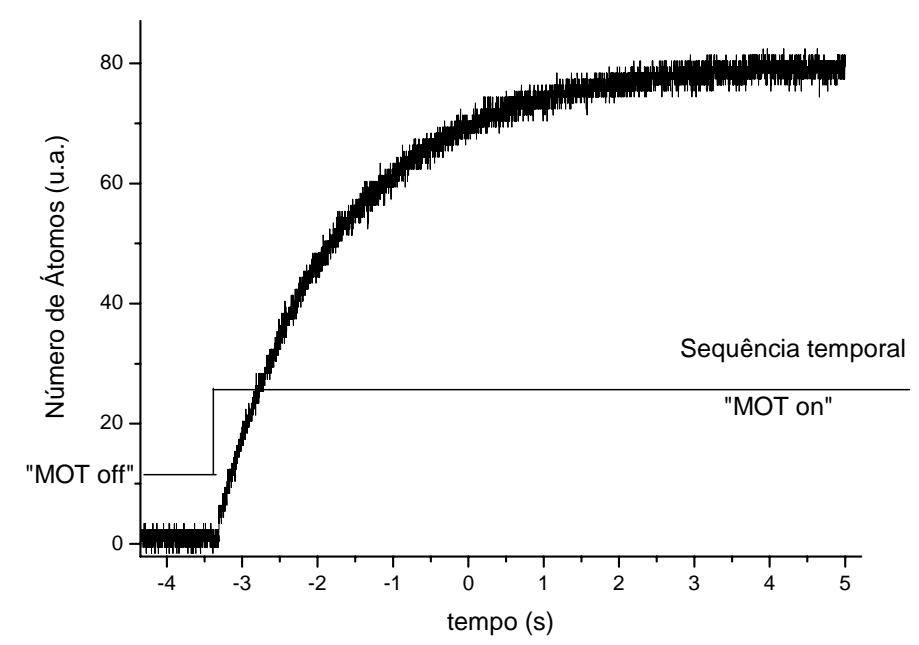

Figura 4-5 Curva de carga de uma armadilha mageto-óptica com lasers de diodo ${ }^{87} \mathrm{Rb}$, obtivemos um sinal máximo de $80 \mathrm{mV}$ correspondendo a 6,6x10 ${ }^{7}$ átomos, "getter" ligado continuamente. 


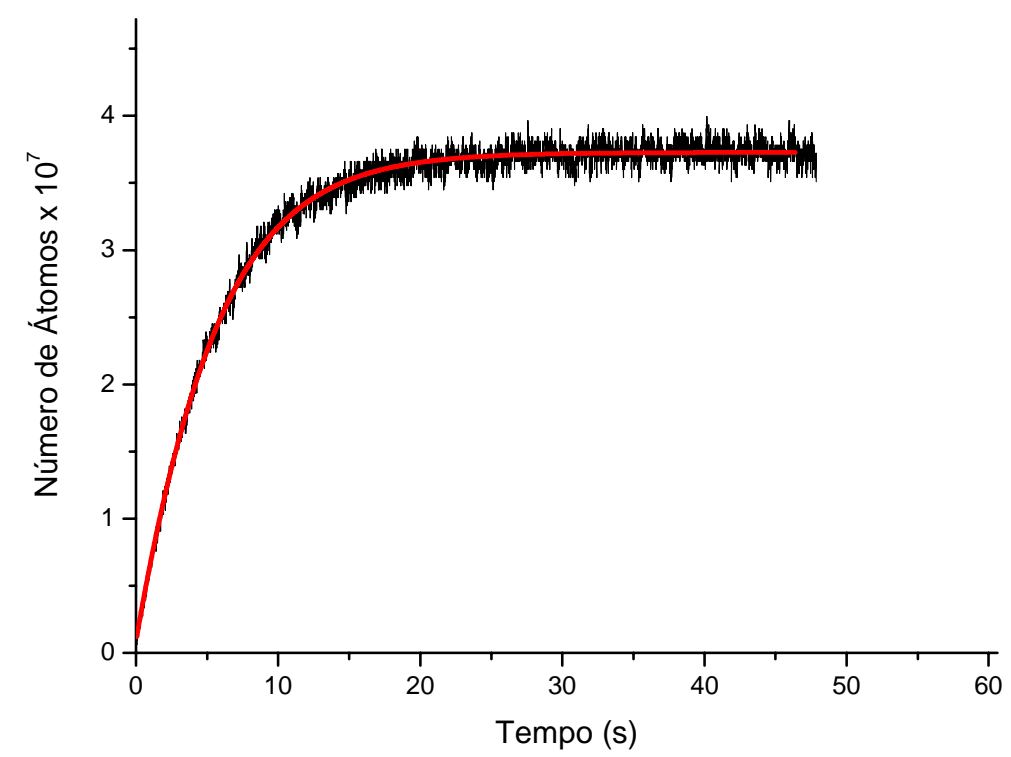

Figura 4-6 Curva de carga de uma armadilha mageto-óptica com laser de Titânio Safira ${ }^{85} \mathrm{Rb}$, obtivemos um número máximo correspondendo a $3,5 \times 10^{7}$ átomos, getter ligado continuamente $(5,4 \mathrm{~A})$.

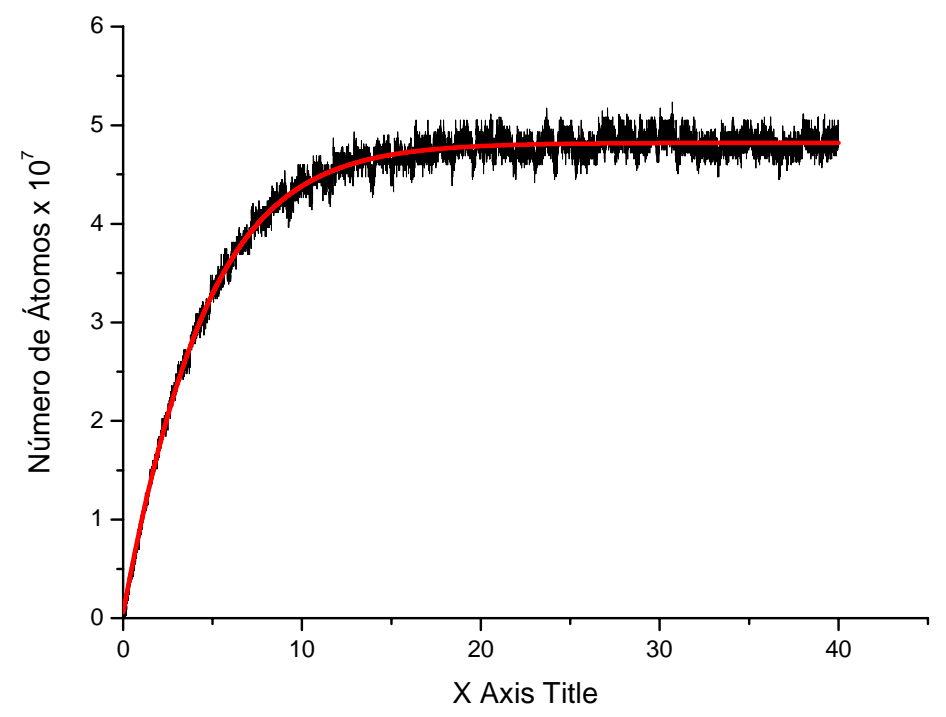

Figura 4-7: Curva de carga de uma armadilha mageto-óptica com laser de Titânio Safira ${ }^{85} \mathbf{R b}$, obtivemos um número máximo correspondendo a $4,8 \times 10^{7}$ átomos, getter ligado continuamente (5,85 A).

A dinâmica atômica nessas armadilhas poder ser compreendida a partir de uma relação que considera o comportamento geral do número de átomos em função 
do tempo. A expressão (4.2) é uma boa proposta para a variação do número de átomos em uma armadilha.

$$
\frac{d N}{d t}=L-\gamma N-\beta \int_{\text {Volume }} n^{2}(R, t) d^{3} R
$$

$\mathbf{N}$ representa o número total de átomos dentro do volume da amostra $\mathbf{V}$. L é o termo relacionado ao fluxo de átomos na armadilha; $\gamma$ é um parâmetro devido às colisões entre os átomos frios da amostra e os átomos térmicos do vapor residual presente no interior da câmara; $\beta$ é o termo relacionado às colisões que ocorrem somente entre os átomos dentro da armadilha, e $\mathbf{n}(\mathbf{R}, \mathbf{t})$ é a densidade atômica no interior do volume de aprisionamento. A princípio podemos supor que $\mathbf{n}(\mathbf{R}, \mathbf{t})=\mathbf{n}$ é constante e a solução da equação 4.2 torna-se:

$$
N(t)=N_{0}\left(1-e^{-(\gamma+\beta n) t}\right)
$$

Que é um valor razoável conforme estudos realizados por outros pesquisadores [45]. Por outro lado, temos o formato da figura 4-3 que deixa explícito a escolha de uma distribuição gaussiana para a densidade, assim podemos fazer uma escolha $\mathrm{n}(\mathrm{r}, \theta, \phi)=\mathrm{n}_{0} \mathrm{e}^{-2(\mathrm{r} / \mathrm{w})^{2}}$ e resolver a equação diferencial. Neste caso a solução analítica da equação diferencial (4.1) torna-se:

$$
N(t)=\frac{D}{2 b} \tanh \left[\frac{D}{2} t+\frac{1}{2} \ln \left(\frac{D+\gamma}{D-\gamma}\right)\right]-\frac{\gamma}{2 b}
$$


em que:

$$
\begin{aligned}
& D=\sqrt{4 b L+\gamma^{2}} \\
& b=\frac{8 \beta}{w^{3} \pi^{3 / 2}}
\end{aligned}
$$

Assim podemos obter os valores típicos dessas constantes ajustando a curva de carga do MOT com a expressão (4.4). Podemos comparar esses valores observando a tabela a seguir, aumentando a corrente no getter obtemos um número máximo de átomos maior, pois temos um fluxo L maior. Por outro lado os termos de perdas por colisão aumentam em conseqüência.

\begin{tabular}{|c|c|c|c|c|}
\hline $\begin{array}{c}\text { Corrente } \\
\text { getter (A) }\end{array}$ & $\begin{array}{c}\mathbf{L}\left(\mathbf{N}_{\text {átomos }} / \mathbf{s}\right) \\
\mathbf{x ~ 1 0}\end{array}$ & $\gamma\left(\mathbf{s}^{\mathbf{- 1}}\right)$ & $\boldsymbol{\beta}\left(\mathbf{c m}^{\mathbf{3}} \mathbf{s}^{-\mathbf{1}}\right)$ & $\mathbf{N}_{\text {átomos }}$ \\
\hline 5,4 & $6,42(0,08)$ & $0,135(0,005)$ & $2,32(0,2)$ & $\mathbf{x ~ 1 0} \mathbf{1 0}^{\mathbf{7} 2}$ \\
\hline 5,85 & $10,15(0,05)$ & $0,161(0,003)$ & $2,35(0,9)$ & 3,5 \\
\hline
\end{tabular}

Tabela 4-6: Valores das constantes de uma curva de carga do MOT

Os valores de $\beta$ e $\gamma$ podem ser comparados com valores encontrados na literatura [34, 48]. A figura 4-8 representa uma medida de curva de carga e logo em seguida uma medida de tempo de vida da armadilha magneto-óptica onde a fonte de átomos é desligada e por mecanismos de perdas a amostra vai perdendo átomos. A seqüência temporal esta descrita junto ao gráfico e percebemos um tempo de vida da ordem de 8 segundos. 


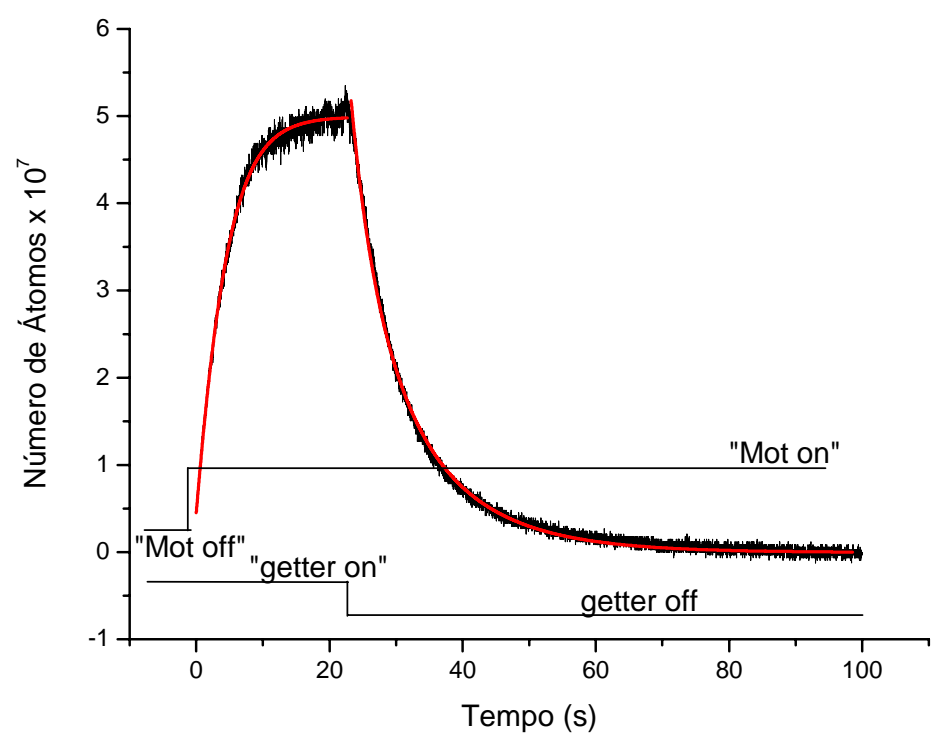

Figura 4-8: Curva de carga e tempo de vida da armadilha mageto-óptica com laser de Titânio Safira ${ }^{85} \mathrm{Rb}$, "getter" ligado continuamente até a saturação da armadilha e desligado em seguida.(5,85A).

A solução analítica para o ajuste da curva de descarga se obtém quando resolvemos a equação diferencial (4.2) com $\mathrm{L}=0$, e com a condição inicial de que $N(0)=N_{0}$, ou seja, no instante inicial o número de átomos na armadilha é igual a $N_{0}$. A solução neste caso se torna:

$$
N(t)=\frac{N_{0} e^{-\gamma t}}{1+\left(\frac{N_{0} b}{\gamma}\right)\left(1-e^{-\gamma t}\right)}
$$

Nesta medida podemos notar a influência dos átomos quentes provenientes do getter que não são aprisionados. Na primeira curva, representando uma curva de carga, obtivemos os valores: $\mathbf{L}=(9,24 \pm 0,06) \times 10^{6}$ átomos/s, $\gamma=(0,134 \pm 0,005) \mathrm{s}^{-1}$ e $\beta=(1,52 \pm 0,08) \times 10^{-12} \mathrm{~cm}^{3} \cdot \mathrm{s}^{-1}$. Na curva de descarga obtivemos $\gamma=(0,083 \pm$ 
$0,003) \mathrm{s}^{-1}$ e $\beta=(1,53 \pm 0,01) \times 10^{-12} \mathrm{~cm}^{3} \cdot \mathrm{s}^{-1}$, sendo o número máximo de átomos aprisionados de $6,4 \times 10^{7}$ átomos. Nas duas medidas o termo $\beta$, relacionado às colisões internas entre átomos aprisionados, se mantêm e o termo $\gamma$, relacionado a colisões com átomos não aprisionados, é menor na curva de descarga do que na de carga. A razão para isso é que ao mesmo tempo em que desligamos nossa fonte de átomos, estamos diminuindo a taxa de colisões causadas por esses átomos.

Para termos uma visão geral do comportamento dos "getters" comerciais, podemos observar na figura 4-9 o número máximo de átomos aprisionados em função da corrente aplicada. Temos 4 pontos que ocupam uma escala de 3,5 Aa 6 A, este limite estabelece o nível mínimo em que podemos observar átomos aprisionados pelo detector em relação ao sinal ruído e o nível máximo limitado no momento por nossa fonte de corrente.

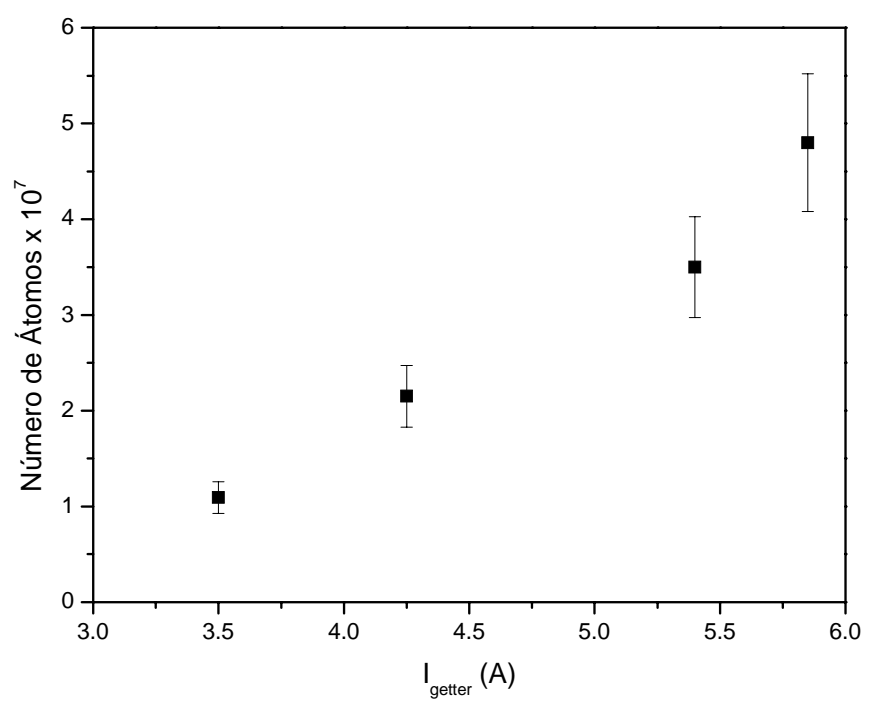

Figura 4-9: Número de átomos aprisionados na armadilha magneto-óptica pela corrente no "getter". 
Outra característica interessante é o comportamento do tempo de vida de descarga da armadilha para uma dada corrente no getter. Na figura 4-10 conforme aumentamos a corrente aumentamos o número de átomos aprisionados e o tempo de vida da armadilha. Existe um ponto crítico, em torno de 4,5 A onde aumentamos a corrente e o tempo de vida da armadilha começa a diminuir, isso é devido ao fato de que a alta corrente no "getter" cria um grande fluxo de átomos aumentando a taxa de colisões dos átomos aprisionados com átomos quentes Rb provenientes do "getter".

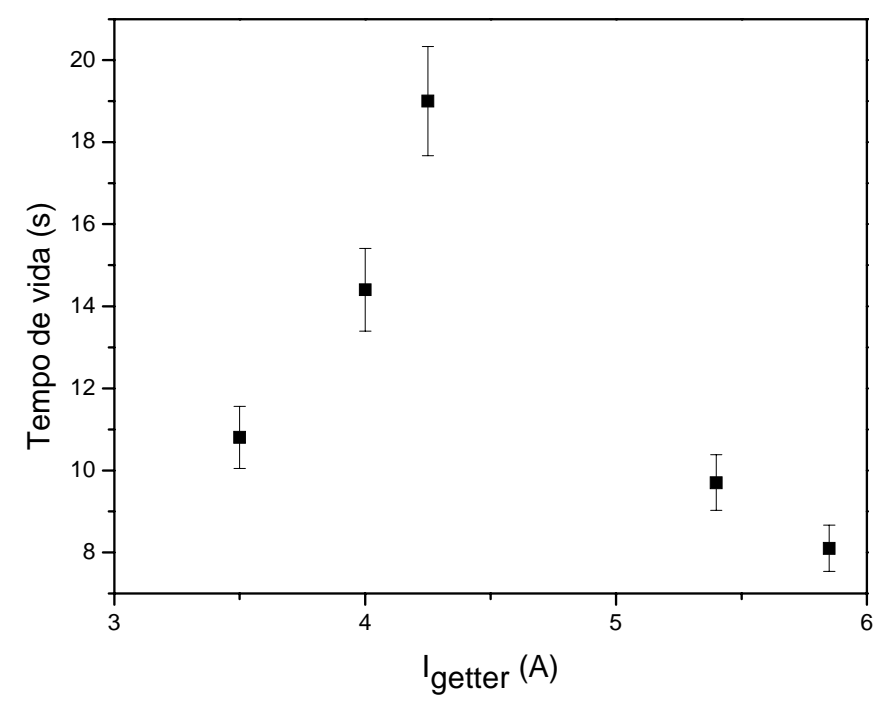

Figura 4-10: Medida do tempo de vida de descarga da armadilha em função da corrente aplicada ao "getter".

\subsection{Armadilha Magnética.}

Um fator importante que devemos considerar é o tempo de vida dos átomos aprisionados apenas pelo campo de quádruplo das bobinas. Desligando e ligando os 
feixes de aprisionamento rapidamente (ordem de $50 \mathrm{~ms}$ ) e com as bobinas ligadas continuamente notamos átomos remanescentes do aprisionamento das bobinas. Por isso decidimos medimos o tempo de vida desta armadilha recapturando os átomos no MOT depois de certo intervalo de tempo que os feixes ficaram desligados, note que desligamos o "getter" $500 \mathrm{~ms}$ antes que os feixes de aprisionamento fossem desligados e mantínhamos desligados durante a recaptura a fim de detectarmos apenas átomos remanescentes da armadilha magnética e não átomos provenientes do “getter". O gráfico da figura 4-9 representa este tipo de medida.

Fizemos várias medidas como esta (figura 4-11) onde construímos uma curva de tempo de vida da armadilha magnética até $400 \mathrm{~ms}$, onde o sinal se extingui (figura 4-12), justificando a construção de um circuito de chaveamento micro-controlado das bobinas, pois a sua influência encobriria o número de átomos aprisionados em um FORT que é estimado uma transferência de menos de 10\% [40].

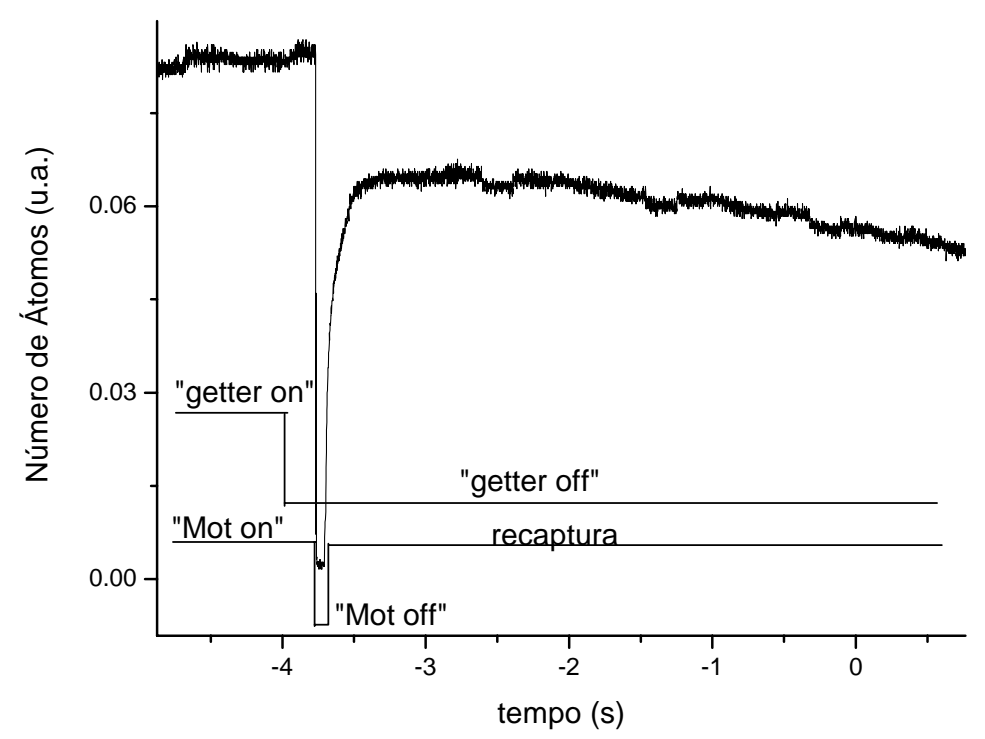

Figura 4-11 Medida do tempo de vida da armadilha magnética formada pelo par de bobinas anti-Helmholtz. O feixe de aprisionamento é desligado e ligado em alguns ms recapturando átomos remanescentes. 


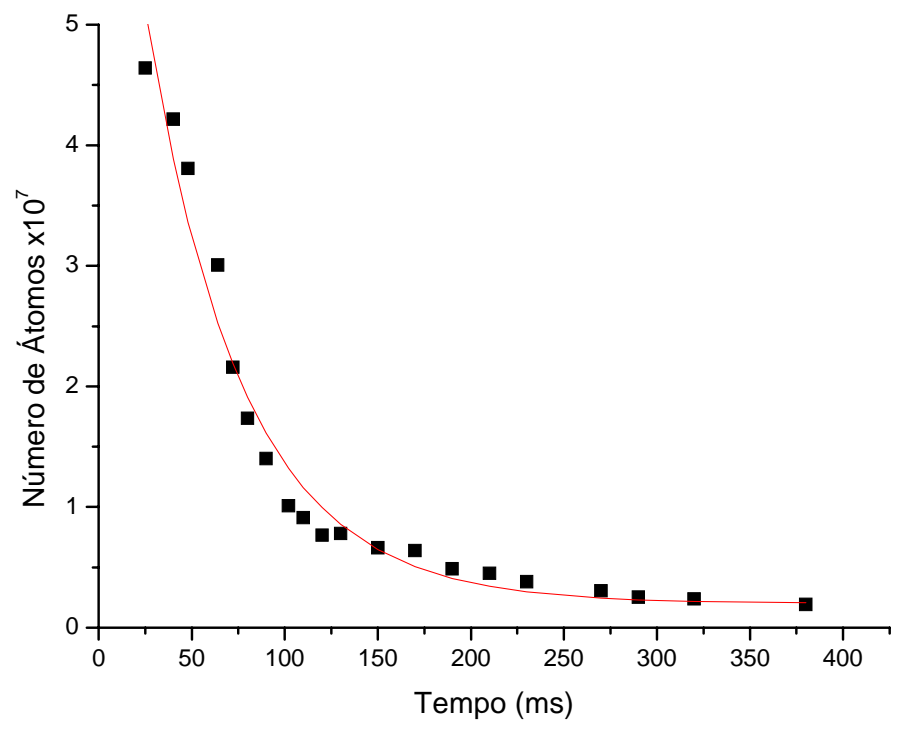

Figura 4-10: Tempo de vida da armadilha magnética evidenciando o efeito das bobinas de aprisionamento.

Com a equação (4.7) fizemos o ajuste da curva de tempo de vida da armadilha magnética em que obtivemos $\gamma=(19 \pm 6) \mathrm{s}^{-1}$ e $\beta=2,3 \times 10^{-14} \mathrm{~cm}^{3} \cdot \mathrm{s}^{-1}$. Com essa medida vemos a taxa de colisão interna é desprezível comparando aos efeitos das colisões com átomos não aprisionados $(\gamma)$. A profundidade de nossa a armadilha magnética é calculada segundo os valores de gradientes mostrados nas figuras 3-11 e 3-12 e obtivemos os valores para os potenciais $\mathrm{U}_{0 \mathrm{z}}=6,1 \mathrm{mK}$ (com relação ao eixo $\mathrm{z}$ das bobinas) e $\mathrm{U}_{0 \mathrm{xy}}=1,9 \mathrm{mK}$ (com relação ao plano xy das bobinas em $\mathrm{z}=0$ ). Mas devido aos baixos gradientes este potencial de estende por $8 \mathrm{~cm}$ deixando a amostra menos densa e diminuindo drasticamente o valor de $\beta$. 


\subsection{A Armadilha de Dipolo.}

Voltamos ao ponto fundamental deste trabalho, cuja idéia central era a obtenção de uma armadilha de dipolo do tipo QUEST. Para isso dispúnhamos de um laser de $\mathrm{CO}_{2}$ comercial GEM-100, fabricado pela Coherent com $130 \mathrm{~W}$ de potência $\lambda=10.6 \mu \mathrm{m}$ e com $\mathrm{w}_{0}=28 \mu \mathrm{m}$ previamente medido correspondendo a uma profundidade do potencial de $\mathrm{U}_{0}=-1,4 \mathrm{mK}$, devido a certos problemas* optamos por construir um FORT a partir de um laser de Titânio Safira em uma potencia de 300 $\mathrm{mW}, \mathrm{w}_{0}=26 \mu \mathrm{m}, \lambda=782,5 \mathrm{~nm}$ e $\mathrm{U}_{0}=-2,3 \mathrm{mK}$. A idéia inicial era seguir uma seqüência temporal como descrito na figura 4-9, adicionaríamos o feixe de Titânio Safira focalizado, responsável pela formação do FORT e desligaríamos e ligaríamos os feixes de MOT e as Bobinas, tentado obter um sinal de recaptura e curvas características.

O aparato utilizado é o mesmo da figura 3-25. O feixe entrava por uma das janelas de 2" focalizado por uma lente de distância focal $25 \mathrm{~cm}$ montada em um sistema transladador com precisão de $0,05 \mathrm{~mm}$. O alinhamento era feito ajustando-se a freqüência do laser na ressonância $(780,24 \mathrm{~nm})$ e observando a destruição do MOT pelo monitor da câmera CCD.

Não pudemos obter esta evidência devido a vários fatores. Primeiramente, o volume de captura destas armadilhas é muito pequeno, podemos calcular isso pela equação 2.4. Segundo, as flutuações de potência do laser aquecem a amostra (equação 2.10) diminuindo o tempo vida da armadilha, este fator poderia nos prejudicar no caso de tempos de vida da ordem de $25 \mathrm{~ms}$, pois nosso programa

\footnotetext{
*Como descrito no capítulo 3, as janelas de ZnSe foram substituídas por janelas de vidro, devido a demora em seu concerto pelo fabricante continuamos os experimentos com as janelas de vidro no qual impossibilitam o uso de um laser de $\mathrm{CO}_{2}$ de alta potência.
} 
possui um tempo mínimo de chaveamento de $25 \mathrm{~ms}$ o que impossibilitaria a observação do aprisionamento. Além isso acreditamos que o sinal de átomos aprisionados observado em nosso fotodetector seria da ordem do ruído $\sim 3 \mathrm{mV}$, que corresponderia a uma transferência de menos de 1\% [49].

As melhorias que devem ser feitas no sentido de obter uma evidência do aprisionamento seria a estabilização da potência do laser via modulador acustoóptico (AOM), observando que este tipo de equipamento havia sido construído para utilização em laser de $\mathrm{CO}_{2}$. A utilização de um outro feixe para gerarmos um préestágio de molasses em que reduziremos a potencia do feixe de rebombeio e aumentaremos o detunning do feixe de aprisionamento como encontrado na literatura [40]. Sendo esperada uma transferência de $40 \%$ dos átomos aprisionados no MOT para a armadilha de dipolo. 


\section{Capítulo 5}

\section{Conclusão e Perspectivas}

O objetivo original deste trabalho era a construção e demonstração de uma armadilha de dipolo utilizando um laser de $\mathrm{CO}_{2}$ de alta potência. Para isso, era necessário que dominássemos novas e modernas tecnologias experimentais que nunca haviam sido utilizadas pelo nosso grupo. Entre elas podemos destacar o uso de reservatórios "getters" como fonte de átomos; a utilização de um laser de $\mathrm{CO}_{2}$ e sua ótica; a construção das bobinas em vácuo e a construção de uma câmara de vácuo com grande acesso óptico.

Sem duvidas, tivemos sucesso em utilizar os reservatórios químicos como fonte de átomos; inclusive hoje esta técnica é utilizada em outras armadilhas/experimentos em nosso grupo. Além disso, conseguimos operar com sucesso as bobinas responsáveis pelos campos magnéticos dentro do vácuo. Também dominamos o uso do sistema laser de $\mathrm{CO}_{2}$, sua ótica e seu controle de potência através de um modulador acusto-óptico. Uma das limitações com certeza foi a introdução do laser na câmara de vácuo através das janelas de $\mathrm{ZnSe}$; o que se 
mostrou mais complicado do que o esperado. As janelas apresentaram vários vazamentos durante o processo de aquecimento ("baking") para obtermos ultra-alto vácuo. De forma que foi impossível mante-las no lugar, e foi necessário envia-las para o fornecedor para conserto; e devido a cronogramas não mais as colocamos de volta.

Também devemos salientar que ainda não esta claro se os problemas de vazamento não são intrínsecos da própria câmara. Pois mesmo sem as janelas de ZnSe a pressão final não atingiu a planejada que era menor que $5 \times 10^{-11}$ torr; mas ficou uma ordem de grandeza mais alta. Acreditamos que isto deve ser devido à construção da mesma, pois nossa oficina mecânica nunca construiu uma câmara tão grande e com tantos acessos óticos para ser utilizada em uma pressão tão baixa. Problemas de solda e adaptação de materiais podem ter levado a uma câmara que não nos permite atingir o vácuo desejado.

De qualquer forma, pretendemos resolver estes problemas de vácuo através de duas opções distintas. No caso das janelas de alto vácuo de $\mathrm{ZnSe}$ faremos uma ante-câmara no seu lado exterior com uma pressão de $10^{-5}$ torr, enquanto seu interior ficará exposto a pressão interna da câmara $\left(<10^{-9}\right.$ torr). E esta ante-câmara se comunicará com o mundo exterior via uma outra janela de ZnSe. Desta forma, iremos diminuir o fluxo de gás que vazará pela janela de alto vácuo de ZnSe. Esta é uma solução que já foi realizada por outros grupos recentemente, e dispomos dos elementos necessários para implementa-la rapidamente. Os problemas de vácuo da câmara parecem ser intrínsecos e não a muito que possamos fazer. Visto que já tentamos várias vezes fechar seus vazamentos em nossa oficina. Assim a solução mais apropriada será a importação de uma câmara construída especial para este fím por uma das várias empresas que operam neste ramo nos Estados Unidos. E 
particular, optaremos por comprar da mesma empresa que o Grupo do Prof. Ketterle compra. Além destes problemas, tivemos o infortúnio de ter 2 dos nossos lasers de diodo com problemas no componente emissor, o que nos obrigou envia-los para o fornecedor e comprometeu seriamente o que podíamos realizar.

De qualquer forma, demonstramos o aprisionamos átomos de ${ }^{85} \mathrm{Rb}$ em uma armadilha magneto-óptica e analisamos sua dinâmica, obtendo resultados das taxas de perdas provocadas por colisões entre átomos aprisionados e átomos quentes provenientes do vapor de fundo e do "getter". Pode-se observar que o aumento a taxa de colisões com o gás de fundo aumenta quando trabalhamos com uma taxa de carga da armadilha relativamente alta. A otimização do uso deste componente é necessário para o aumento do tempo de vida das armadilhas. E no futuro próximo será fundamental controlar os reservatórios de $\mathrm{K}$ e $\mathrm{Rb}$ simultaneamente.

Apesar destas limitações experimentais; pudemos nos familiarizar com os conceitos físicos das técnicas de aprisionamento, ressaltando a técnica de aprisionamento via interação de dipolo com feixe focalizado. Pudemos caracterizar os lasers a serem utilizados na sua construção com isso podemos calcular a profundidade do potencial e o volume da amostra aprisionada. Além disso, um sistema de controle com interface em LabView foi construído para transferência controlada de átomos em uma armadilha magneto-óptica para uma armadilha de dipolo, tal programa nos permitira a inclusão de novos canais para a obtenção de um pré-estágio de molasses em que reduziremos a potencia do feixe de rebombeio e aumentaremos o detunning do feixe de aprisionamento como encontrado na literatura [40]. Estes conhecimentos deverão ser mostrar úteis na próxima fase deste projeto.

Com esse trabalho estamos prontos a seguir com a obtenção de uma armadilha de dipolo. Essa armadilha será capaz de aprisionar átomos de Rb e K em 
densidades muito altas e durante longos períodos de tempo, tornando possível a realização de estudos detalhados de processos colisionais neste regime de temperatura. $\mathrm{O}$ estudo da dinâmica temporal das moléculas nesse tipo de armadilha possibilitará a observação regular de fenômenos colisionais de baixa energia ocorrendo numa amostra pura de moléculas diatômicas, livres de quaisquer outros tipos de influência externa. Além disso, esperamos ser capazes de resfriar a amostra através de resfriamento evaporativo e assim atingir o regime de degenerescência quântica. Nossa expectativa é realizar estudos colisionais no regime de degenerescência quântica em redes ópticas; com a possibilidade de aprisionar as moléculas. Com isso, deveremos inserir nosso grupo em áreas modernas de pesquisa envolvendo átomos frios a nível internacional. 


\section{Referências Bibliográficas}

[1] Cook, R. J. Atomic motion in resonant radiation: An application of Ehrenfest's theorem, Phys. Rev. A. 20, 224 (1979).

[2] Chu, S.; Hollberg L.; Bjorkholm, J. E.; Cable, A. and Ashkin, A. Threedimensional viscous confinement and cooling of atoms by resonance radiation pressure. Phys. Rev. Lett. 55, 48 (1985).

[3] Raab,E. L.; Prentiss,M.; Cable, A.; Chu,S. and Pritchard,D. E. Trapping of Neutral Sodium Atoms with Radiation Pressure. Phys. Rev. Lett. 59, 2631 (1987). [4] Metcalf, H. and der Straten, P. V. Laser Cooling and Trapping. SpringerVerlarg, New York, (1999).

Anderson, M. H.; Ensher,J. R.; Matthews,M. R.; Wieman,C. E.; Cornell

E. A. Observation of Bose-Einstein Condensation ia Dilute Atomic Vapor. Science, 269, p. 198-201, 14/07/1995.

[6] Davis,K. B.; Mewes,M. O.; Andrews,M. R.; van Druten,N. J.; Durfee, D. S.; Kurn,D. M.; Ketterle, W. Bose-Einstein Condensation in a Gas of Sodium Atoms. Phys. Rev. Lett. 75, n. 22, p. 3969-73, 1955. 
Einstein Condensation in an Atomic Gas with Attractive Interactions. Phys. Rev. Lett., 75, n. 9, p.1687-90, 1995.

[8] Bradley, C.C.; Sackett, C. A; Hulet.R. G. Bose-Einstein Condensation of Lithium. Observation of Limited Condensate Number. Phys. Rev. Lett., 78, n.6, p.985-9, 1997.

[9] Weiner,J.; Bagnato V. S.; Zílio, S. C. and Julienne, P. S. Experiments and theory in cold and ultracold collisions. Rev. Mod. Phys. 71, 1 (1999).

[10] Drag, C.; Laburthe, B.; Dulieu, O.; Comparat, D.; Vatasescu, M.; Boussen, S.; Guibal, S.; Crubellier, A. and Pillet, P. IEEE J. Quantum Electron, 36, 1378 (2000),

[11] Thorseim, H. J.; Wiener, J. and Julienne, P. S. Laser-induced photoassociation of ultracold sodium atoms. Phys. Rev. Let. 58, 2420 (1987).

[12] Scheingraber, H. and Vidal, C. R. J. Chem. Phys. 66, 3694 (1977).

[13] Fioretti, A.; Comparat, D.; Crubellier, A.; Dulieu, O.; Masnou-Seeuws, F. and Pillet P. Formation of Cold $\mathrm{Cs}_{2}$ Molecules through Photoassociation Phys. Rev. Lett 80, 4402 (1998).

[14] Gabbanini, C.; Fioretti, A.; Lucchesini, A.; Gozzini, S. and Mazzoni. Cold Rubidium Molecules Formed in a Magneto-Optical Trap. Phys. Rev. Lett. 84 (13), 2814-7 (2000).

[15] Nikolov, A.; Eyler, E. E.; Wang, X.; Li, J.; Wang, H.; Stwalley, W. and Gould, P. Observation of Ultracold Ground-State Potassium Molecules. Phys. Rev. Lett. 82 (4), 703-6 (1999).

[16] Fatemi, F.; Jones, K.; Lett, P. and Tiesinga, E. Ultracold ground-state molecule production in sodium. Phys. Rev. A 66, 053401 (1-7) (2002). 
[17] Helmerson, K. Quantum optics: Giving a boost to atoms. Nature 402, 587-8 (1999).

[18] Bahns, J.; Gould, P. and Stwalley, W. Formation of cold $(T \leq 1 K)$ molecules. Adv. Mol. Opt. Phys. 42, 171-224 (2000).

[19] Vanhaecke, N.; Melo, W. S.; Tolra, B.; Comparat, D. and Pillet, P. Accumulation of Cold Cesium Molecules via Photoassociation in a Mixed Atomic and Molecular Trap. Phys. Rev. Lett 89, 063001 (2002).

[20] Takekoshi, T.; and Kneize, R. Optics Letters 21, 77-9 (1996).

[21] Takekoshi, T.; Patterson, B. and Kneize, R. Phys. Observation of Optically Trapped Cold Cesium Molecules. Rev. Lett. 81, 5105-8 (1998).

[22] Mancini, M.W.; Telles, G.D.; Caires, A.R.L.; Bagnato, V.S.; Marcassa, L.G., Observation of Ultracold Ground-State Heteronuclear Molecules Phys. Rev. Lett. 92, 133203, (2004).

[23] Yariv, A., Quantum Eletronics, $2^{0}$ Ed.

[24] Zílio, S. C..Óptica Moderna - Fundamentos e Aplicações (2001).

[25] Fuentealbat, P. and Reyes, O. Polarizabilities and hyperpolarizabilities of the alkali metal atoms 1. At. Mol. Opt. Phys. 26, 2245-2250 (1993).

[26] Ashkin, A. Trapping of atoms by resonance radiation pressure. Phys. Rev. Lett., 40, 729, (1977).

[27] Chu, S.; Bjorkholm, J. E.; Ashkin, A. and Cable, A. Experimental observation of optically trapped atoms. Phys. Rev. Lett., 57, 314, (1986).

[28] Cohen-Tannoudji, C. Atom Photon Interactions: basic processes and applications. J. Wiley, New York, 1992.

[29] Miller, J. D.; Cline, R. A. and Heinzen, D. J. Far-off-resonance optical trapping of atoms. Phys. Rev. A, 47, R4567, (1993). 
[30] O'Hara, K. M.; Granade, S. R.; Gehm, M. E.; Savard, T. A.; Bali, S.; Freed, C. and Thomas, J. E. Ultrastable $\mathrm{CO}_{2}$ laser trapping of lithium fermions. Phys. Rev. Lett., 82, 4204, (1999).

[31] Takekoshi, T.; and Knize, R. J. $\mathrm{CO}_{2}$ laser trap for cesium atoms. Opt. Lett., 21, 77, (1996).

[32] Friebel, S.; D'Andrea, C.; Walz, J.; Weitz, M. and T. Hansch, W. $\mathrm{CO}_{2^{-}}$ laser optical lattice with cold rubidium atoms. Phys. Rev. A., 57, R20, (1998).

[33] Weidemuller, M.; Engler, H.; Nill, M.; Weber, T. and Grimm, R. Lithium and cesium in a quasi-electrostatic $\mathrm{CO}_{2}$-laser trap. Laser Spectroscopy. $14^{\text {th }}$ International Conference. ICOLS99, page 336, 1999.

[34] Rapol, U. D.; Wasan, A. and Natarajan, V. Loading of a Rb magnetooptic trap from a getter source. Phys. Rev. A, 64, 023402 - 2001.

[35] Bartalini, S.; Herrera, I.; Consolino, L.; Pappalardo, L.; Marino, N.; D'Arrigo, G. and Cataliotti, F. S. Full characterization of the loading of a magnetooptical trap from an alkali metal dispenser. Eur. Phys. J. D 36, 101-104 (2005)

[36] Bagnato, V. S. Curso de "Espectroscopia Atômica e Manipulação Óptica de Átomos”. In: II Escola de Verão Jorge André Swieca, São Carlos, 1990.

[37] Grimm, R.; Weidemüller,M.; and Ovchinnikov, YB. Optical Dipole Traps for Neutral Atoms. Adv. At. Mol. Opt. Phys. 42, 95 (2000).

[38] Arnaud, J. A. Modes of propagation of optical beams in helical gas lense., Appl. Opt. 10, 2775-2776 (1971).

[39] Cohen, D. K.; Little, B. and Luecke, F. S. Techniques for measuring 1[mgr ]m diam Gaussian beams. Appl. Opt. 23, 637- (1984)

[40] Kuppens, S. J. M.; Corwin, K. L.; Miller, K. W.; Chupp, T. E. and Weiman, C. E. Loading an optical dipole trap. Phys. Rev. A, 62, 013406. 
Metcalf, H. J.; Bergeman, T.; Erez, G. Magnetostatic trapping fields for neutral atoms. Phys. Rev. A, 35, 1535-1546, (1987).

[42] Delchar, T. A. Vaccum Physics and Techniques, First Edition 1993.

[43] Steck, D. A.; Rubidium 87 D line Data, Los Alamos National Laboratory, 25 September 2001.

[44] MacAdam, K. B.; Steinbach, A. and Weiman, C. A narrow-band tunable diode laser system with grating feedback, and a saturated absorption spectrometer for Cs and Rb. Am. J. Phys., 60, 1098-1111, (1992).

Marcassa, L.; Bagnato, V.; Wang, Y.; Tsao, C.; Weiner, J.; Dileu, O.;

Band, Y. B.; Julienne, P. S. Colisional loss rate in a magneto-optical trap for sodium atoms: light-intensity dependence. Phys. Rev. A, 47, p.R4563-6 (1993).

[46] Peters, M. G.; Hoffmann, D.; Tobiaxon, J. D.; Walker, T. Laser-induced ultracold $R b\left(5 S_{1 / 2}\right)+R b\left(5 P_{1 / 2}\right)$ collisions. Phys. Rev. A, 50, p.R906-9 (1994).

[47] Townsend, C. G.; Edwards, N. T.; Cooper, C. J.; Zetie, K. P.; Foot, C. J.; Steane, A. M.; Szriftgiser, P.; Perrin, H. and Dalibard, J. Phase-space density in the magneto-optical trap. Phys. Rev. A 52, 1423-40 (1995).

[48] Hoffmann, D.; Feng, P.; Willianson III, R. S.; Walker, T. Excited-State Collisions of Trapped ${ }^{85}$ Rb Atoms. Phys. Rev. Lett, 69, p.753-6, (1992).

[49] Chu, S.; Bjorkholm, J. E.; Ashkin, A. and Cable, A. Experimental observation of optically trapped atoms. Phys. Rev. Lett., 57, 314, (1986). 